Portland State University

PDXScholar

Spring 6-6-2017

\title{
Using Critical Physical Geography to Map the Unintended Consequences of Conservation Management Programs
}

Melanie Malone

Portland State University

Follow this and additional works at: https://pdxscholar.library.pdx.edu/open_access_etds

Part of the Agriculture Commons, and the Natural Resources and Conservation Commons Let us know how access to this document benefits you.

Recommended Citation

Malone, Melanie, "Using Critical Physical Geography to Map the Unintended Consequences of Conservation Management Programs" (2017). Dissertations and Theses. Paper 3639.

https://doi.org/10.15760/etd.5523

This Dissertation is brought to you for free and open access. It has been accepted for inclusion in Dissertations and Theses by an authorized administrator of PDXScholar. Please contact us if we can make this document more accessible: pdxscholar@pdx.edu. 
Using Critical Physical Geography to Map the Unintended

Consequences of Conservation Management Programs

by

Melanie Malone

A dissertation submitted in partial fulfillment of the requirements for the degree of

\author{
Doctor of Philosophy \\ in \\ Earth, Environment and Society
}
Dissertation Committee:
Martin Lafrenz, Chair
Eugene Foster
Nathan McClintock
Veronica Dujon

Portland State University

2017 
(C) 2017 Melanie Malone 


\begin{abstract}
A variety of conservation trends have gained and lost favor throughout the years in agriculture, with U.S. Farm Bills often influencing what conservation practices are implemented by farming communities throughout the U.S. This dissertation focuses on the unintended consequences of conservation management practices in the Fifteenmile Watershed of Wasco County, Oregon. Specifically, I seek to address how farmer enrollment in various conservation techniques, loosely defined as no-till agriculture, has affected soil and water quality through the increased use of herbicide, and subsequently rendered ecological and human health vulnerable. Using a critical physical geography framework, I address both the biophysical factors and social structures that have coproduced changes in soil and water quality in the study area of this research through intensive physical field data collection, spatial analysis, social surveys, and interviews. I also demonstrate how three neoliberal sets of processes: market-friendly reregulation; state rollback and deregulation; and the creation of self-sufficient individuals and communities, have transformed the human socio-environmental relationship to agriculture. These processes have had significant effects on the policies governing how soil and water quality are managed on both a state and national level, and have created a dependence on enrollment in conservation practices that may ultimately prove counterproductive for long term goals of environmental protection and sustainability.
\end{abstract}




\section{Acknowledgements}

Many thanks to my committee for their contributions during my time in the $\mathrm{PhD}$ program. To Martin Lafrenz, who took me on as a student after I had been enrolled in the program for quite some time, and who humored me while I explored connections between geomorphological and social realms, but encouraged me to stay close to my sedimentary roots, pun intended. To Nathan McClintock, for inspiring me to continue with my interests and for introducing me to all kinds of words and literatures that I had never heard of before entering my program but now have found indispensable to my research. Many thanks for all your guidance and for being an example of the type of scholar I aspire to be one day. To Gene Foster, for graciously imparting knowledge about all of the nuances of government regulations versus academic research and illuminating all sorts of policy and regulatory conundrums that I have been pondering for years. To Veronica Dujon, whom I always enjoyed listening to in IGERT classes and who has an enviable knack for summarizing long, complex, social and historical theories that drive larger environmental policies during seemingly casual conversations and discussions.

Many thanks to my husband, Kevin, who was often the first person to read various drafts of my work and for giving the type of critical eye that only a super, detail-oriented engineer could give. He was often the first to evaluate my thoughts on everything from critical theory to soil science to every other topic I dabbled in, which took him far out of the range of his comfort zone. His reviews of my work resulted in many amusing, but productive conversations that forced me to explain and defend my ideas better, and I think this dissertation benefited because of his insight. 
To all the wonderful people that make up the IGERT. You all have inspired me in so many ways. Thanks to Marissa Matsler and Erin Goodling, for providing special support as mentors in the IGERT program, for giving me valuable advice in times of need, and for providing your friendship. To Samantha Hamlin, for being my partner-in-crime in the program and a source of therapy throughout. To Mary Ann Rozance, for being the ultimate academic bag lady, Diana Denham, for her inquisitive and thoughtful approach to research, and Ashlie Denton for providing positive feedback on research collaborations. Thanks to Basma Mohammed for joining me in my earliest adventures in the field and assisting with difficult sampling. Also thanks to Kim Heavener, Darrell Brown, Dave Ervin, Elise Granek, and Alan Yeakley for providing a huge amount of institutional support. This dissertation would not have been possible without you all.

Thanks to Mike Young, who was the best intern I could have ever asked for during the sweltering heat of the summer of 2015, and to Amy Hemingway for being a stellar GIS intern! Also, thanks to all those that joined me for a random day of field work here and there.

Thanks to Rebecca Lave and the rest of the CPG crew for collaborating on many ideas that helped to make this dissertation a reality.

To my parents, siblings, and larger extended family, thanks for inspiring me to keep up my work on environmental issues and for giving me too much praise for what I actually work on and accomplish.

Finally, thanks and praise to God, for enabling me to get through this dissertation program with support all along the way. For me, the completion of this degree is attributable to nothing short of a miracle! 


\section{Table of Contents}

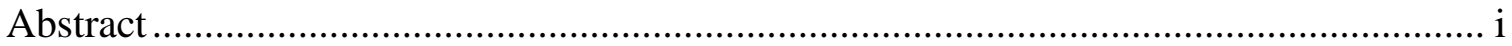

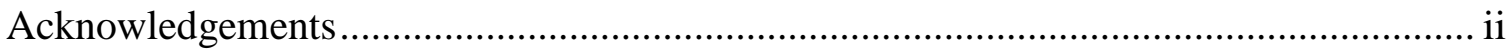

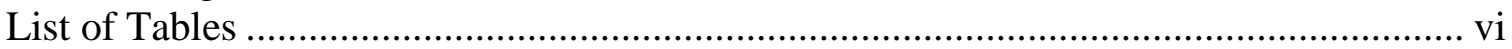

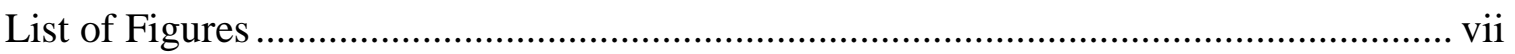

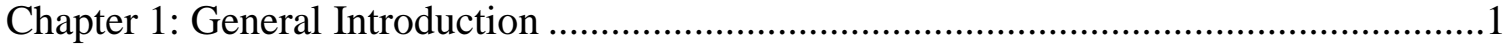

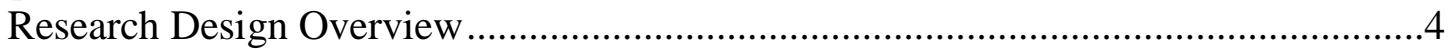

Chapter 2: A Mixed-Methods Approach to Determine How Conservation

Management Programs and Techniques Have Affected Herbicide Use and

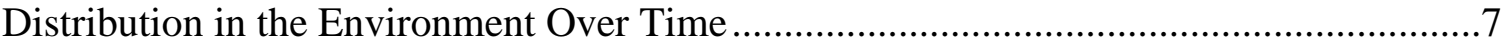

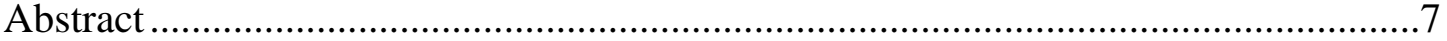

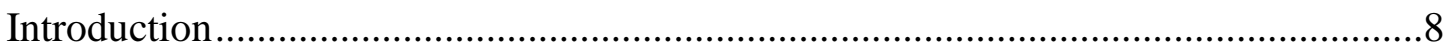

Herbicide Use Trends in Conservation Agriculture...........................................

Concerns About Glyphosate ........................................................................11

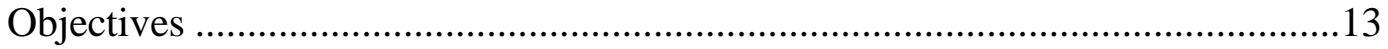

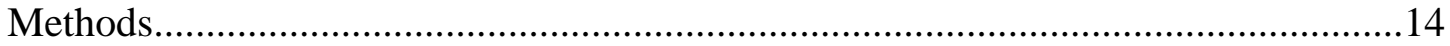

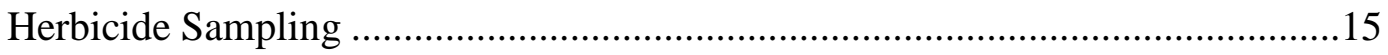

October 2015 Glyphosate and AMPA Samples..............................................16

May 2016 Co-located Glyphosate and AMPA Samples.....................................18

July 2016 and August 2016 Glyphosate, AMPA, and Chlorinated

Herbicide Samples ....................................................................................18

Sampling Equipment Decontamination and Laboratory Methods.......................19

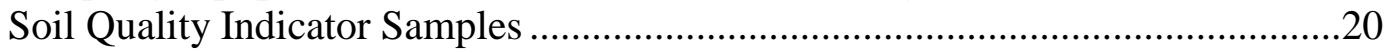

Spatial Analysis- NDVI Remote Sensing Analysis ........................................21

Drone Sample Site Selection and Field Verification .......................................24

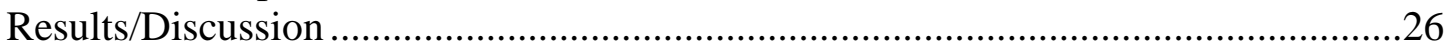

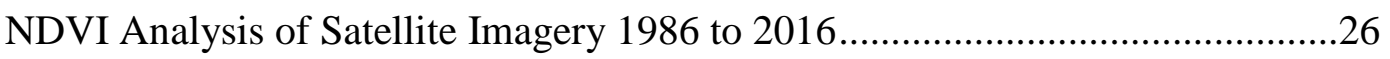

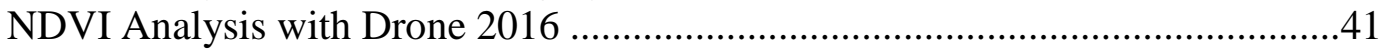

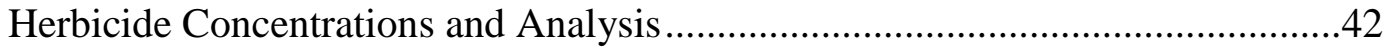

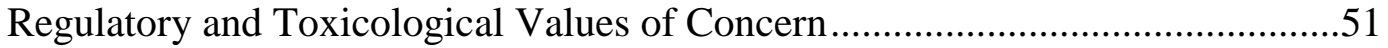

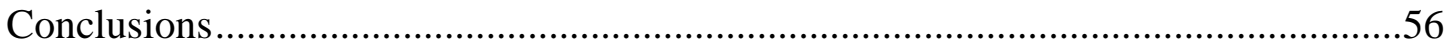

Chapter 3: Impacts of Farming Practices and Conservation Management

Programs and Techniques on Sediment Cascades .....................................................58

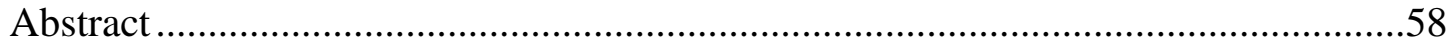

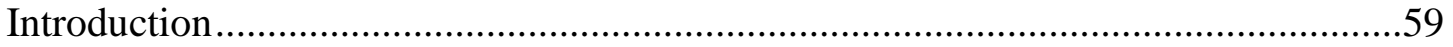

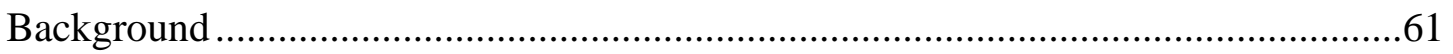

The Contribution of Past Farming Practices to Sediment Cascades .....................6. 62

Conservation Practices Contribution to Sediment Cascades ................................63

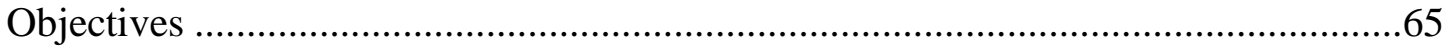

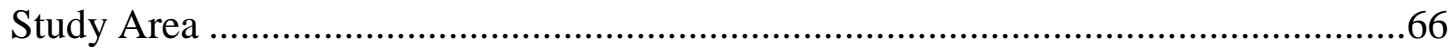

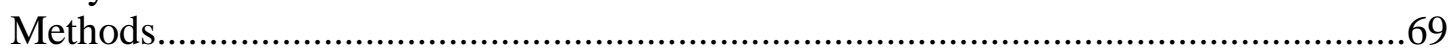

Determining Source Contributions with Cesium-137...................................69

Determining Human and Geophysical Impacts on Sediment Cascades ................73

Analysis of Historical Imagery ..................................................................74 


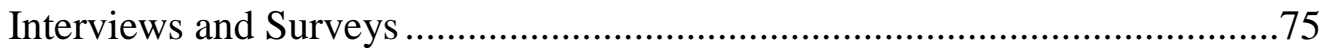

Mapping of Floodplains and Terraces with LiDAR ....................................76

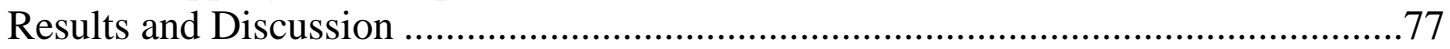

Sediment Source Contributions Determined by Cesium-137 Analysis .................77

How Humans Practices and Environmental Conditions Have Influenced

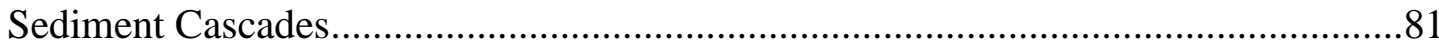

Past Farm Practices that Likely Influence Sediment Cascades ...........................82

Ephemeral Gullies Related to Farming Practices .........................................8 82

Wind Erosion Related to Past Farming Practices ........................................84

Current Farm Practices that Likely Influence Sediment Cascades .......................85

Equipment Variations in Equipment, Tillage Practices and Soil

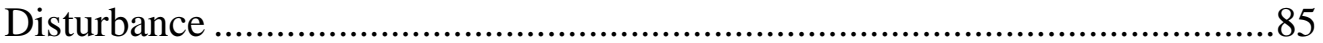

Stream Modifications and Unrecognized Sources of Sediment ..............................90

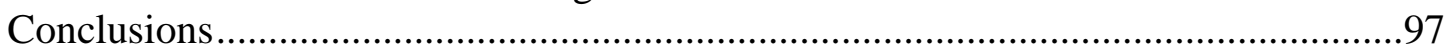

Chapter 4: A Critical Physical Geographical Analysis of Conservation

Management Practices: Implications for Soil Quality, Water Quality, and Farm

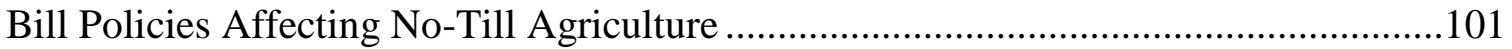

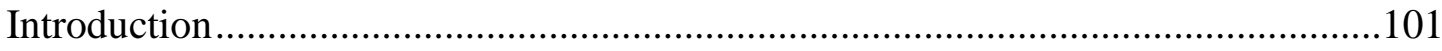

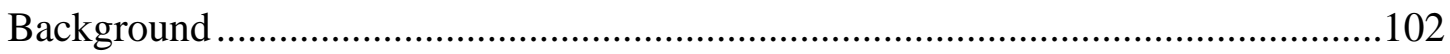

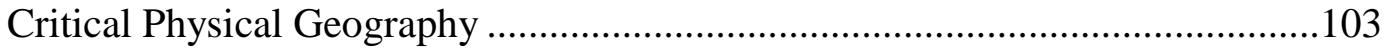

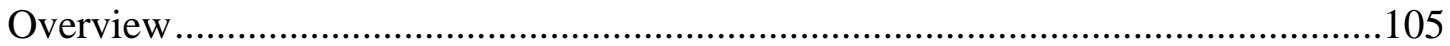

Farm Bills Lay the Groundwork for No-Till .....................................................107

Market-Friendly Reregulation: Why No-till Became the Conservation

Method of Choice on the National Level...........................................................109

Market Friendly Reregulation in the Fifteenmile Watershed ............................118

The Environmental Impacts of Market Friendly Reregulation..........................123

State Rollback and Deregulation National Level and in the Fifteenmile

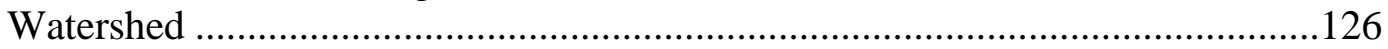

Self Sufficient Individuals and Community in the Fifteenmile Watershed .........138

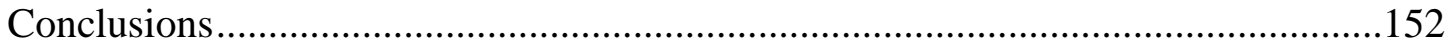

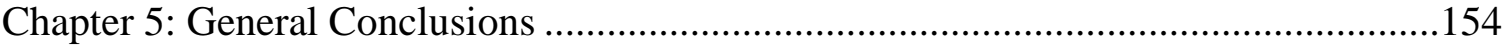

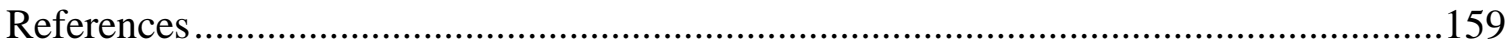




\section{List of Tables}

Table 2.1 Farm Bills and conservation programs that influenced agricultural practices in the Eightmile and Fifteenile Watersheds.

Table 2.2 Detections of glyphosate and AMPA in Water ................................................44

Table 2.3 Detections of glyphosate and AMPA in sediment............................................45

Table 2.4 Detections of glyphosate and AMPA in field soils............................................46

Table 3.1. Mean contributions of sediment from different source areas with calculated standard deviations and standard errors of the mean.

Table 3.2. Table showing categories of conservation tillage and residue ......

Table 3.3. Differences between erosion rates based on type of tillage used

Table 3.4. Differences between erosion rates based on variations in the range of

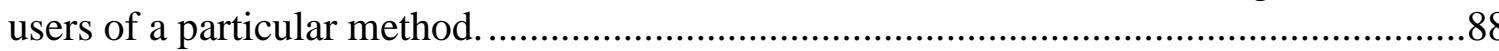




\section{List of Figures}

Figure 2.1 Study area showing locations of soil, sediment, and surface water samples in the Fifteen and Eightmile Watershed of Wasco County

Figure 2.2 Photo demonstrating sampling scheme for herbicide sampling on hillslopes and adjacent streams

Figure 2.3 An example of drone imagery used to verify NDVI values..............................26

Figure 2.4 Changes in Vegetation Health from 1986 to 2016 .........................................27

Figure 2.5 The changes in vegetation health within a 100 foot buffer area from 1986 to 2016

Figure 2.6 Changes between vegetation types (1986 to 1990) ……………………..........32

Figure 2.7 Changes between vegetation types (1990 to 1994) ...........................................33

Figure 2.8 Changes between vegetation types (1998 to 2000) ...........................................33

Figure 2.9 Changes between vegetation types (2008 to 2011) ...........................................34

Figure 2.10 Changes between vegetation types (2011 to 2015) ........................................36

Figure 2.11 Annual precipitation in Wasco County, OR ...............................................36

Figure 2.12 June monthly precipitation in Wasco County, OR ……………………….......37

Figure 2.13 July monthly precipitation in Wasco County, OR ………………………........37

Figure 2.14 Annual mean temperature in Wasco County, OR ...........................................38

Figure 2.15 June monthly mean temperature in Wasco County, OR .................................38

Figure 2.16 July monthly mean temperature in Wasco County, OR …………………......38

Figure 2.17 Areas that remained unhealthy between 1986 and 2016 ...............................41

Figure 2.18 Months of herbicide spraying and concentrations of glyphosate and AMPA detected in water samples...............................................................................47

Figure 2.19 Months of herbicide spraying and concentrations of glyphosate and

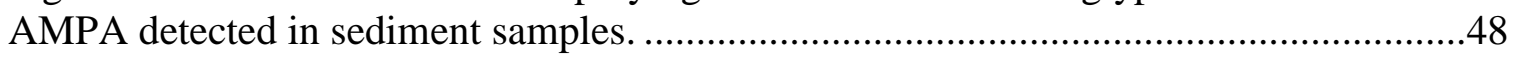

Figure 2.20 NDVI drone image of area near sample location SD-5 ..............................49

Figure 2.21 NDVI drone image of sample location SD-12 .........................................49

Figure 2.22 Concentrations of glyphosate and AMPA versus soil texture in sediment and soil.

Figure 2.23 Sediment, water, and soil concentrations of glyphosate and AMPA in

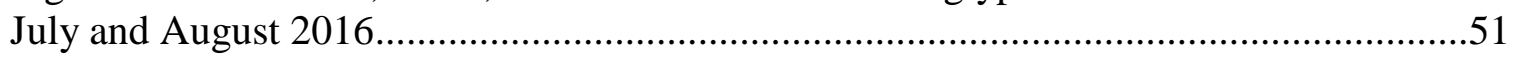

Figure 2.24 Figure of glyphosate human and ecological health impacts ..........................53

Figure 3.1. Study Area...........................................................................................67

Figure 3.2. Examples of floodplains and terraces mapped using the TerEX Tool ...........77 


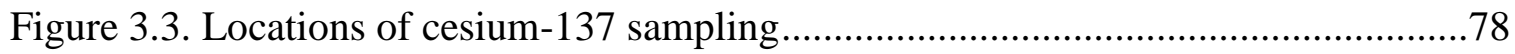

Figure 3.4. An example of an ephemeral gully from the years 1939 to present...............84

Figure 3.5. Figure showing an example of a highly modified stream in the watershed.

Figure 3.6 Locations where the TerEx tool identified likely floodplain and eroding terraces throughout the watershed

Figure 3.7 RBS sites in fair or poor conditions

Figure 4.1 Economic, regulatory, and environmental trends that have influenced conservation farm bills.

Figure 4.2, Herbicide resistance, trends in commercial sales, and regulatory trends influencing increased glyphosate use and human and environmental health

concerns 116 


\section{Chapter 1: General Introduction}

Soils, as intrinsic parts of largely land-based ecosystems, provide us with the most basic means to sustain ourselves, including the purification and cycling of major sources of water...Most life on land would therefore not even exist without soils and, indeed, neither would we. We all depend on soils for our very survival because, at a minimum, we all have to drink water and eat. -Salvatore Engel-Di Mauro, Ecology, Soils, and the Left: An Ecosocial Approach

As environmental consequences of living in the age of the Anthropocene intensify, humans need to think critically about the consequences of land management techniques and what social and physical factors contribute to environmental degradation. This dissertation research critically examines the effects of conservation management techniques, loosely referred to as no-till agriculture, and its effects on soil and water quality issues in the Fifteenmile Watershed of Wasco County, Oregon.

No-till farming gained widespread acceptance across the U.S. in the early 1990s after a variety of intensive agricultural policies and practices in earlier decades threatened production of soils and food, and after deepening public concern arose over unsustainable environmental practices (Hall, 1998; Lehrer, 2010; Rigdon, 2011). In contrast to conventional tillage, which can promote the runoff of sediment, fertilizers and pesticides into rivers, lakes and oceans, no-till seeks to minimize soil disruption (Huggins and Reganold, 2008). No-till farmers leave crop residue on fields post-harvest, where it protects the soil from erosion by acting as a mulch and by fostering soil productivity that increases organic matter. Instead of using a plow to turn the soil and open the ground, notill farmers push seeds down through the organic matter from prior crops, minimizing direct disturbance of the soil (Montgomery, 2007). 
The majority of farmers in Wasco County have been engaging in no-till practices since the late 1990s and early 2000s with varying degrees of success. Although environmental conditions such as erosion and elevated levels of sediment in streams visually appear better in the watershed, several monitoring studies have indicated that sediment in streams have not improved, and unprecedented amounts of herbicide use, namely glyphosate, pose new threats to ecological and human health. These problems are not unique to the watershed, but are symptomatic of varying degrees of implementation of no-till across the U.S. (Huggins and Reganold, 2008, Rigdon, 2011). As such, an investigation of the causes of inadequate implementation of no-till are warranted and are increasingly needed as approximately $40 \%$ of U.S. land is currently managed with no-till systems (USDA, 2017). The trajectory and outcomes of no-till in The Fifteenmile Watershed has mimicked many of those on a national level. Therefore, the watershed acts as an ideal location to investigate the advantages and disadvantages of its implementations.

In this dissertation, I dedicated considerable research efforts to collecting soil and sediment samples from fields and streams throughout the county to investigate soil quality because so much of how no-till affects the environment has to do with how soils are managed. As such, an important contribution of this dissertation will be its contributions to literature on social processes that affect soil quality and processes that lead to its degradation and erosion. In the past decade or so of research, there has been a call amongst soil scientists and historians studying soil science to include humans as a major soil forming factor (Engel-Di Mauro, 2014; Richter, 2007; Swidler, 2009). Until well into the 20th century, nearly all pedology articles and texts mentioned little or 
nothing about the human role in soil formation (e.g., Byers et al., 1938). Historically, pedology has emphasized the natural environment and minimized humanity's influence (Dudal et al., 2002). Yet, recently multiple scientists (Engel-Di Mauro, 2015; Lave et al., 2013 McClintock, 2015; 2013 Richter, 2007; Swidler, 2009) have argued for inclusion of humans as either a serious component to soil formation or as a major soil forming factor. Engel-Di Mauro (2014) argues that human contribution to soil-making should be considered as ancient as the human species, in one degree or another, since land-based organisms always had some effect on the formation and development of soils. As noted by Wells and Noller (1999) and Showers (2006), the job of the pedologist has always been to provide information about the properties and processes of Earth's soil, and contemporary pedologists need to understand it as a historical and cultural body as well. The accelerating pace of global soil change challenges pedologists not only to quantify how soils are affected by humanity (Stroganova et al., 1997; Zitong et al., 1999; Schaetzl and Anderson 2005; Galbraith, 2006) but also to understand how human impacted soils interact with the wider environment. The job of the pedologist has expanded from one attending to Earth's soil as a natural body, to one that includes all of human relations with soils in the global environment.

Richter (2007) argues that as land uses intensify and data from long-term soil experiments accumulate, the rate dependence of changes in soil properties is being directly observed, and much of what has previously been conceived as being slow to change is in fact relatively dynamic from decade to decade. On time scales of decades, anthropedogenesis can rapidly alter acidification and salinization; organic matter dynamics; translocations of solutes, colloids of silicate clay, organic matter, and $\mathrm{Fe}$ and 
Al oxides; and redoximorphic features, surface charge properties, aggregation, porosity, gas and water relations, and even rooting depth and texture. A number of long-term soil experiments (Gerzabek et al., 2001; Richter et al., 2007) and repeated soil surveys (Bellamy et al., 2005) provide evidence for soil change on relatively short (i.e., human) time scales. Given that some of society's most important scientific questions concern the future of soil (for example, whether soil productivity for crops can be doubled in the next 50 years, or whether soil-management control can be established to minimize adverse effects on the atmosphere and water) far greater attention needs to be paid to quantifying how Earth's soils are changing over time scales of decades (Richter, 2007). Therefore, the historical treatment of soils and its physical manifestations must be studied in order to understand its effects on various societies (Swidler, 2009, Engel-Di Mauro, 2014).

The following chapters describe how conservation practices have affected processes such as soil erosion and chemical inputs, which directly influence soil development and degradation. Further, the contents of these chapters will speak to the increasingly short decadal time scales upon which soils are changed. Many no-till farmers have only been practicing no-till for less than 20 years, but the impacts to soil quality and the broader environment have been substantial.

\section{Research Design Overview}

The goals of this dissertation are two-fold. First, I recommend tools and methodologies that will help land managers identify the current social and environmental data gaps that hinder efforts to improve soil and water quality conditions in the county and across the U.S. Secondly, I explore how farmers and land managing authorities' engagement with the physical and social processes of conservation management 
techniques may contribute to issues with soil and water quality. The goals of the project will be met by the use of a "critical physical geography" (CPG) framework, which is at the frontier of synthesizing human and physical geography (Lave, 2013). Use of CPG will identify how land managers and scientists can improve the incorporation, and applicability of, both physical and social scientific data to conservation management techniques to achieve the best outcome for soil and water resources. As I engage the CPG framework, I use a variety of physical and social research methods, including: field sampling, spatial analysis, semi-structured interviews, and critical theory.

The following chapters address the questions of how to monitor and address the implementation of no-till conservation management techniques in agricultural settings that are experiencing the unintended consequences of uneven conservation measures. The findings in each chapter provide answers to particular knowledge gaps in current understandings of how conservation management techniques affect soil and water quality in the Fifteenmile Watershed, which are reflective of broader patterns of land managed under no-till systems nationwide. Chapter 2 investigates the outcomes of increased herbicide use in the Fifteenmile Watershed, with the goal of determining what concentrations of glyphosate are present in the watershed already and if they pose concerns for human and ecological health. Chapter 3 evaluates the relative effectiveness of various conservation management techniques that have been used over time in the watershed, and the relative effectiveness of no-till at resolving sedimentation issues in the watershed. Chapter 4 evaluates the roles of quasi-state actors and larger agrienvironmental policies driven by U.S. farm bills, with particular emphasis on the impacts of farm bills implemented from 1985 forward. These bills have had the most effects on 
how conservation methods have been implemented and explain the rise of no-till as the conservation method of choice for market-based neoliberal processes that have shaped farmers' interactions with the land and water they manage.

The broader impact of this research will be a contribution to the literature that argues for humans as a major factor for soil formation. An understanding of human contributions to soil formation is critical for resolving issues with conservation programs in agricultural systems (Engel-Di Mauro, 2014, Richter, 2007). Soil and landforms have no predetermined destiny in the presence of humans, and as such, soil acts as a historical record of management techniques (Swidler, 2009). A large part of establishing the significance of humans in the process of soil formation will be to contribute to the literature on how soil is changing over increasingly short, decadal time periods instead of longer millennial scales as has been done in the past (Richter, 2007). This project will show how soil quality has changed over decades through unprecedented amounts of increased herbicide use and how erosional sources have changed over the spans of decades via changes in conservation practices. 


\title{
Chapter 2: A Mixed-Methods Approach to Determine How Conservation Management Programs and Techniques Have Affected Herbicide Use and Distribution in the Environment Over Time
}

\begin{abstract}
Many proponents of no-till agriculture claim that it is a sustainable alternative to conventional agriculture. No-till agriculture has the ability to reduce fuel consumption, increase soil moisture, reduce soil erosion and increase organic matter (Williams and Wuest, 2014). Although no-till agriculture provides many benefits to soil ecosystems and humans, it remains unclear whether it increases herbicide use overall in the long term for communities that use it as their primary source of conservation agriculture (FernandezConejo, 2013; Friedrich and Kassam, 2012), and the amount of herbicide use varies from agricultural community to community. The impacts of increased herbicide use have significant implications not only for soil quality but also for water quality. The preponderance of literature suggests that no-till has increased herbicide use, but it is usually difficult to quantify how much herbicide has increased in a given location and to directly correlate changes in herbicide use to changes in soil and water quality. This paper provides several methods to determine how herbicide use has changed over time in an agricultural community in Oregon that switched over to no-till in the late 1990s and early 2000s. These methods include: spatial analysis of remote sensing satellite imagery of vegetation health along streams; use of a drone fitted with an agricultural camera to detect vegetation health; soil, sediment, and water sampling for the most commonly used herbicides in the study area; interviews with, and collection of data from, farmers; and agency record review of herbicides used in the area. By conducting these methods, this
\end{abstract}


study shows where stream vegetation health continues to be an issue in the agricultural community, and where concentrations of a commonly used herbicide in the community may be impacting human and ecological health. This study has important implications for impacts to soil and water quality over time in agricultural communities, as many researchers have noted the need to determine the long term effects of conversion to no-till and other forms of conservation agriculture (Huggins and Reganold, 2008; Montgomery, 2007; Service, 2007, Williams and Wuest, 2014). By providing these methods, communities heavily engaged in multiple forms of conservation agriculture may be able to track how herbicide use is changing in real time and on shorter decadal time spans in places where conservation agriculture is practiced. Therefore, they may also be able anticipate the long term effects of herbicide use on soil, sediment, and water quality and derive the causes for changes in the quality of each.

\section{Introduction}

Since the late 1990s and early 2000s, wheat farmers in Wasco County, Oregon have gradually converted from conventional tilling practices to no-till and direct seeding agricultural practices. No-till and direct seed, while technically different, are used interchangeably among farmers in the study area and much of the Pacific Northwest. Both no-till and direct seed are forms of conservation agriculture that refer to the practice of minimal tillage or no-tillage that cause between $15-30 \%$ of soil disturbance within a row width (NRCS, 2006), which generally is achieved by the use of farm equipment that minimizes the area of disturbance during planting and harvesting activities (Friedrich and Kassam, 2012). Both practices minimize soil erosion by leaving crop stubble and residue on the ground after harvest, increase soil moisture and organic material, and generally 
reduce fuel consumption for farmers (Williams and Wuest, 2014). While many of the economic and environmental improvements of these conservation management techniques have been significant, interviews with farmers and herbicide distributors in the county, as well as a review of the National Agricultural Statistics Service (NASS) database (USDA, 2012), Oregon Department of Agriculture Pesticide Use database records, and collection of herbicide use records from farmers in the county, all indicate that herbicide use in the study area has increased since the onset of no-till and direct seed agriculture (hereafter referred to as no-till). The increased use of herbicides in soils may be resulting in increased herbicide runoff to streams that is harmful to human and ecological health. However, no studies have been conducted to determine herbicide concentrations in streams or to assess the overall effectiveness of no-till since the majority of the county converted.

\section{Herbicide Use Trends in Conservation Agriculture}

Although there are numerous comparative studies focused on differences between conventional tillage and no-till, no clear consensus has been established regarding the effect of conservation tillage on herbicide use (Fernandez- Conejo, 2012; Friedrich and Kassam, 2012). Location, climate, and soil type all affect how long herbicides persist in the soil when used with reduced tillage systems (Hager and Nordby, 2008). Interviews and discussions with farmers and herbicide distributors in Wasco County reveal glyphosate, commonly known as Roundup, is the most commonly used herbicide in the county among wheat farmers and has been used in increasing amounts since the onset of conservation management techniques. This increase mimics a nationwide increase of glyphosate use in the U.S., which is primarily due to the spread of herbicide resistant 
weeds that have been coproduced with genetically modified crops (Benbrook, 2016; Culpepper, 2006; Givens et al., 2009; Hembree and Shrestha, 2005; Koger et al., 2004 Powles, 2008; Shesthra et al., 2007). Since 1974 when glyphosate was released to the market, over 1.6 billion kilograms of glyphosate active ingredient have been applied in the U.S. alone, and of that, two-thirds of the total volume of glyphosate applied in the U.S. from 1974 to 2014 has been sprayed in just the last 10 years (Benbrook, 2016). In 2014 , the amount of glyphosate that farmers sprayed was enough to apply $\sim 1.0 \mathrm{~kg} / \mathrm{ha}(0.8$ pound/ acre $)$ on every hectare of U.S.-cultivated cropland and nearly $0.53 \mathrm{~kg} / \mathrm{ha}(0.47$ pounds/acre) on all cropland worldwide (Benbrook, 2016). Between 1996 and 2011, 527 million pounds of herbicides were used in herbicide resistant crops in the U.S. in excess of what would have been needed in non-resistant crops (Benbrook, 2012). Although much of the increase in glyphosate is due to the rise of "Roundup Ready" crops that are resistant to glyphosate damage, the increase in glyphosate is also due to the rise of conservation tillage practices, such as no-till (Service, 2007).

Farmers in the study area use a variety of glyphosate-based mixtures to control weeds prior to and after harvest, as well as to control weeds in fallow fields throughout the year. Because glyphosate is a broad spectrum (e.g. non-selective) systemic herbicide that kills most herbaceous plants and cannot be used for live crops (Kremer and Means, 2009), other herbicides (mostly chlorinated herbicides such as 2,4-D and Dicamba) are applied less frequently to actively growing crops. Glyphosate and chlorinated herbicides are applied in a number of ways in the study area. Most farmers currently use their own boom sprayers or other spray devices to deploy herbicides before harvest and throughout the year to keep weeds under control. In the past, herbicide was frequently deployed by 
aerial crop dusters and is still sometimes used on a smaller number of farms, but has fallen out of favor due to expense and lack of precision during spray. Though most farmers use glyphosate on their fields, there are areas where spraying is avoided, such as on land that is enrolled in conservation programs like the Conservation Reserve Program (CRP) or the Conservation Reserve Enhancement Program (CREP) along streams. Farmers are not supposed to spray CRP/CREP lands, because these lands that are classified as environmentally sensitive. Generally, farmers try to avoid spray to these areas, both as a matter of compliance with their program specifications, and as a cost saving measure.

\section{Concerns About Glyphosate}

The concomitant increase in herbicide use, particularly glyphosate, in Wasco County and the U.S is concerning for several reasons. Glyphosate was once widely believed to be safe, but an increasing amount of literature is showing that glyphosate is not safe for human or ecological health (Grandjean, 2014; Porter, 2010; Relyea, 2005; Schinasi and Leon 2014). In 2003, researchers found that Polyethoxylated tallowamine (POEA), a surfactant ingredient most often used in Roundup, accounted for more than $86 \%$ of Roundup toxicity on microalgae and crustaceans (Tsui and Chu, 2004). In a 2008 USGS study, glyphosate was measured at high concentrations in vernal pools and adjacent flowing waters in Washington, D.C., with the highest concentration of $328 \mu \mathrm{g} / \mathrm{L}$ exceeding the freshwater aquatic life standard for glyphosate (Battaglin et al., 2009). A 2005 study by Relyea found that Roundup alone is "extremely lethal" to amphibians in concentrations found in the environment (Relyea, 2005). For human health, a recent and major review of 44 scientific studies found that glyphosate exposure doubles farmers' risk 
of developing non-Hodgkin's lymphoma (Schinasi and Leon, 2014). A 2014 study by Grandjean and Landrigan classified glyphosate and several other pesticides as an industrial chemical known to be toxic to the human nervous system. Researchers in a 2005 study evaluated associations between glyphosate exposure and cancer incidence in the Agricultural Health Study (AHS), a cohort study of 57,311 licensed pesticide applicators, and found that glyphosate had a suggested association with multiple myeloma (De Roos et al., 2005).

The EPA acknowledges that glyphosate has the potential to contaminate surface water because it does not readily break down in water or sunlight (EPA, 1993a) but has still maintained glyphosate's 1991 EPA classification as a Group E carcinogen (evidence of non-carcinogenity for humans) (EPA, 1993b). While the EPA has not classified glyphosate as a probable carcinogen (and even increased levels of acceptable use in 2013), the World Health Organization has classified it as such as of 2015 (IARC, 2015). Further, a number of critics say that there is no safe dose of glyphosate due to endocrine disrupting qualities and have stated concerns over its effect on human and ecological health (Grandjean and Landrigan, 2014; Porter, 2010; Schinasi and Leon, 2014).

Despite generalizations that glyphosate degrades quickly and is strongly adsorbed to soil (Mamy, 2005), numerous studies show that glyphosate is available to soil and rhizosphere microbial communities as a substrate for direct metabolism leading to increased microbial biomass and activity (Haney et al., 2000; Wardle and Parkinson, 1990). In another study, Simonsen et al. (2008) demonstrated that agricultural soils amended with phosphorus fertilizers show elevated levels of unbound glyphosate as a result of soil sorption sites being occupied by competing phosphate ions which left 
glyphosate available for potential uptake by plant roots, microbial metabolism, and/or leaching into groundwater.

The half-life of glyphosate in soil ranges from 2 to 215 days, and from 2 to 91 days in aquatic systems (Giesy et al., 2000; Grunewald et al., 2001; NPIC, 2008; Vera et al., 2010). Microbial processes primarily drive the degradation of glyphosate into another compound called aminomethylphosphonic acid (AMPA) (Battaglin et al., 2014; Kremer and Means, 2009). Glyphosate and AMPA are very water soluble, but AMPA degrades more slowly than glyphosate (Grunewald et al., 2001). AMPA has a soil half-life that ranges from 60 to 240 days and an aquatic half-life that is comparable to that of glyphosate (Giesy et al., 2000; Bergstrom et al., 2011). Substantial increases to total phosphorous in aquatic systems (Vera et al., 2010) can occur as a result of AMPA's ultimate degradation to inorganic phosphate, ammonium, and $\mathrm{CO} 2$ (Borggaard and Gimsing, 2008). The main degradation product AMPA is frequently detected in soils subjected to frequent glyphosate applications (Fomsgaard et al., 2003).

\section{Objectives}

While farmers have used a variety of conservation management practices since the mid-1980s, none have been as impactful to the environmental quality of the study area as the switch to no-till, whereby $95 \%$ of farm land has been enrolled in no-till practices to date (NRCS, 2016). No-till was implemented in the county in an effort to conserve soil and therefore reduce the amount of soil and sediment introduced to streams that created water quality issues in the area. However, land managers did not thoroughly consider the implications and effects of how increased herbicide use associated with no-till would affect environmentally sensitive areas. Therefore, this research attempts to examine areas 
in the study area that are environmentally sensitive to herbicide increases such as riparian areas along streams both inside and outside of CRP and CREP conservation easements. The three main objectives of this study were to 1) determine if there have been changes in vegetation health in environmentally sensitive areas along streams running through agricultural property over the past several decades as a result of increased herbicide use in the study area 2.) determine if there are locations where vegetation health does not improve and 3) determine what concentrations of herbicides are in soils, sediments, and surface water in streams in the study area and how they compare to soil and water quality standards, and human and ecological health studies on herbicides.

\section{Methods}

This study was conducted in the Fifteenmile and Eightmile Watersheds of Wasco County, Oregon (Figure 2.1). A mixed-methods approach was employed to complete the objectives of this study to determine if increasing herbicide use could be detected in vegetation along streams within and outside of CREP land and streams adjacent to CRP land to determine what concentrations of herbicide were present in each sampling location. The approach involved the following methods:

1. Collection of surface water, soil, and stream sediment samples to obtain concentration levels of herbicide from agricultural fields and streams running through agricultural fields over a two-year period from 2015 to 2016. The majority of samples were analyzed for glyphosate and its derivative product AMPA. A one-time sampling event of chlorinated acid herbicides was also conducted. Soil and sediment samples were also analyzed for physical and chemical properties that are known to influence herbicide concentration and persistence. The majority of sample collection took place in the 
Fifteenmile Watershed, because the majority of wheat farms are located in this area of the county.

2. Analysis of remotely sensed imagery of vegetation health collected by Landsat satellites 5TM, which collected 30-meter resolution satellite data of the earth's surface from 1982 to 2012, and from the Landsat $7 \mathrm{TM}+$ satellite which collected the same type of imagery from 1999-2016 (NASA, 2017). Imagery was classified into vegetation health categories (described below) and analyzed for changes and trends in vegetation health over that time period.

3. Sample collection using imagery collected by a drone fitted with an agricultural camera to detect herbicide drift and overland runoff from farm fields to vegetation in and near streams in locations where herbicide should not be present (e.g. CREP land or land adjacent to CRP fields). This method was used to determine if vegetation that was stressed or unhealthy could be detected during field collection. It also worked as a ground-truth to the Landsat satellite imagery that was at a much coarser resolution than the resolution of the imagery collected by drone (typically between 5 to $15 \mathrm{~cm}$ resolution). Vegetation values obtained by drone were compared to the values collected in remotely sensed imagery data to assess the accuracy of vegetation health categorized in Landsat imagery.

Details on the methodologies are discussed below.

\section{Herbicide Sampling}

According to herbicide distributors and all of the farmers involved in the study, farmers have to spray their fields with herbicide at least twice a year, and most spray between two and four times a year. The most common time for herbicide applications are 
in spring (May) before summer harvest, in the summer on fallow fields (July and August), and then again in the fall right before, or as farmers are planting, their seed (September). Glyphosate is the herbicide of choice for fallow fields and may be applied during all of the aforementioned months in fallow fields. Glyphosate cannot be applied in actively growing fields because of its non-selective formulation, and farmers use chlorinated herbicides such as 2,4-D and Dicamba that will not damage crops that are alive during application of herbicide. While it would have been ideal to collect as many chlorinated herbicide samples as glyphosate and AMPA, sampling for all compounds was cost prohibitive to this study. Therefore, collection of chlorinated herbicide samples was limited to surface water in streams and in soil or sediment near streams, and was only collected during one sampling event in July. October 2015 Glyphosate and AMPA Samples

Sample collection for herbicides began in the fall of 2015. Herbicide samples were not collected in September due to difficulties with access to fields/streams that arose from farmers simultaneously planting seed and spraying herbicide during that time. Therefore, the first year that samples were collected, samples were collected in early October 2015. Sample locations for all months are shown in Figure 2.1. Five sediment and eight water samples were collected from streams running across six different farm properties. Samples were analyzed for glyphosate and AMPA and were collected inside and outside of CRP/CREP lands to assess if there were any differences in herbicide concentration between lands that were or were not protected. 


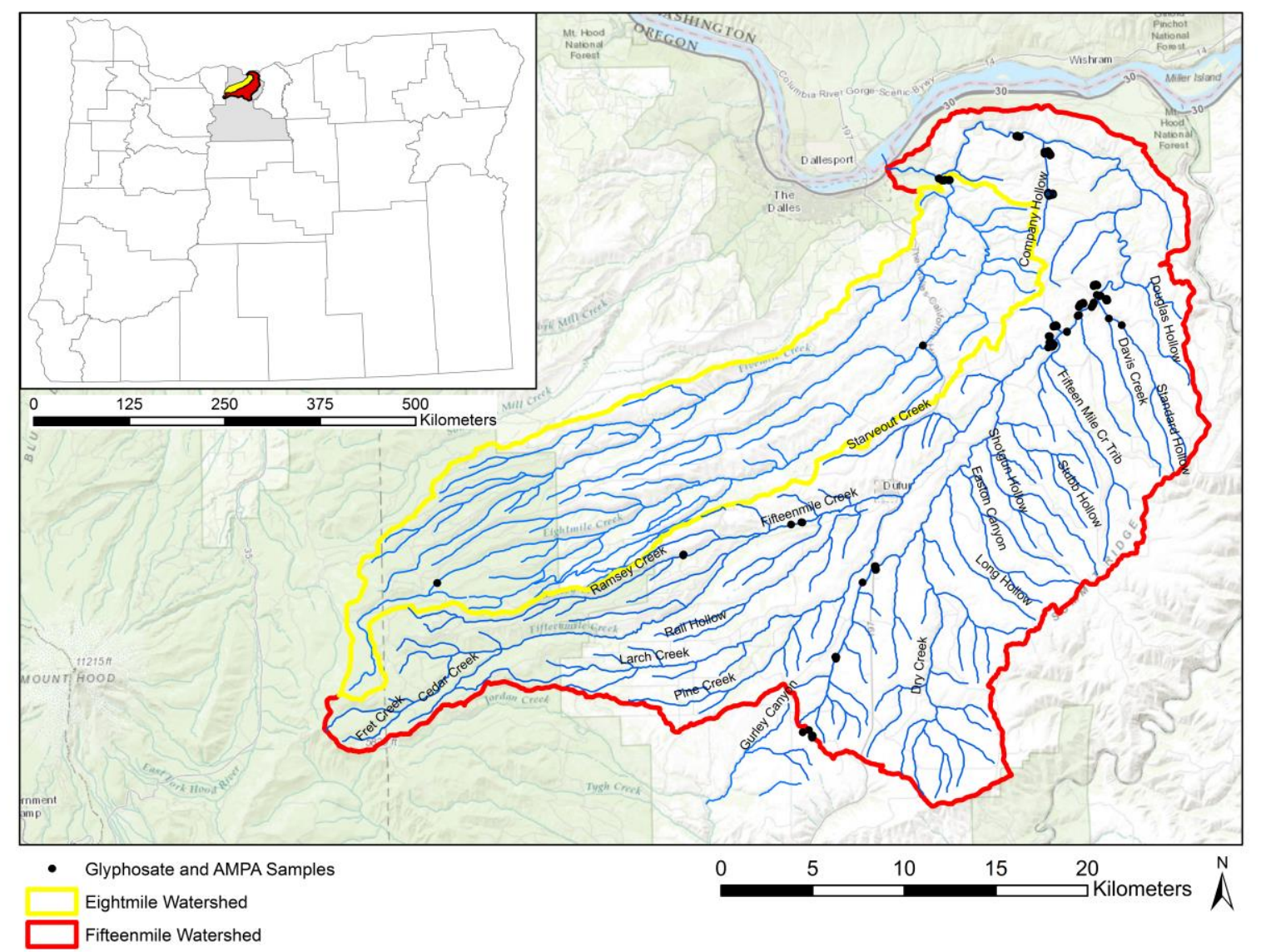

Figure 2.1 Study area showing locations of soil, sediment, and surface water samples in the Fifteen and Eightmile Watershed of Wasco County (shown in gray). Samples were collected and analyzed for glyphosate, AMPA, and chlorinated herbicides during the years 2015 and 2016.

At each location, water was collected upstream of the person sampling prior to disturbing the sediment in the stream for sediment collection by placing a laboratory approved certified clean bottle into the stream and allowing it to fill with water. Once the water sample had been collected, the sediment from the streambed was collected by either a 2 inch diameter PVC tube that was decontaminated prior to use with Alconox and deionized (DI) water or a shovel that was decontaminated in the same way. The selection of the method to use depended on flow conditions in the stream and depth that could be obtained by each instrument. The soil/sediment samples taken from 0 to 30 centimeters 
below ground surface were loosened with the sampling instrument and placed in lab assigned, certified clean sampling jars. Each sampling location was recorded with a Trimble Juno GPS unit.

May 2016 Co-located Glyphosate and AMPA Samples

Seventeen samples comprised of eight sediment and nine water samples were collected from stream channels throughout the study area that would most represent waterways affected by no-till farming. Samples were collected with the same collection procedures as those collected in October 2015. Samples were collected inside and outside of CRP/CREP and were analyzed for glyphosate and AMPA.

July 2016 and August 2016 Glyphosate, AMPA, and Chlorinated Herbicide Samples

Twenty six soil and sediment samples and ten water samples were collected from five hillslopes and their adjacent streams on each farm property in the study area and analyzed for glyphosate, AMPA, and chlorinated herbicides. Transects representing the top, middle, and toeslope positions of the hillslope were used for composite sampling (Figure 2.2). Along each hillslope transect, between four and five discrete soil samples, depending on the size of the hillslope (Zapata, 2003), were collected from a depth of 0 to $30 \mathrm{~cm}$ and composited into one sample representing its respective transect. This depth was chosen because it represents the portion of the soil that is most likely to move with overland flow (Zapata, 2003). A separate transect representing the in-stream sediment that drained the depositional area of the hillslope (i.e. the area that would capture runoff from the hillslope above) was also sampled on each property. Samples collected along transects in in-stream sediment were discrete and not composited. In total, four transects (representing top, middle, toe, and in-stream channel) were devised for each property. 


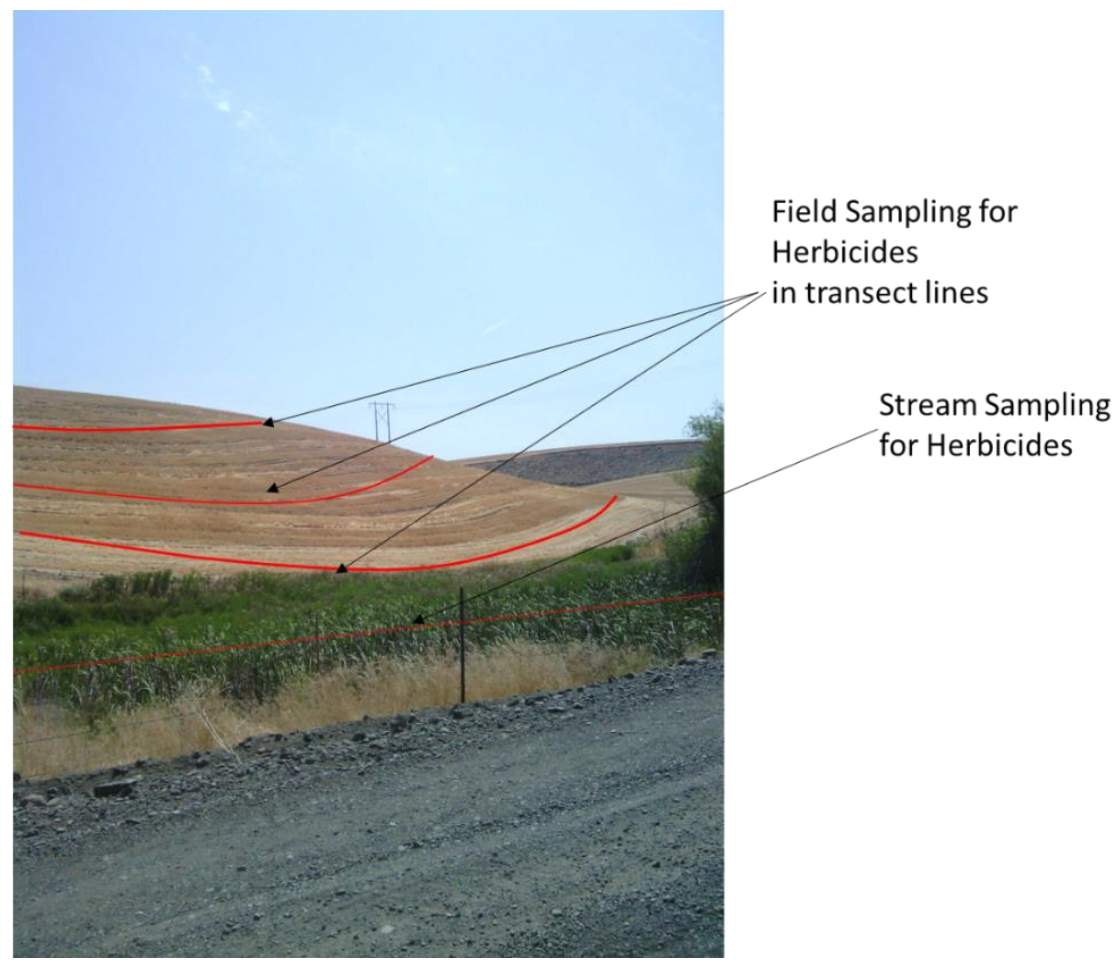

Figure 2.2 Photo demonstrating sampling scheme for herbicide sampling on hillslopes and adjacent streams. Discrete samples along transects were composited into one sample for each transect line. Samples collected in streams were not composited, but were collected in the area of natural drainage from the hillslope above.

\section{Sampling Equipment Decontamination and Laboratory Methods}

Prior to initial use and between sample locations, all non-dedicated sampling equipment used for sample collection was rinsed with DI water, brushed with DI water and Alconox soap, and rinsed and sprayed with DI water again before use. Collected surface water, soil, and sediment samples were placed in certified clean, glass amber bottles for glyphosate/AMPA and clear glass bottles for chlorinated herbicides recommended by the laboratories analyzing the samples. Samples were labeled, placed on ice in an insulated cooler, and delivered to a private environmental laboratory with accreditation by the National Environmental Laboratory Accreditation Program (NELAP) or to the USGS National Water Quality Lab in Lawrence, Kansas. For glyphosate and 
AMPA, both the private laboratory and USGS laboratory used liquid chromatography/ mass spectrometry method LCGY (https://ks. water.usgs.gov/lcgy) to analyze water samples, with a method detection limit (MDL) of 0.02 micrograms per liter $(\mu \mathrm{g} / \mathrm{L})$. The USGS Liquid Chromatography Mass Spectrometry method LCGS (https://ks.water.usgs.gov/current-analytical-methods) for soil and sediment was used to analyze soil and sediment samples, with a MDL of 0.02 micrograms per kilogram $(\mu \mathrm{g} / \mathrm{kg})$ and $1(\mu \mathrm{g} / \mathrm{kg})$. For chlorinated acid herbicides, EPA Method 515.3 was used by the private laboratory to analyze the samples with an MDL of $0.1(\mu \mathrm{g} / \mathrm{L})$ for water and an MDL that ranged between 0.0194 to 0.0198 milligrams per kilogram $(\mathrm{mg} / \mathrm{kg})$ for soil and sediment.

\section{Soil Quality Indicator Samples}

Like most herbicides, persistence and degradation of glyphosate, AMPA, and chlorinated herbicides depends on the physical and chemical characteristics of soil or sediment to which it is applied (Kremer, 2009; Simenson, 2008). Therefore, a portion of each soil and sediment sample from 2015 and 2016 were dedicated to analysis for physical and chemical soil quality indicators including $\mathrm{pH}$, total exchange capacity, organic matter, soluble salts (salinity), phosphorous content, and also for soil texture to determine if any soil properties had an influence on herbicide concentrations or if any correlative patterns could be deduced. Samples analyzed for physical and chemical characteristics were analyzed either at Portland State University in a soils lab or at the private laboratory Brookside Laboratory, Inc. Soils were analyzed for physical analysis (soil texture) by Hydrometer Method ASTM D422, 2007 and for chemical characteristics 
by Brookside method S005 for Bray II phosphorus, soluble salts, and pH, Organic Matter, Total Exchange Capacity, Soluble Salts, and Mehlich III Extractable P. Spatial Analysis- NDVI Remote Sensing Analysis

One of the primary goals of this study was to deduce whether or not herbicide drift and runoff have been affecting vegetation health near streams since no-till agriculture became the primary form of agriculture in the study area. Because it would be impossible to retroactively sample water, sediment, and soil for trends in increasing or decreasing herbicide concentration, the Normalized Difference Vegetation Index (NDVI) was used to determine if herbicide drift and runoff to stream corridors with riparian vegetation varied with practices in conservation management techniques and programs practiced in the study area. The working assumption of this research was that if herbicide use has increased since no-till became widely practiced, then herbicide drift during application (known to be a problem in the study area to some sensitive crops) and herbicide runoff from overland flow to riparian vegetation near streams would also increase as well. Most farmers in the study area have either enrolled riparian stream areas crossing their properties into CREP, which creates a buffer around streams to protect environmentally sensitive species, and/or have pro-actively planted vegetation near streams to prevent erosion from field runoff since the early 2000s when no-till was also widely spreading throughout the county.

The NDVI can detect vegetation that is dead or stressed from vegetation spray or runoff from agricultural fields (Henry et al., 2004). It is a commonly used and wellestablished method (Griffith, 2002; Henry et al, 2004; Trivero, 2013) to determine vegetation health in a variety of environments and is a defined ratio of the near-infrared 
and visible spectral bands from remote sensing imagery. NDVI is calculated as: NDVI = (NIR-RED)/(NIR+RED). Index values range from -1 to +1 where open water is the most negative, concrete, rock and bare ground are close to 0 , and healthy dense vegetation is close to +1 (NASA, 2016; Trivero, 2013). NDVI can be derived from any imagery with a red and a near-infrared spectral band, but due to the spatial and temporal resolution and the history and availability of its data, Landsat imagery is one of the best sources for monitoring long-term and ongoing landscape trends at a fairly high spatial resolution (Wulder et al. 2012). Higher greenness values, especially during the late growing season when water availability is limited, indicate healthy vegetation (Griffith, 2002).

In the study area and much of the Pacific Northwest, the late growing season in the study area is July and early August (Small et al., 1990). Therefore, imagery from the last two weeks of July from Landsat 5TM satellites and the Landsat 7TM+ satellite was downloaded and analyzed for vegetation health representing the past $30+$ years in the study area. To determine if vegetation health in riparian areas had been affected by conservation practices, 100-foot buffers of vegetation along riparian stream corridors were extracted from Landsat images from years when conservation practices and notill/direct seed were likely to affect stream vegetation: 1986, 1990, 1994, 1996, 2000, 2003, 2006, 2008, and 2011, 2015 to 2016. The width of 100 feet was chosen because it is the average buffer width of CREP land in the state or Oregon (DEQ, 2010, U.S. Fish and Wildlife Service, 2009). Table 2.1 shows a variety of conservation programs that have been practiced in the study area that were driven by farm bills passed since 1985 . The year 1986 was chosen as the start date for analysis of imagery because it occurred 
after the first year that sweeping conservation efforts were made in 1985 to most of the

study area.

Table 2.1 Farm Bills and conservation programs that influenced agricultural practices in the Eightmile and Fifteenile Watersheds. Conservation programs influenced vegetation health near streams and water quality in agricultural landscapes by reducing soil erosion, changing herbicide practices, and encouraging enrollment in programs that maintain stream health. The programs in the table were widely practiced in the watersheds of the study area and likely influenced vegetation health and stream quality in and near streams.

\begin{tabular}{|c|c|c|}
\hline Year & $\begin{array}{l}\text { Farm Bill Title or Conservation } \\
\text { Agriculture Program Implemented }\end{array}$ & Impact to Farms \\
\hline 1985 & $\begin{array}{l}\text { Food Security Act of } 1985 \text { Conservation } \\
\text { Reserve Program (CRP) established }\end{array}$ & \multirow[b]{2}{*}{$\begin{array}{l}\text { Multiple conservation efforts to reduce soil } \\
\text { erosion, including strip-cropping/ divided slope } \\
\text { systems. Some farmers take land out of } \\
\text { production and set aside in CRP contracts for } \\
\text { payment. The } 1990 \text { bill changed CRP by } \\
\text { expanding the list of eligible lands for contract } \\
\text { to include marginal pasture lands converted to } \\
\text { wetlands and allowed marginal pasturelands to } \\
\text { be devoted to trees in or near riparian areas, and } \\
\text { lands that may cause an environmental threat to } \\
\text { water quality. }\end{array}$} \\
\hline 1990 & $\begin{array}{l}\text { Food, Agriculture, Conservation and Trade } \\
\text { Act of } 1990\end{array}$ & \\
\hline 1996 & $\begin{array}{l}\text { Federal Agricultural Improvement and } \\
\text { Reform Act of 1996. Conservation } \\
\text { Reserve Enhancement Program (CREP) } \\
\text { established. Environmental Quality } \\
\text { Incentives Program (EQIP) established. }\end{array}$ & $\begin{array}{l}\text { Conservation practices extend to land } \\
\text { surrounding streams and riparian areas. Some } \\
\text { farmers receive payments from EQIP program } \\
\text { for enrolling land into no-till agriculture and for } \\
\text { establishing riparian vegetation buffers along } \\
\text { streams that run through agricultural land. } \\
\text { Farmers able to purchase equipment needed for } \\
\text { no-till agriculture. }\end{array}$ \\
\hline $\begin{array}{l}2000- \\
2002\end{array}$ & $\begin{array}{l}\text { Farm Security and Rural Investment Act of } \\
\text { 2002. Conservation Security Program } \\
\text { (CSP) established. }\end{array}$ & $\begin{array}{l}\text { CSP continues to provide financial and technical } \\
\text { assistance to promote the conservation and } \\
\text { improvement of soil, water, air, energy, plant } \\
\text { and animal life, and significant provisions for } \\
\text { conservation purposes. In this time period most } \\
\text { farmers convert to no-till in the county. }\end{array}$ \\
\hline 2008 & $\begin{array}{l}\text { Food, Conservation, and Energy Act of } \\
\text { 2008. Agricultural Water Enhancement } \\
\text { Project (AWEP) established. }\end{array}$ & $\begin{array}{l}\text { Reinforced conservation programs. AWEP } \\
\text { provision places more emphasis on water } \\
\text { conservation through changing irrigation } \\
\text { practices in the county. }\end{array}$ \\
\hline 2014 & Agricultural Act of 2014 & $\begin{array}{l}\text { Conservation practices continue to be } \\
\text { reinforced. Not much is changed in no-till } \\
\text { practices in the county. }\end{array}$ \\
\hline
\end{tabular}

Once vegetation in 100 foot buffered areas near streams were extracted from the Landsat multispectral imagery, the Image Analysis toolbar in ArcMap was used to convert the imagery into NDVI images. The NDVI index vegetation categories of not 
vegetation (all values below 0.1 ), sparse vegetation ( 0.1 to 0.2$)$, moderate vegetation health ( 0.2 to 0.55$)$, and very healthy vegetation $(0.55$ to 1.0$)$ were assigned to each image (Herring and Weier, 2000). These NDVI values represent the typical range of healthy vegetation in many environments around the world (Herring and Weier, 2000)

and were found to be consistent with the health of vegetation in the study area. Inspection of one-meter resolution National Agriculture Imagery Program (NAIP) aerial imagery verified that values in each NDVI category typically matched the vegetation health assigned in the satellite imagery. Once the satellite images were classified into the vegetation health categories, change detection statistics were performed in the software program ENVI. Change detection statistics were used to calculate the changes that occurred between each progressive year and also to determine the initial and final stages of vegetation health from year to year.

\section{Drone Sample Site Selection and Field Verification}

Landsat imagery provided useful historical analysis of vegetation health that may have been impacted by herbicide drift and runoff (and was the only option to detect how often it occurred in the past). However, the use of an Unmanned Aerial Vehicles (UAV), commonly referred to as a drone, in the field provided a finer scale resolution of vegetation stress caused by herbicide drift and runoff than could be provided with satellite imagery alone. The drone was also useful for determination of vegetation health at the time of sample collection. The use of drones has been significantly increasing in the past few years to monitor crop health and crop spraying of various agrochemical inputs (Estrin, 2015; Hunt, 2010). For this study, a DJI Phantom 4 drone fitted with a NDVI-7 optical grade glass narrow multi-band filter camera lens was used to capture 
images of possibly stressed vegetation during May and July 2016 when crops had recently been sprayed. At each stream that was sampled, the drone (fitted with a GPS unit) was flown over stream segments comprised of a mixture of healthy, dead, and stressed vegetation. After flights were completed, the imagery obtained from the drone was downloaded, georeferenced, and post processed for NDVI values using the Image Classification Tool in ArcMap software to ground-truth vegetation values. Images taken by drone were mosaicked together in ArcMap into an area that covered the same spatial extent covered by Landsat satellite imagery.

To determine how similar NDVI values collected by drone were to those collected by satellite, NDVI pixel values from vegetation (e.g. trees, low lying grasses, and shrubs near streams) were randomly selected using the ArcMap Data Management Tool "Create Random Points" within ten image locations near streams (Figure 2.3). Thirty random points were generated within the 100 -foot boundary of riparian vegetation for each location where drone imagery had been collected and where samples were taken. The average vegetation values for the cells in the random point locations in drone imagery were compared to the values of the vegetation in the cells of the satellite imagery to determine how closely the values in each type of imagery resembled one another.

While images were taken in May and July of 2016, only drone images collected during the month of July were compared for NDVI values of satellite images because of the phenological growth stage of vegetation in July. Since late July and early August are the months for peak biomass growth in vegetation in the study area (Small et al., 1990), images from this time period were likely the most useful for vegetation health analysis. 
The use of the drone during May assisted in identifying sample locations in areas where vegetation stress from herbicide spray could not be seen with the naked eye.

\section{NDVI Drone Imagery}
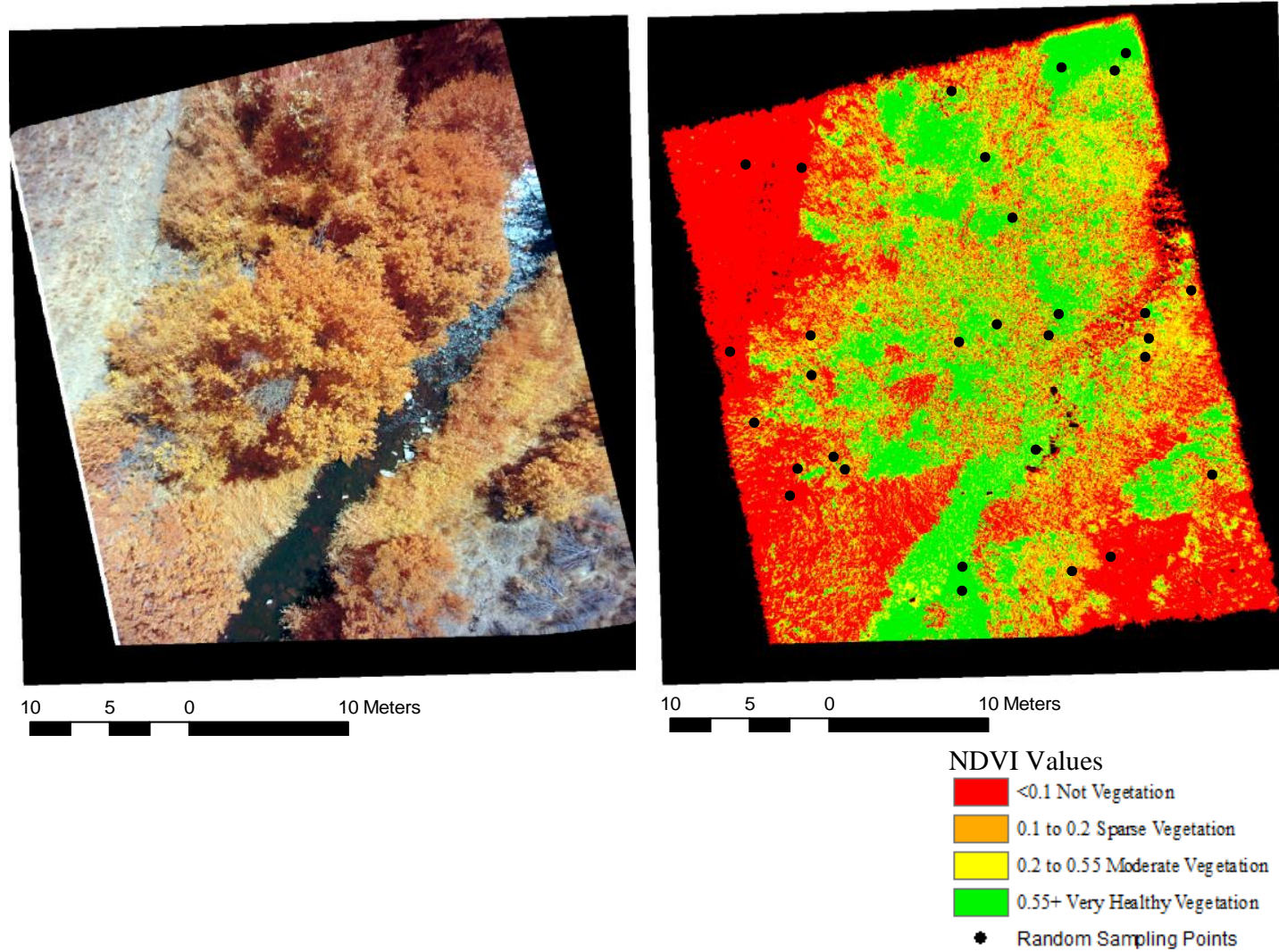

Figure 2.3 An example of drone imagery used to verify NDVI values. The image on the left shows a picture of a riparian area that was collected by the NDVI-7 camera on the drone. With the raw NDVI image, green healthy vegetation appears in yellow/orange/gold while other surrounding surfaces and dead or stressed vegetation appears in grey or brown. The raw NDVI image must be post-processed to obtain the actual NDVI values, which the image on the right shows. Some aquatic plants in the stream display as green (very healthy vegetation) in the post-processed image. The small black dots in the image represent the random sampling points that were generated to verify NDVI pixel values between images collected by drone and images collected by Landsat Satellite.

\section{Results/Discussion}

NDVI Analysis of Satellite Imagery 1986 to 2016

Figure 2.4 shows the trend in vegetation health from 1986 to 2016 in both the

Fifteenmile and Eightmile Watersheds. In general, the trend for very healthy vegetation 
(0.55 or higher on the NDVI scale), declined from 1986 to 1996 and then steadily rose from 1996 to 2011 . Moderately healthy vegetation ( 0.2 to 0.55 on the NDVI scale)

fluctuated slightly in the amount retained from the mid-30th percentile to mid to upper 40th percentile, but retained the same general health over the whole period from 1986 to 2011. Unhealthy or sparse vegetation health (0.2 to 0.55$)$ decreased from 1986 to 1996 , increased between 1996 and 2003, and then decreased to levels near the previous 1986 level in 2011. Post 2011, a sharp decline in all vegetation health categories (except the not vegetation category) occurred due to severe droughts in Oregon in the years 2014 and 2015. In this year, the areas classified as not vegetation increased from below $20 \%$ of vegetation to over $80 \%$.

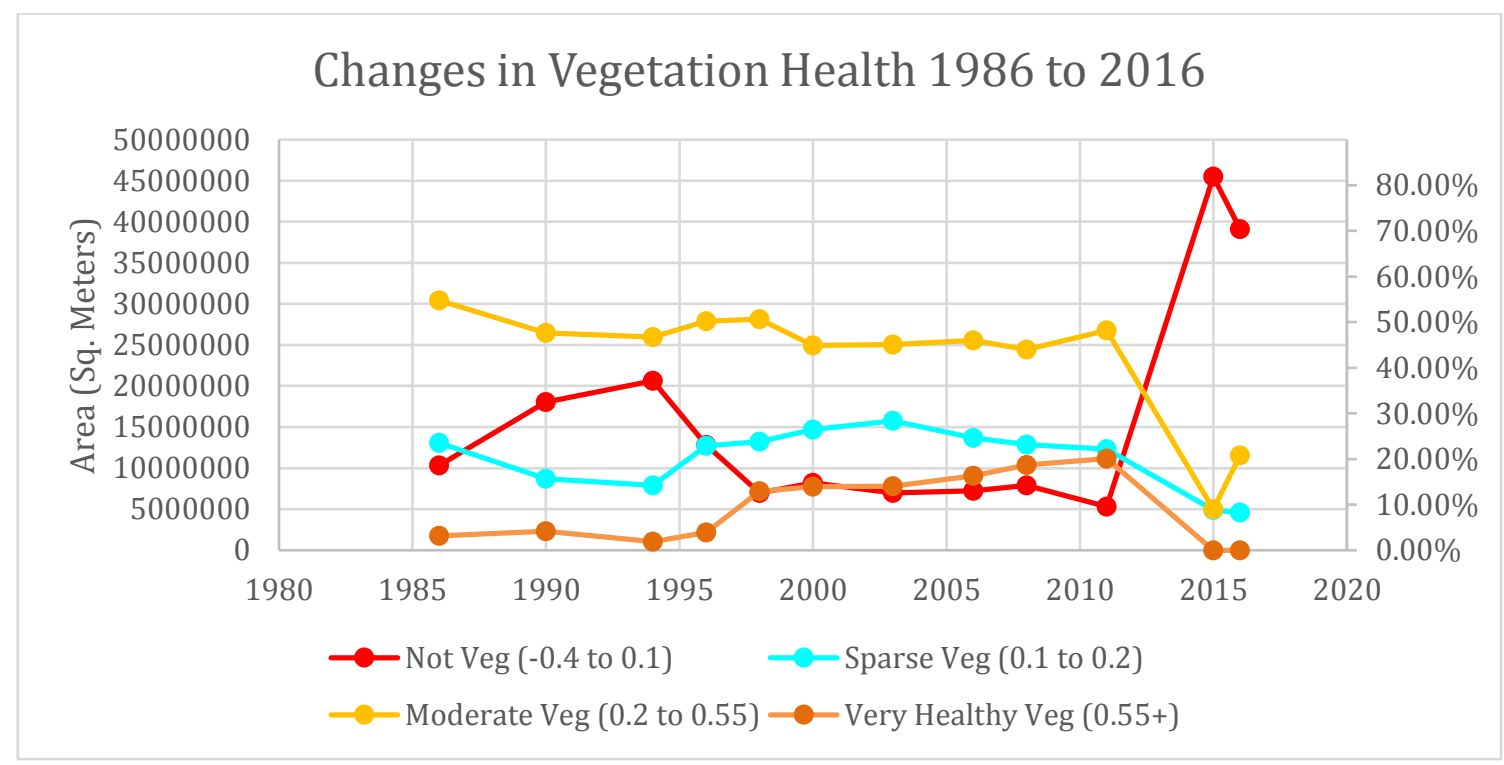

Figure 2.4 Changes in Vegetation Health from 1986 to 2016. The trend lines in the graph show how vegetation has changed during the years when farmers were most active in conservation programs in the study area. Over time, vegetation health has generally improved especially in comparison to vegetation health prior to no-till agriculture.

The vegetation health in various segments of riparian areas that changed over time is shown in Figure 2.5, which shows Landsat imagery of the streams in the Fifteenmile and Eightmile Watersheds classified by NDVI value. These images make it clear that 
vegetation health in the areas near streams were heavily influenced by conservation programs that influenced runoff- carrying herbicide to streams and increases in protected riparian areas enrolled in CREP. Especially significant are the years from the late 1990s to early 2000s when large swaths of CREP riparian areas were planted and no-till was becoming widespread in the county. During the 1996 to 2000 period, vegetation health in the very healthy category increased by almost $20 \%$. 
Stream Health Changes 1986 to 2016

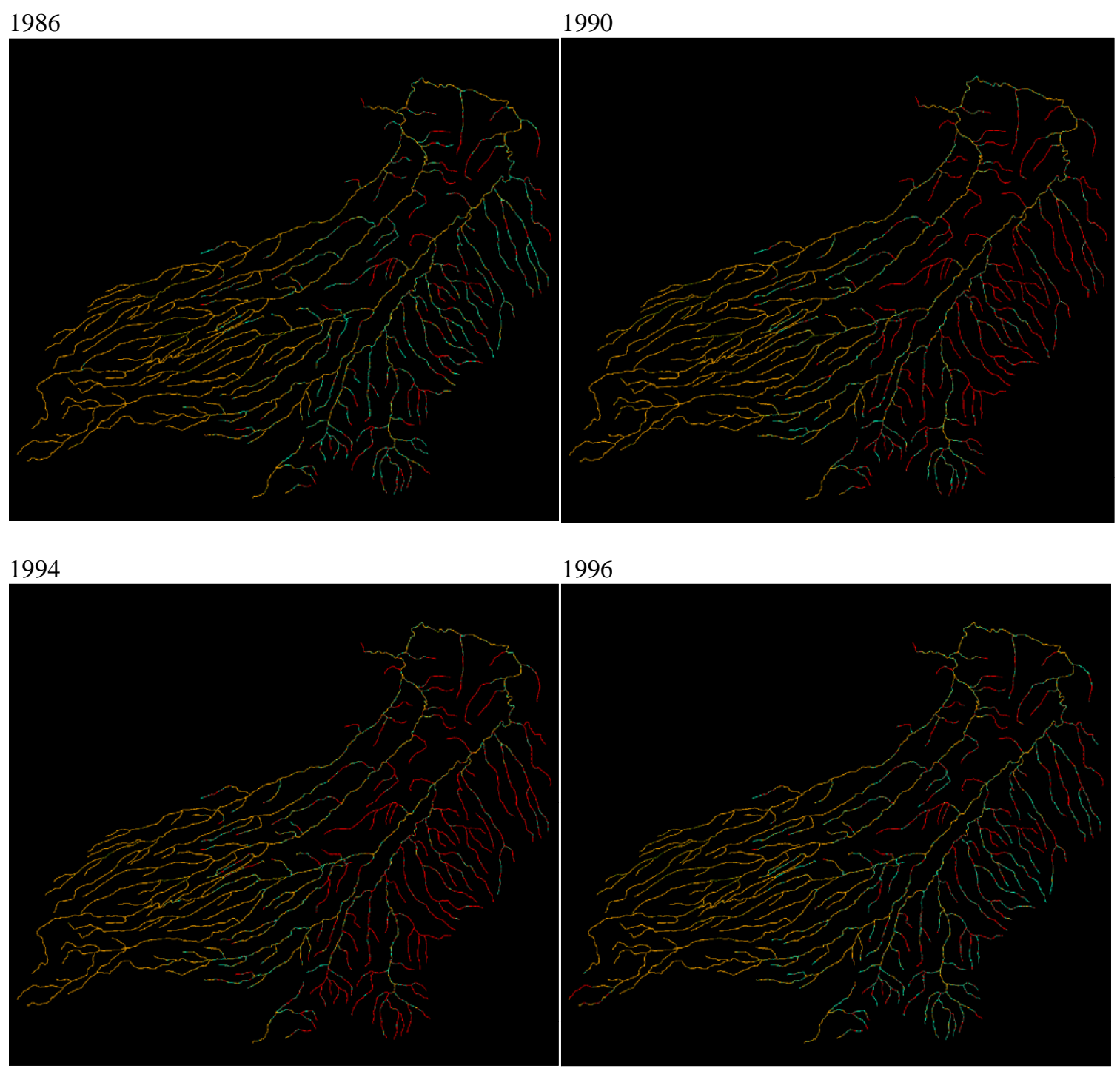



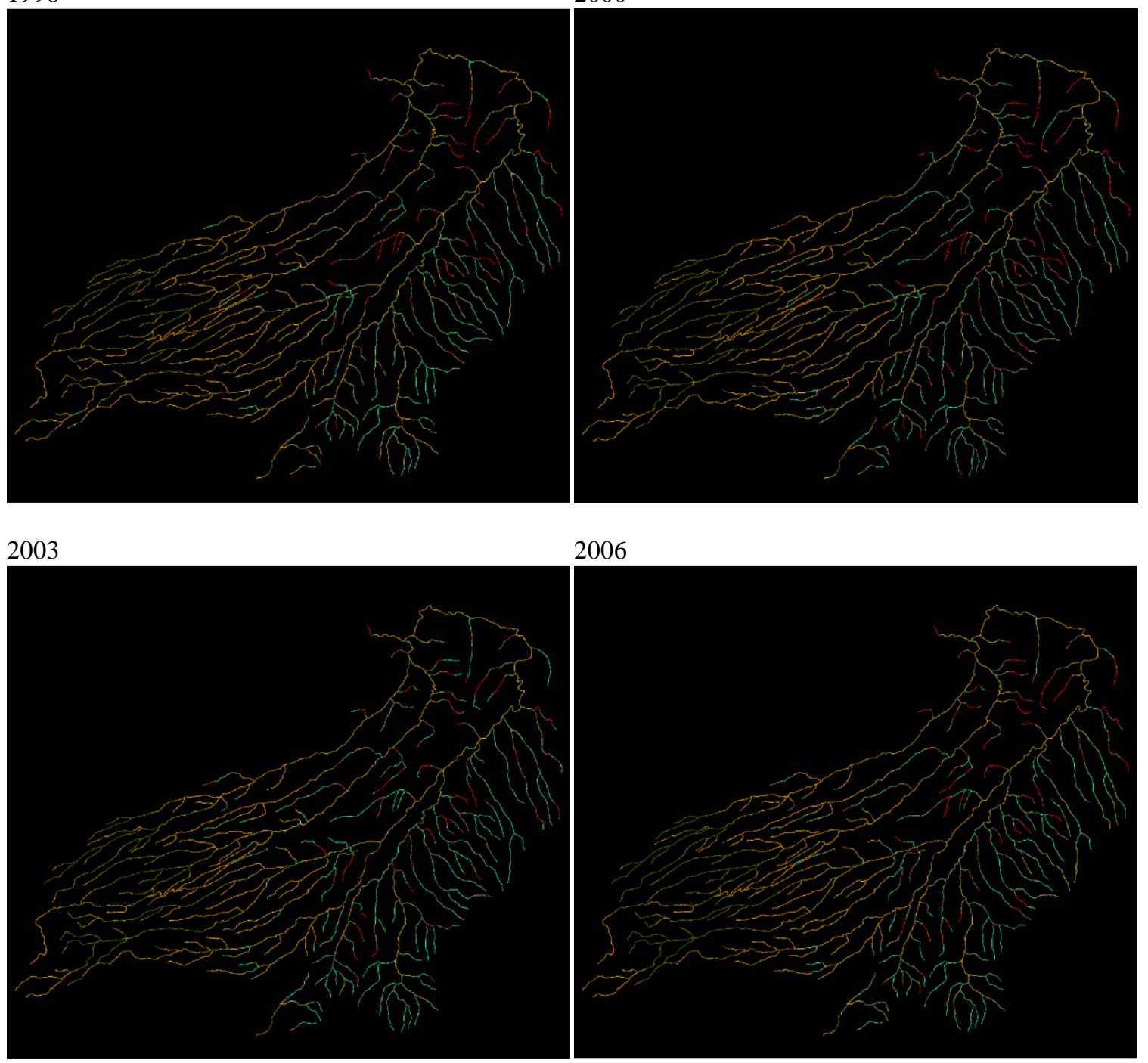

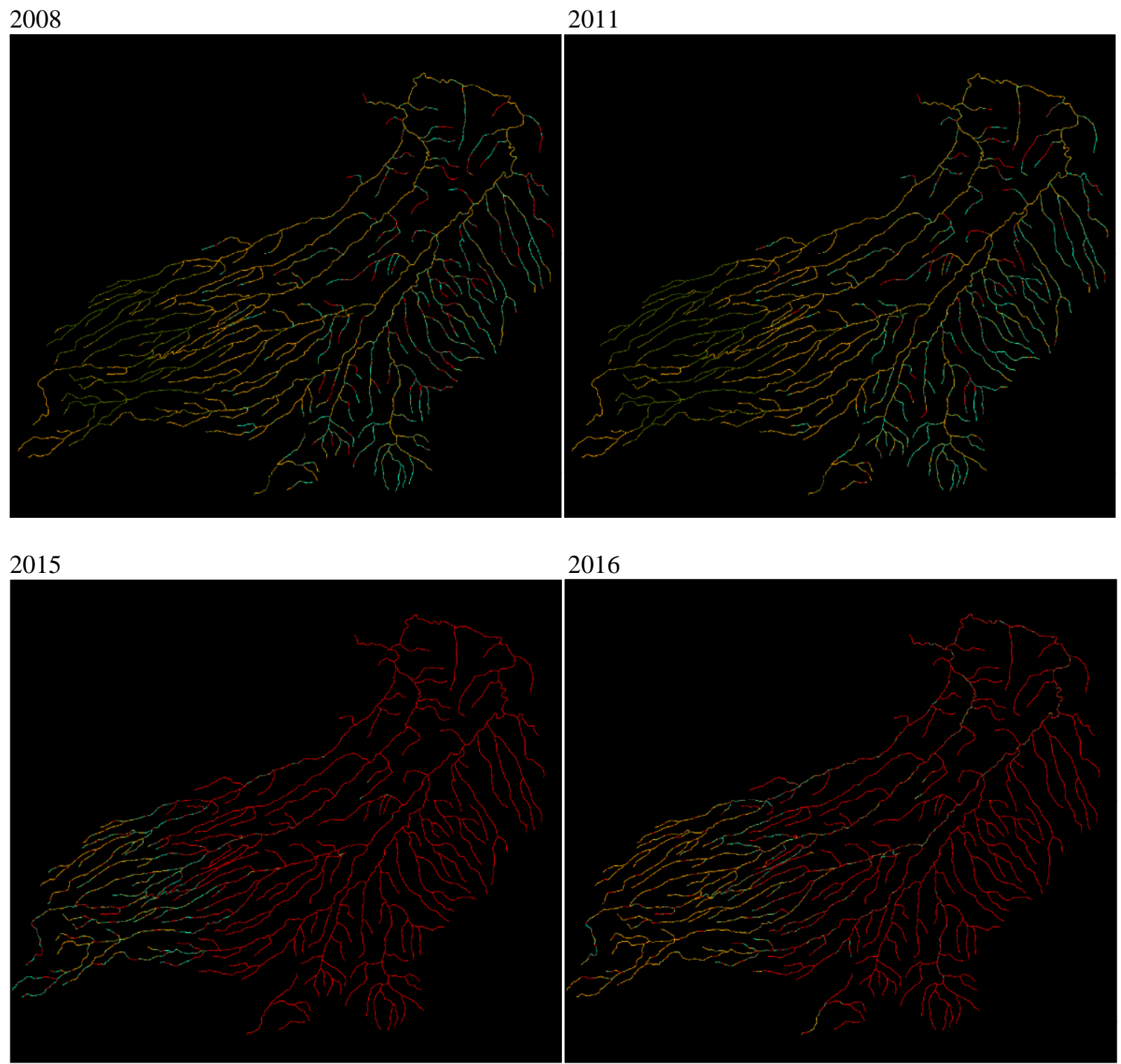

Figure 2.5 The changes in vegetation health within a 100 foot buffer area from 1986 to 2016. Stream segments in red indicate areas without vegetation (not vegetation category), stream segment in blue indicate sparse vegetation, stream segments in yellow indicate moderate vegetation health, and stream segments in green indicate very healthy vegetation.

To fully understand if vegetation health improved or declined overall, it was also useful to look at the initial vegetation health category versus the final vegetation health category of areas along streams. The information was derived by examining the series of stream health changes from 1986 to 2016 in Figure 2.5 and by examining the graphs in Figures 2.6 through 2.9. For example, in Figure 2.6, slightly less than 10 million $\mathrm{m}^{2}$ of vegetation in the not vegetation category remained categorized as not vegetation between 
1986 and 1990. Significantly less vegetation in the not vegetation category converted to the sparse vegetation, moderate vegetation, and very healthy vegetation categories. The majority of vegetation in the moderate vegetation category remained as such between the same period of time, with approximately 25 million $\mathrm{m}^{2}$ of vegetation.

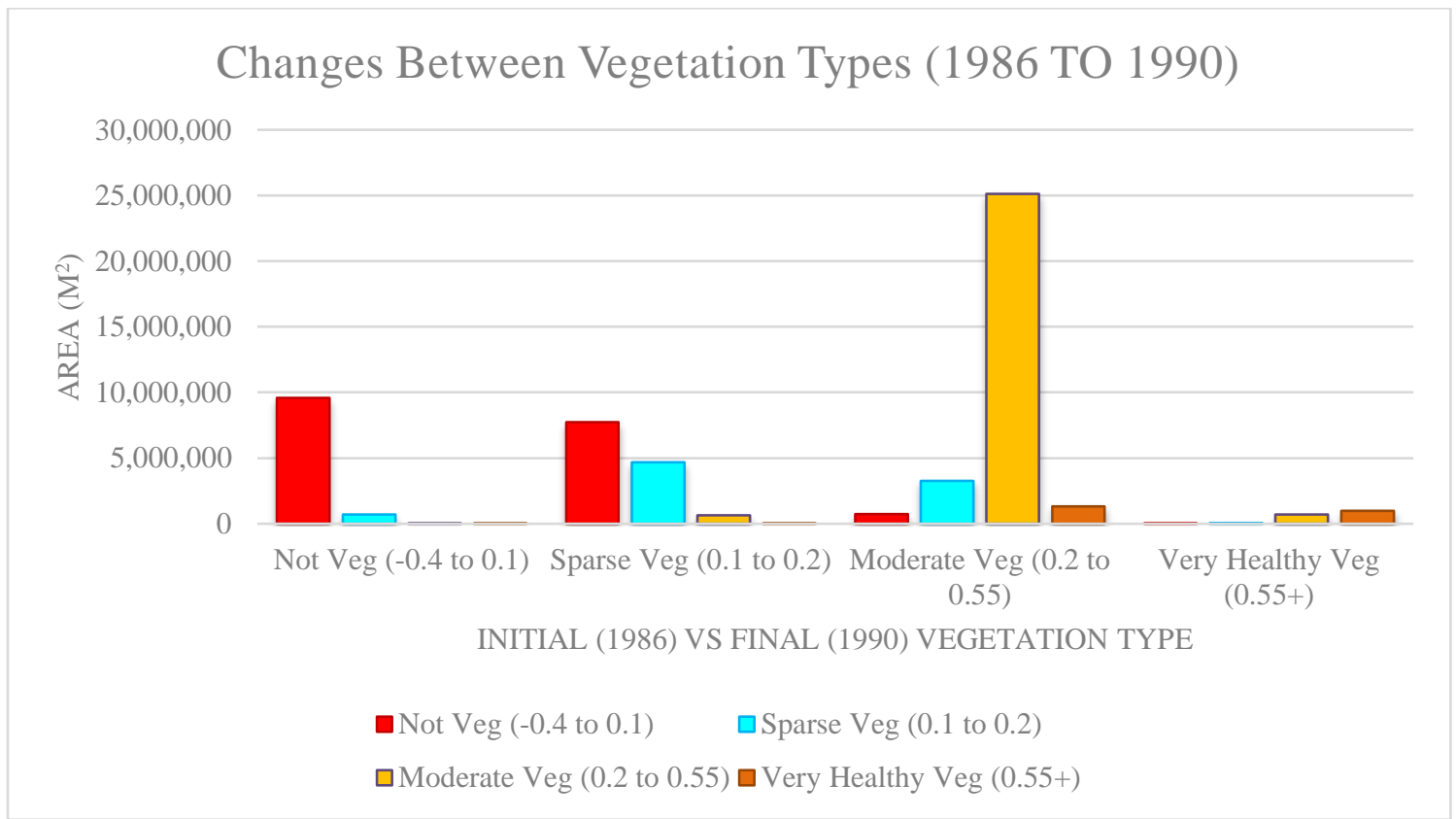

Figure 2.6 Changes between vegetation types (1986 to 1990). 


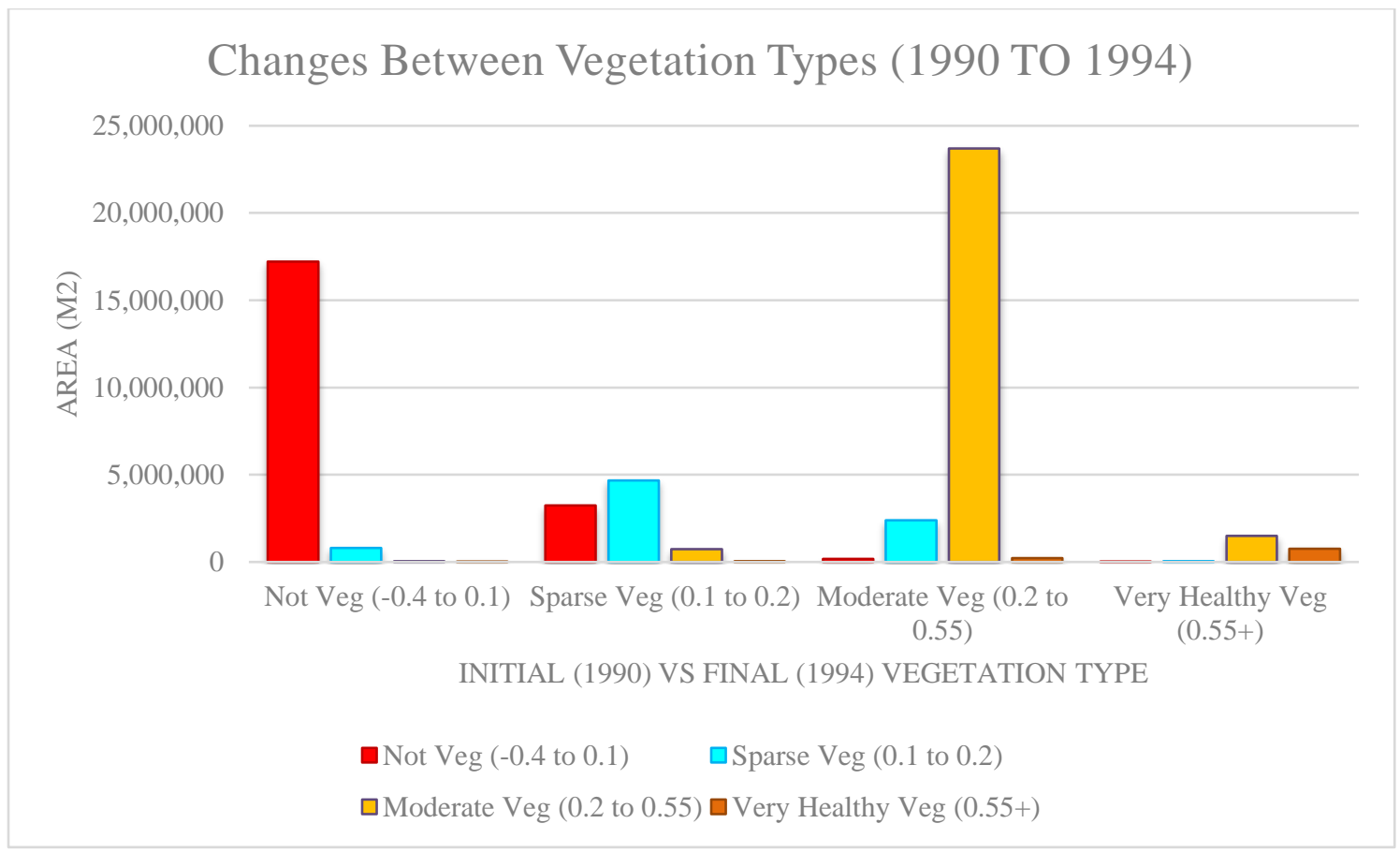

Figure 2.7 Changes between vegetation types (1990 to 1994).

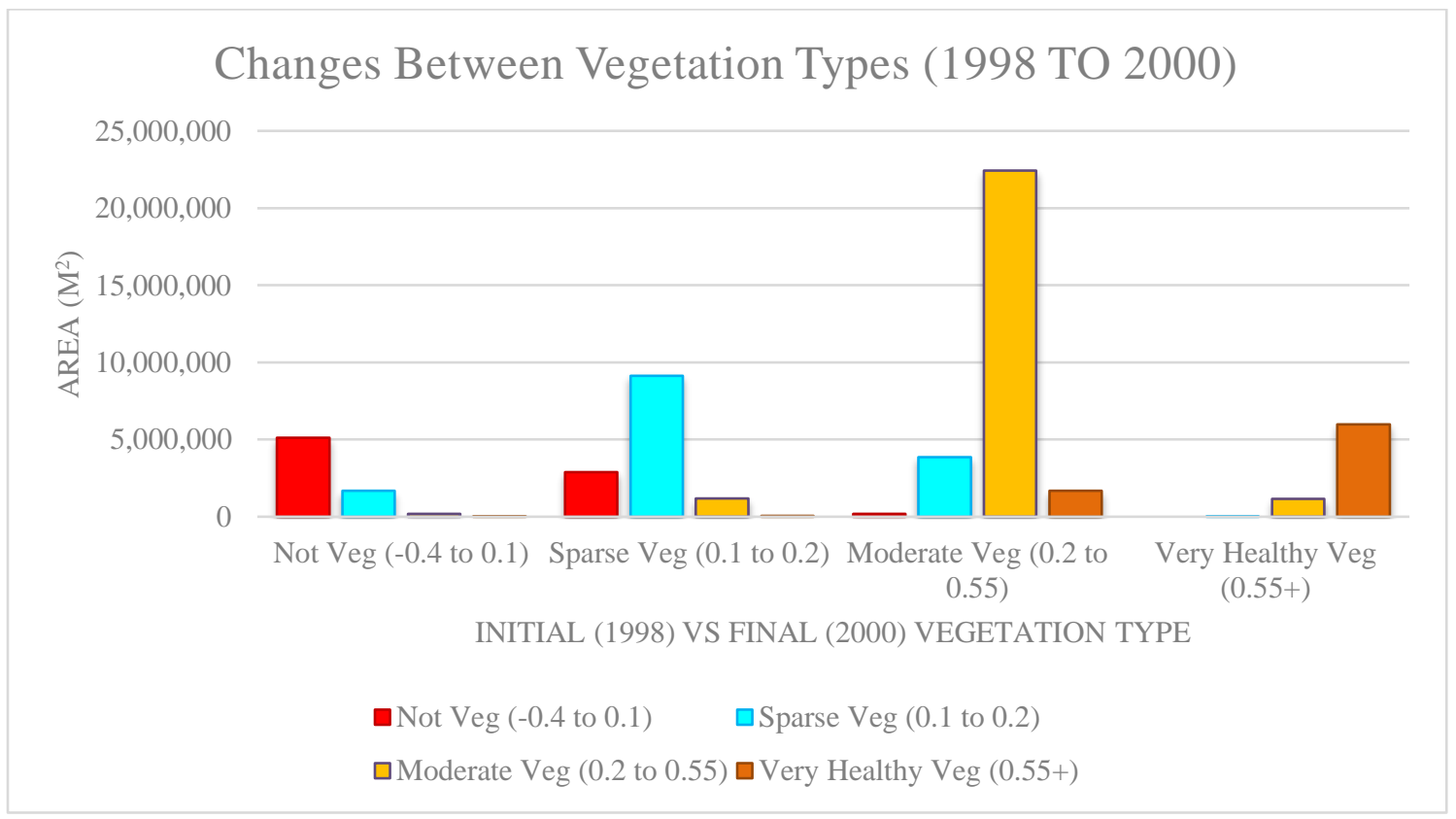

Figure 2.8 Changes between vegetation types (1998 to 2000). 


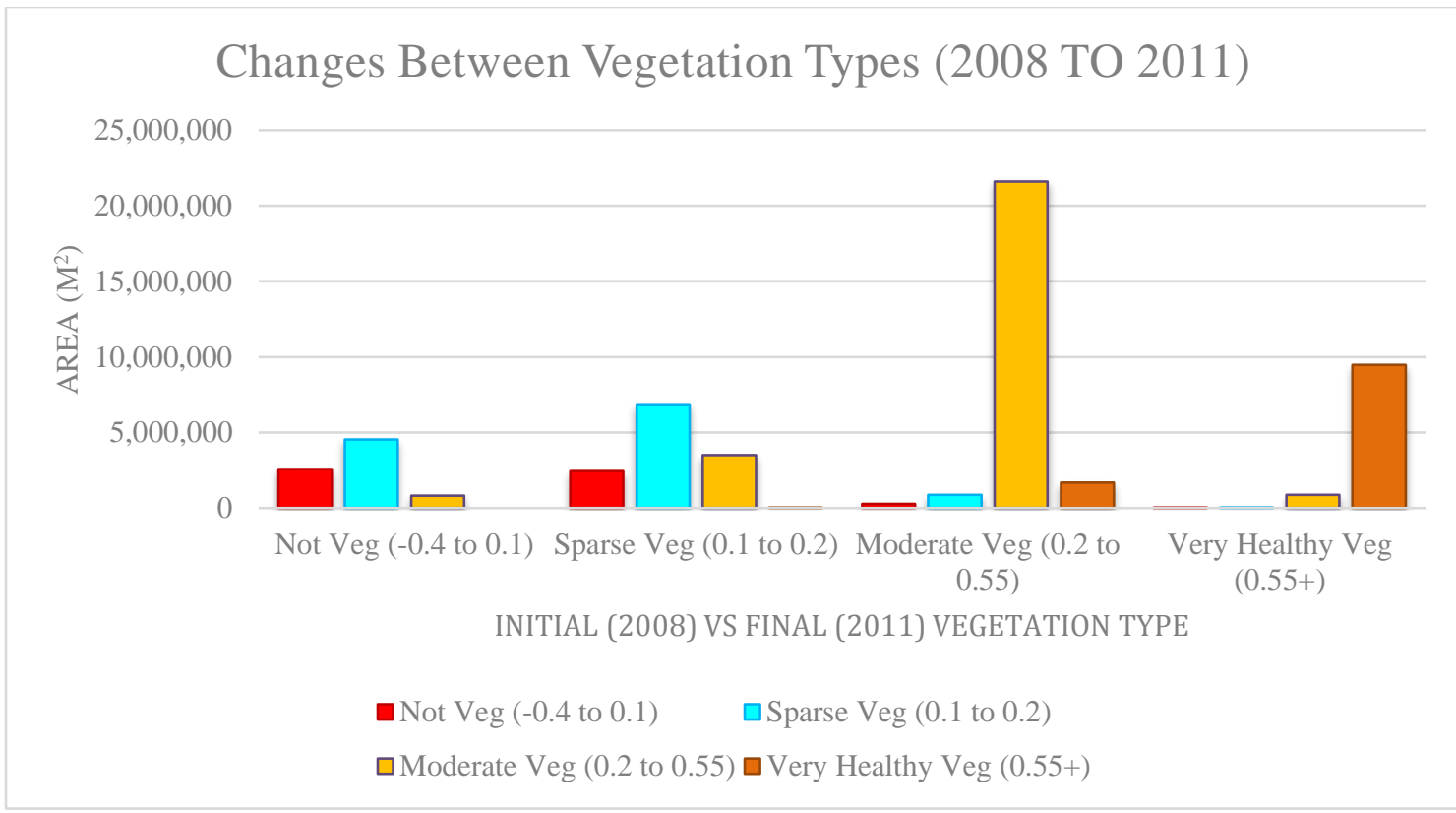

Figure 2.9 Changes between vegetation types (2008 to 2011).

The figures demonstrate that streams that were formerly in lower vegetation health categories initially increased in the 1980s and early 1990s, particularly from 1986 to 1990 and 1990 to 1994, showing that stream health was in general decline during these years when conservation programs were in the early stages of introduction in the study area. The 1998 to 2000 period shows a dramatic improvement in vegetation near streams that were formerly in the not vegetation category in 1994. This improvement can likely be attributed to the large amount of streams that were enrolled in CREP due to the 1996 farm bill. Conversations with farmers and a list of streams and dates from the local Soil and Water Conservation District (SWCD) showed that the majority of streams in the study area were enrolled into CREP in the late 1990s (e.g. 1996/1997) and also in the early 2000s from 2001 to 2003 . Record flooding in early 1996 also likely contributed to increases in vegetation health. Several agency employees in the watershed indicated that vegetation health along streams improved after the flood. The trend in vegetation health 
improvement continued incrementally, culminating in the 2008 to 2011 data that shows vegetation health increasing dramatically (Figure 2.9).

The graph comparing 2011 to 2015 (Figure 2.10) for both the Fifteenmile and Eightmile Watersheds shows significant declines in vegetation health. The year 2015 was classified as a drought year in Oregon and, therefore, it is not surprising that vegetation health was in decline during this year. PRISM precipitation data and temperature data (PRISM, 2017) (Figures 2.11 through 2.16) show that precipitation was lower during the year 2015 and it was also the hottest year on record in approximately 30 years. Examination of the graphs reveal that while precipitation was low in 2015 and likely contributed to vegetation stress during that year, the sharp decline in vegetation health was more likely attributed to the high temperatures of that year more than precipitation. For example, the year 2003 received even less precipitation than the year 2015 and vegetation health still improved during that year. Further, sharp increases in temperature occurred during the month of June in 2015, and July temperatures were elevated as well.

It should also be noted that a large portion of the vegetation near streams was classified in the not vegetation category during 2011 to 2015 and 2015 to 2016 in the satellite imagery, which is somewhat misleading. An inspection of the NAIP imagery and experience from field work during these years revealed that the pixels in the satellite imagery were assigned to the majority value of the NDVI pixels in the imagery, which cover a cell of $30 \times 30 \mathrm{~m}$. While the vegetation in riparian areas was definitely stressed during the drought year, to say that no vegetation was present is not accurate. Vegetation in riparian areas during the year 2015 was present, but was not as dense as in previous years and more dead vegetation was present. More bare rock and soil (e.g. the not 
vegetation category) was exposed within the riparian area during this year and the majority value of NDVI values for those bare surfaces were assigned to the cells representing the riparian areas in the watershed. Therefore, the drastic change between 2011 and 2015 and 2016, is more representative of a large amount of dead and stressed vegetation exposing bare rocks and soil, rather than there being no vegetation at all.

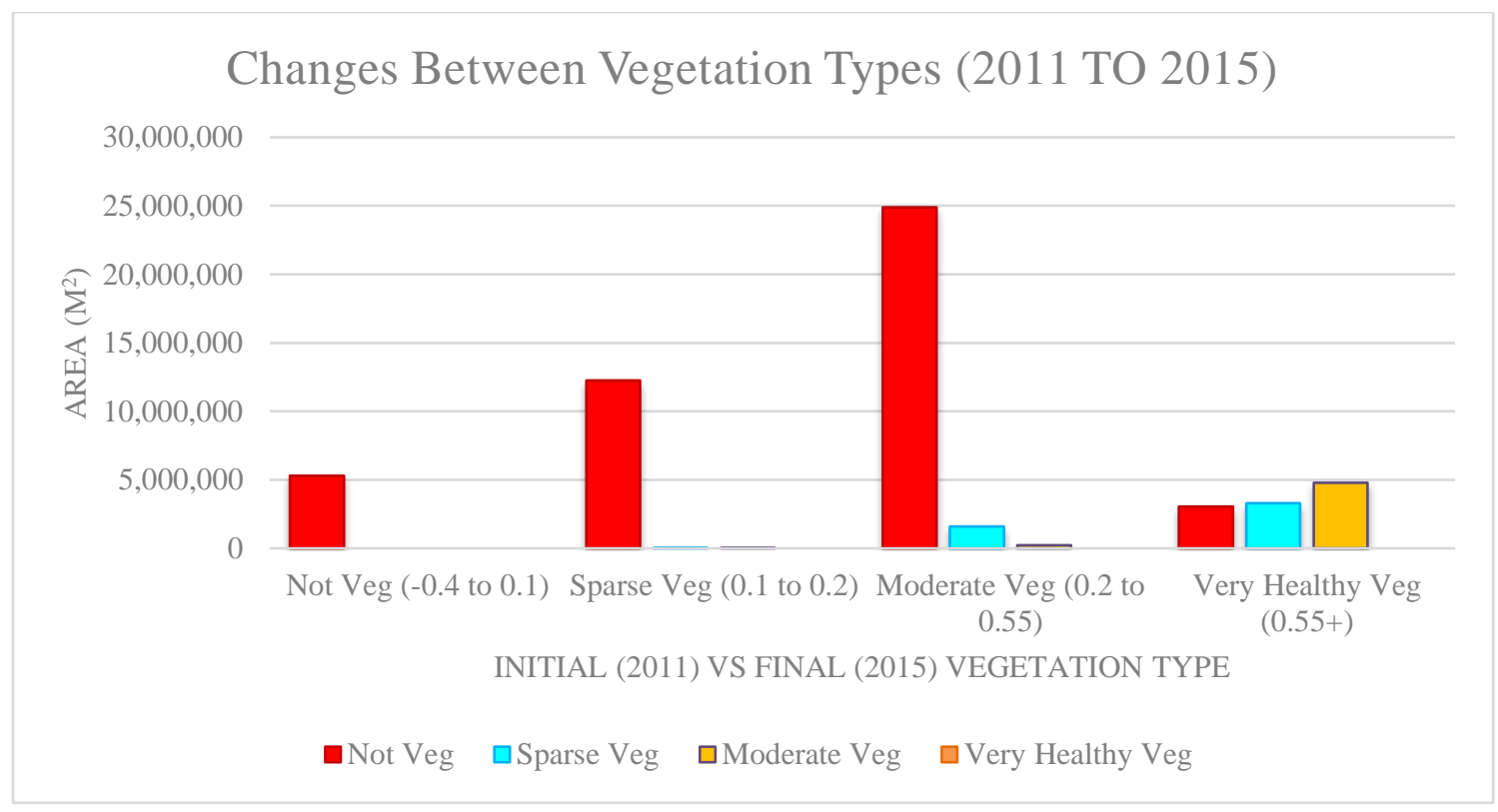

Figure 2.10 Changes between vegetation types (2011 to 2015).

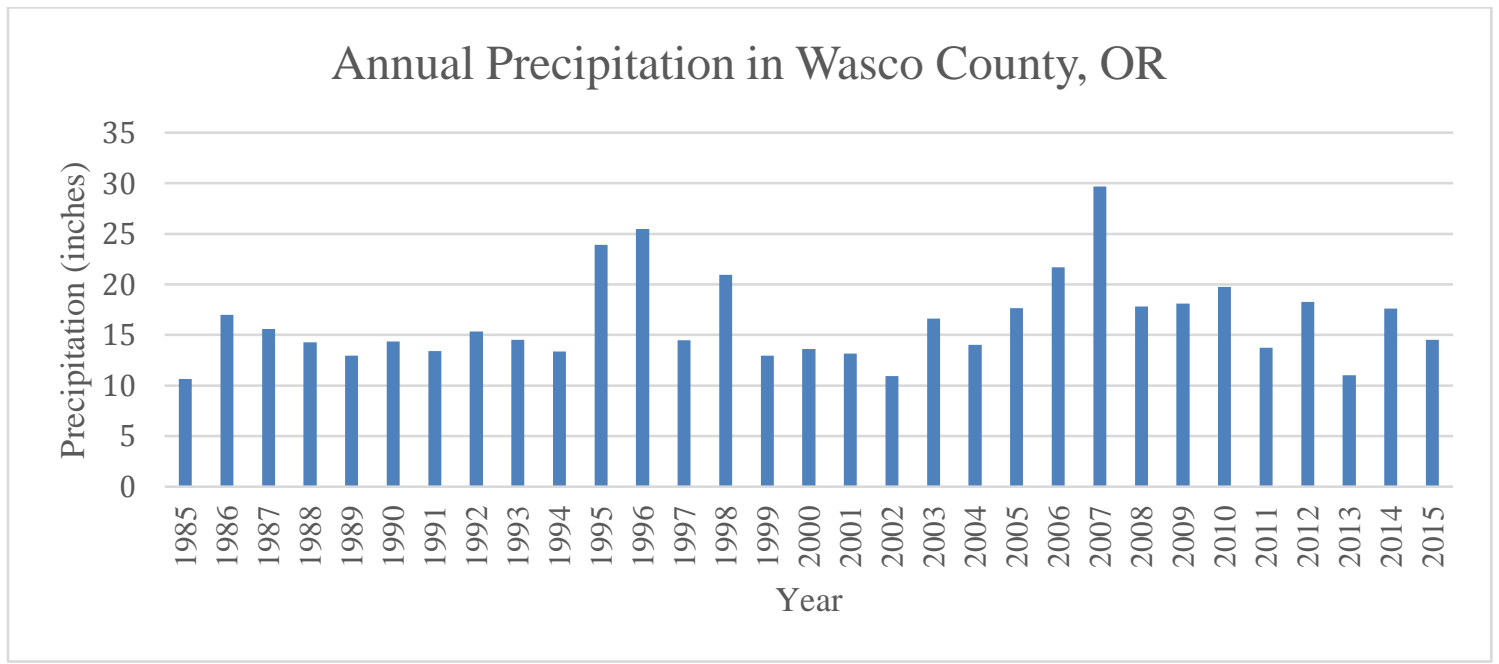

Figure 2.11 Annual precipitation in Wasco County, OR. 


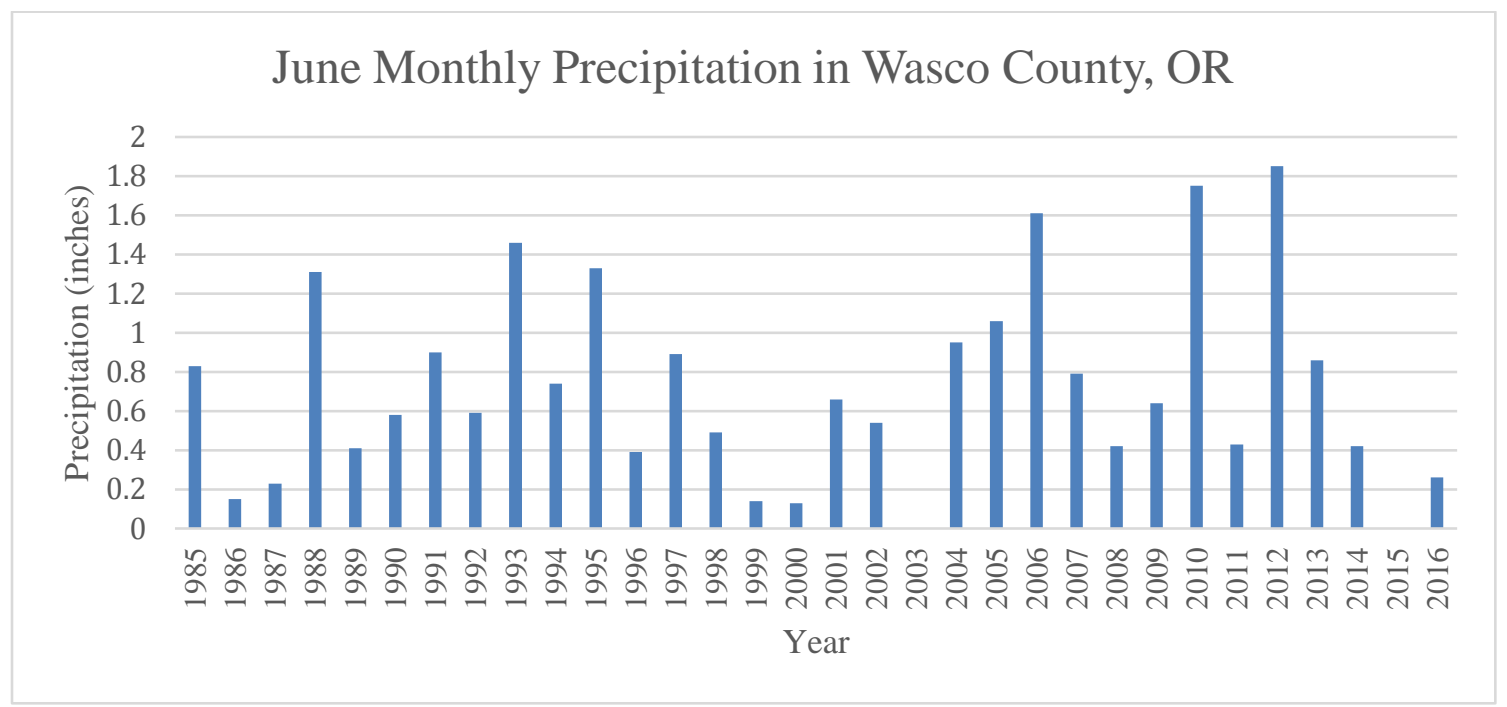

Figure 2.12 June monthly precipitation in Wasco County, OR.

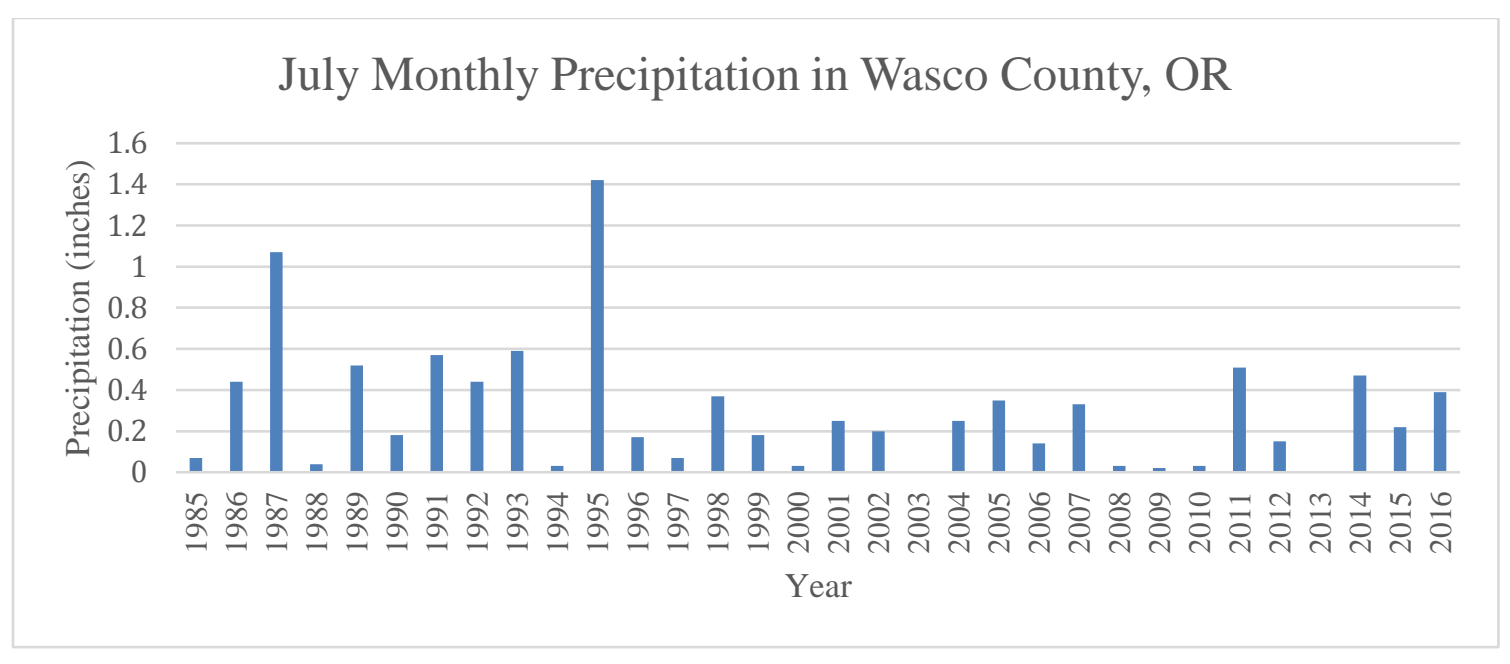

Figure 2.13 July monthly precipitation in Wasco County, OR. 


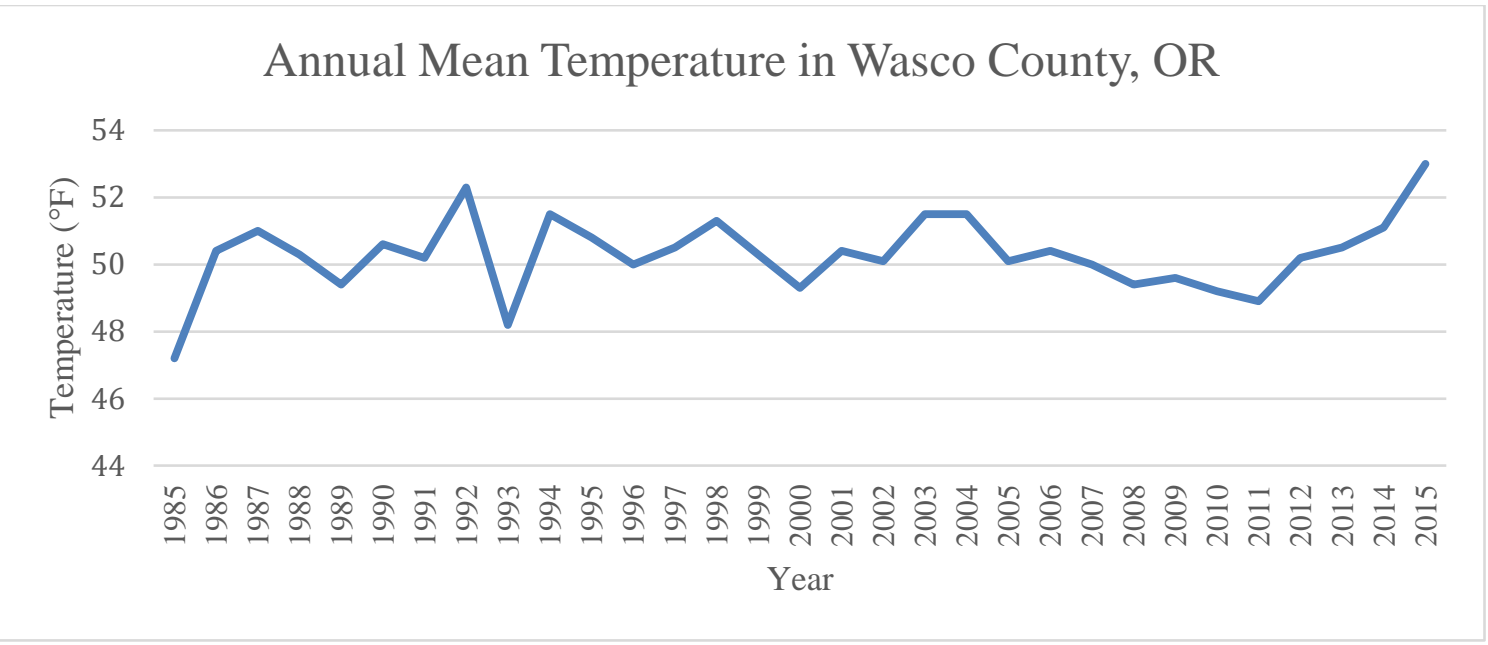

Figure 2.14 Annual mean temperature in Wasco County, OR.

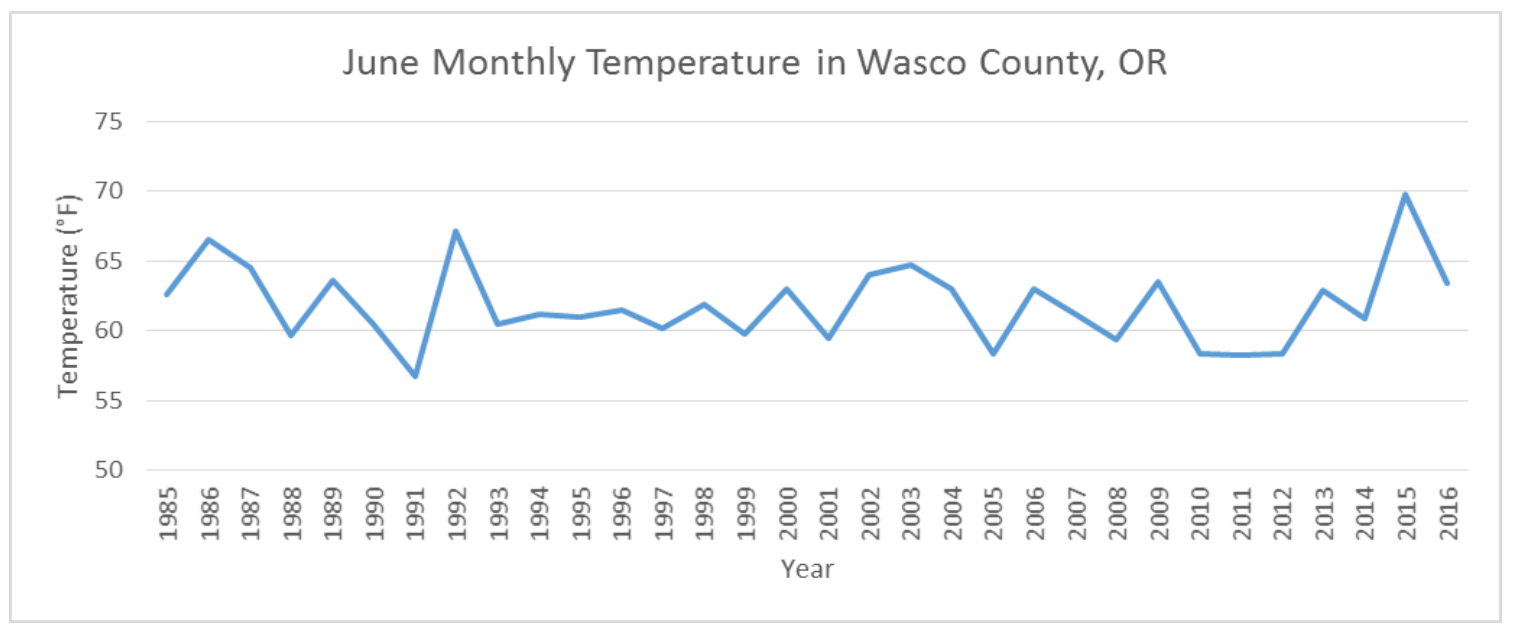

Figure 2.15 June monthly mean temperature in Wasco County, OR.

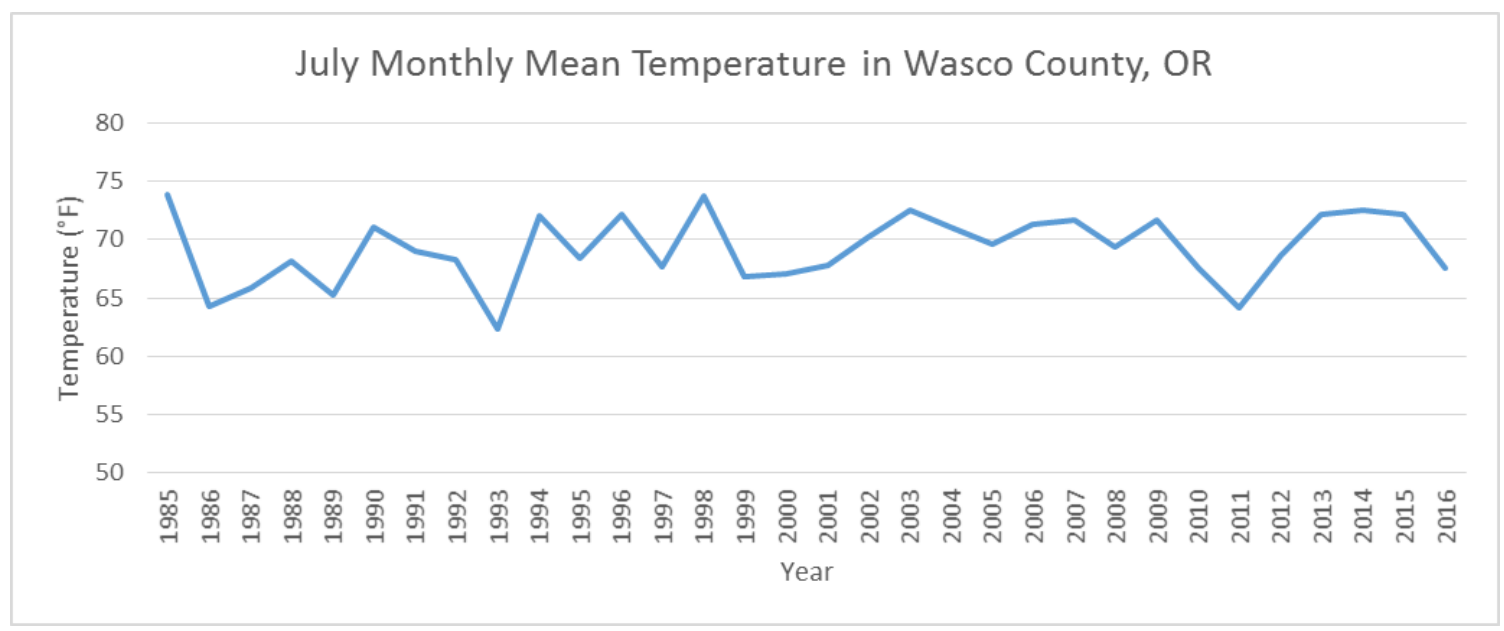

Figure 2.16 July monthly mean temperature in Wasco County, OR. 
In some locations, stream health never improved between 1986 and 2011, regardless of temperature and precipitation changes (Figure 2.17). Vegetation that fell into the always unhealthy not vegetation category accounted for approximately 732,000 square meters of vegetation, which is approximately $1.3 \%$ of the $55,566,000$ square meters of vegetation in the Fifteenmile and Eightmile Watersheds in the 100 foot buffer area surrounding streams. These locations were mostly located in the eastern portion of unnamed tributary streams of the Fifteenmile Watershed. Analysis of aerial imagery in these locations shows that areas that did not improve were often located in the following locations: at the steep termination areas between two farm fields that had little stream vegetation; in locations where steep, rocky cliffs make vegetation growth difficult in general; in locations where only ephemeral streams occur in the wettest years; or in locations along roads or near overpasses where vegetation historically does not grow well or is managed by road crews.

Two samples (samples SD-1 and SD-11) were collected within areas that remained unhealthy between 1986 and 2016. The concentrations of glyphosate in the sediment of these samples were $1.9 \mu \mathrm{g} / \mathrm{kg}$ and $13 \mu \mathrm{g} / \mathrm{kg}$ respectively, and AMPA concentrations were $13 \mu \mathrm{g} / \mathrm{kg}$ and $22 \mu \mathrm{g} / \mathrm{kg}$. Other samples were not collected within areas that consistently have remained unhealthy between 1986 to 2016, but further investigation into these areas would be warranted given that many of these areas share many characteristics of other riparian areas with healthy vegetation.

It is unlikely that vegetation that remains in the unhealthy vegetation categories remains as such because of drought conditions or vegetation variety. If weather patterns were affecting the areas that consistently had unhealthy vegetation, they would likely 
improve during at least some of the years when other vegetation improved as well. Further, many of the persistently unhealthy locations are comprised of vegetation varieties that are similar to other locations throughout the watershed with similar corridor widths and healthy vegetation.

Based on ground-truth images collected with the drone, herbicide persistence is likely the cause of persistent unhealthy vegetation. The drone was flown in locations that showed signs of recent herbicide spray in many locations throughout the watershed and in the two sample locations (SD-1 and SD-11) that were collected in the consistently unhealthy vegetation category. Many of the ground-truthing flights took place in the areas between riparian vegetation and the field, where farmers usually spray to keep weeds from creeping into crop areas. NDVI vegetation values for vegetation that was intentionally sprayed with herbicide and those in or near the stream (that should not have been sprayed) were within $5 \%$ of each other. The similarity in values between sprayed vegetation and riparian areas within proximity to the spray would indicate that either some herbicide drift had occurred, or that runoff to the stream had occurred and had affected vegetation health.

As will be discussed shortly, glyphosate and AMPA were found in the majority of stream sediment and water samples throughout the watershed, including in locations that never improved in vegetation health. This would indicate that although vegetation health has improved in riparian areas in the watershed overall, glyphosate and AMPA are still making their way into streams in the watershed. Hence, the widespread persistence and effects of glyphosate and AMPA are likely contributing factors to the persistence of 
unhealthy vegetation in these locations that otherwise seem to be ideal for healthy vegetation growth.

\section{Riparian Areas that Remained Unhealthy 1986 to 2016}

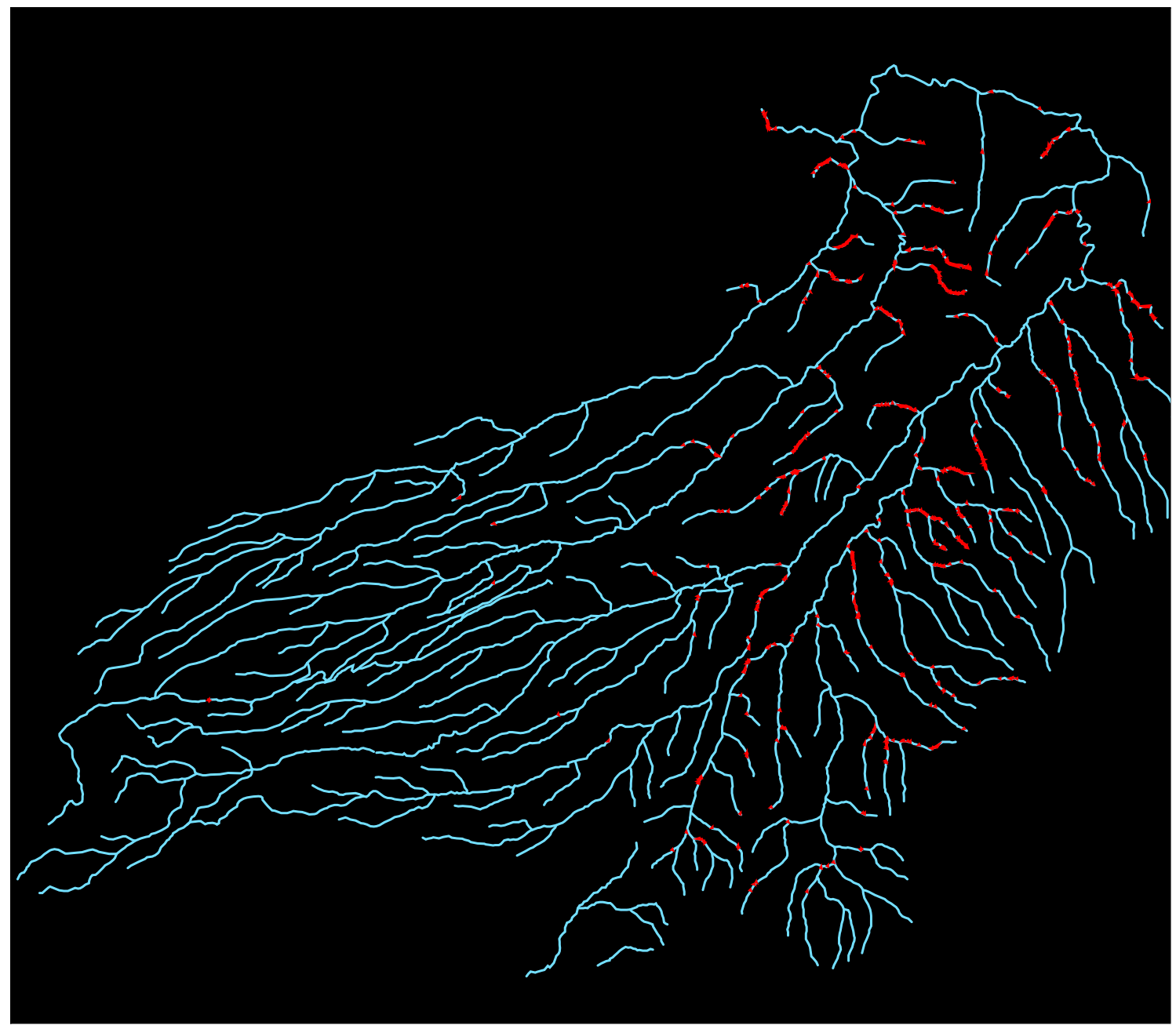

Figure 2.17 Areas that remained unhealthy between 1986 and 2016. The areas shown in red never improved in stream health and account for $1.3 \%$ of the vegetation in riparian areas within 100 feet of streams.

\section{NDVI Analysis with Drone 2016}

The drone proved to be useful in selecting locations that were stressed during field collection in May and June 2016. The camera was able to detect varying ranges of vegetation health that were not visible to the naked eye and aided in choosing sites for 
sampling of herbicides. An overlay of sample locations with NDVI post processed imagery typically revealed vegetation in the sparse vegetation health category range of 0.1 to 0.2 .

The NDVI values from 2016 Landsat 7TM imagery were compared with NDVI values in images collected by drone in order to act as a ground-truth to see how closely NDVI values matched. The images were mosaicked into areas representing the vicinity of the satellite imagery cells in the Landsat imagery and randomly sampled as described in the Methods section of this paper. Once random sampling was performed and the average of the drone imagery was calculated and compared to satellite imagery of the same spatial extent, it was found that the NDVI values between the two types of imagery only varied between $1-5 \%$, indicating that vegetation health was accurately assessed by the satellite imagery. The NDVI imagery and classification products of Landsat satellites 5TM and 7TM are very similar, and data from the two sensors can be used interchangeably to measure and monitor the same landscape phenomena (Vogelman, et al., 2001).

\section{Herbicide Concentrations and Analysis}

As mentioned previously, glyphosate and AMPA samples were collected in October 2015, May 2016, and July 2016/August 2016 (Tables 2.2 through 2.4). Chlorinated herbicide samples were collected only during July 2016 due to budgetary restrictions for sample collection. In all sample locations, chlorinated herbicides were not detected above the MDL of 0.1 micrograms per liter in water $(\mu \mathrm{g} / \mathrm{L})$ or above the MDL for soil and sediment which ranged between 0.0194 to $0.0198 \mathrm{mg} / \mathrm{kg}$, therefore, the data for the chlorinated herbicide samples is not shown or further discussed. 
Glyphosate and/or AMPA was detected in the majority of samples collected in all media. Simple linear regressions were used to determine if there were any significant differences between concentrations within CRP/CREP boundaries versus those outside of conservation corridors and none were found. In water, glyphosate was detected in 15 of the 27 samples collected and concentrations ranged from 0.02 to $0.11 \mu \mathrm{g} / \mathrm{L}$. In sediment, glyphosate was detected in 14 of 24 samples collected with detections that ranged from $0.024 \mu \mathrm{g} / \mathrm{kg}$ to $240 \mu \mathrm{g} / \mathrm{kg}$. In samples collected from soils on fields, glyphosate was detected in 8 of the 15 samples collected and detections ranged from 0.02 to $0.076 \mu \mathrm{g} / \mathrm{kg}$. Glyphosate's derivative product AMPA was detected in 19 of the 27 samples collected for water and concentrations ranged from 0.02 to $0.2 \mu \mathrm{g} / \mathrm{L}$. In sediment, AMPA was detected in 15 of the 24 samples collected with detections that ranged from 0.023 to 290 $\mu \mathrm{g} / \mathrm{kg}$. Finally, AMPA was detected in 10 of the 15 samples collected in field soils with concentrations that ranged from 0.022 to $0.076 \mu \mathrm{g} / \mathrm{kg}$. All glyphosate and AMPA results are shown in Tables 2.2 through 2.4. 
Table 2.2 Detections of glyphosate and AMPA in Water. Detections above the MDL are indicated in bold.

\begin{tabular}{|c|c|c|c|c|c|}
\hline Sample Name & Date Collected & $\begin{array}{l}\text { Sample } \\
\text { Type }\end{array}$ & $\begin{array}{l}\text { Glyphosate } \\
\text { Result (ug/l) }\end{array}$ & $\begin{array}{l}\text { AMPA } \\
\text { Result (ug/l) }\end{array}$ & $\begin{array}{l}\text { Within } \\
\text { CRP/CREP? }\end{array}$ \\
\hline W1 & $10 / 5 / 2015$ & Water & 0.11 & 0.03 & Yes \\
\hline $\mathrm{W} 2$ & $10 / 5 / 2015$ & Water & 0.03 & 0.02 & Yes \\
\hline $\mathrm{W} 3$ & $10 / 6 / 2015$ & Water & $<0.02$ & $<0.02$ & Yes \\
\hline W4 & $10 / 6 / 2015$ & Water & 0.04 & 0.20 & Yes \\
\hline W5 & $10 / 6 / 2015$ & Water & 0.07 & 0.02 & No \\
\hline W6 & $10 / 6 / 2015$ & Water & 0.04 & $\mathbf{0 . 0 3}$ & No \\
\hline W7 & $10 / 6 / 2015$ & Water & $\mathbf{0 . 0 3}$ & 0.02 & Yes \\
\hline W8 & $10 / 6 / 2015$ & Water & $\mathbf{0 . 0 3}$ & 0.02 & No \\
\hline W9 & $5 / 27 / 2016$ & Water & $<0.02$ & 0.02 & No \\
\hline $\mathrm{W} 10$ & $5 / 27 / 2016$ & Water & 0.08 & 0.05 & No \\
\hline W11 & $5 / 27 / 2016$ & Water & 0.02 & $<0.02$ & Yes \\
\hline W12 & $5 / 27 / 2016$ & Water & 0.02 & $<0.02$ & No \\
\hline W13 & $5 / 27 / 2016$ & Water & 0.04 & 0.05 & Yes \\
\hline W14 & $5 / 28 / 2016$ & Water & $<0.02$ & 0.02 & Yes \\
\hline W15 & $5 / 28 / 2016$ & Water & 0.05 & 0.09 & Yes \\
\hline W16 & $5 / 28 / 2016$ & Water & $<0.02$ & 0.02 & No \\
\hline $\mathrm{W} 17$ & $5 / 28 / 2016$ & Water & 0.02 & $<0.02$ & Yes \\
\hline W18 & $7 / 17 / 2016$ & Water & 0.021 & 0.027 & Yes \\
\hline W19 & $7 / 17 / 2016$ & Water & $<0.02$ & 0.047 & No \\
\hline W20 & $7 / 18 / 2016$ & Water & 0.095 & 0.034 & No \\
\hline W21 & $7 / 18 / 2016$ & Water & $<0.02$ & 0.04 & No \\
\hline W22 & $7 / 25 / 2016$ & Water & $<0.02$ & $<0.02$ & No \\
\hline W23 & $7 / 25 / 2016$ & Water & $<0.02$ & $<0.02$ & Yes \\
\hline W24 & $7 / 26 / 2016$ & Water & $<0.02$ & 0.021 & Yes \\
\hline W25 & $7 / 26 / 2016$ & Water & $<0.02$ & $<0.02$ & Yes \\
\hline W26 & $7 / 27 / 2016$ & Water & $<0.02$ & 0.025 & Yes \\
\hline W27 & $8 / 23 / 2016$ & Water & $<0.02$ & $<0.02$ & No \\
\hline
\end{tabular}


Table 2.3 Detections of glyphosate and AMPA in sediment. Detections above the MDL are indicated in bold.

\begin{tabular}{|l|l|l|l|l|l|}
\hline & Date & Sample Name & $\begin{array}{l}\text { Glyphosate } \\
\text { Result } \\
\text { (ug/kg) }\end{array}$ & $\begin{array}{l}\text { AMPA Result } \\
\text { (ug/kg) }\end{array}$ & $\begin{array}{l}\text { Within } \\
\text { CRP/CREP? }\end{array}$ \\
\hline SD-1 & $10 / 5 / 15$ & Sediment & $\mathbf{1 . 9}$ & $\mathbf{1 3}$ & Yes \\
\hline SD-2 & $10 / 5 / 15$ & Sediment & $\mathbf{1 1}$ & $\mathbf{6 4}$ & Yes \\
\hline SD-3 & $10 / 6 / 15$ & Sediment & $<1.0$ & $<1.0$ & Yes \\
\hline SD-4 & $10 / 6 / 15$ & Sediment & $\mathbf{2 5}$ & $\mathbf{2 8}$ & Yes \\
\hline SD-5 & $10 / 6 / 15$ & Sediment & $\mathbf{2 4 0}$ & $\mathbf{2 9 0}$ & Yes \\
\hline SD-6 & $5 / 27 / 16$ & Sediment & $<1.0$ & $\mathbf{4 . 7}$ & No \\
\hline SD-7 & $5 / 27 / 16$ & Sediment & $\mathbf{3 . 5}$ & $\mathbf{4 . 6}$ & No \\
\hline SD-8 & $5 / 27 / 16$ & Sediment & $<1.0$ & $\mathbf{2 . 2}$ & Yes \\
\hline SD-9 & $5 / 27 / 16$ & Sediment & $\mathbf{1 6}$ & $\mathbf{1 8}$ & No \\
\hline SD-10 & $5 / 27 / 16$ & Sediment & $\mathbf{1 9}$ & $\mathbf{2 5}$ & Yes \\
\hline SD-11 & $5 / 28 / 16$ & Sediment & $\mathbf{1 3}$ & $\mathbf{2 2}$ & Yes \\
\hline SD-12 & $5 / 28 / 16$ & Sediment & $\mathbf{1 7 0}$ & $\mathbf{1 6 0}$ & Yes \\
\hline SD-13 & $5 / 28 / 16$ & Sediment & $\mathbf{9 . 1}$ & $<1.0$ & Yes \\
\hline SD-14 & $7 / 25 / 16$ & Sediment & $<0.02$ & $<0.02$ & Yes \\
\hline SD-15 & $7 / 26 / 16$ & Sediment & $\mathbf{0 . 0 3 6}$ & $\mathbf{0 . 0 7 9}$ & Yes \\
\hline SD-16 & $7 / 26 / 16$ & Sediment & $<0.02$ & $\mathbf{0 . 0 2 3}$ & Yes \\
\hline SD-17 & $7 / 27 / 16$ & Sediment & $<0.02$ & $\mathbf{0 . 0 2 5}$ & Yes \\
\hline SD-18 & $7 / 27 / 16$ & Sediment & $<0.02$ & $<0.02$ & No \\
\hline SD-19 & $7 / 16 / 16$ & Sediment & $\mathbf{0 . 0 3 2}$ & $<0.02$ & Yes \\
\hline SD-20 & $7 / 17 / 16$ & Sediment & $<0.02$ & $\mathbf{0 . 0 3 6}$ & Yes \\
\hline SD-21 & $7 / 17 / 16$ & Sediment & $<0.02$ & $<0.02$ & Yes \\
\hline SD-22 & $7 / 17 / 16$ & Sediment & $\mathbf{0 . 0 3 4}$ & $<0.02$ & No \\
\hline SD-23 & $7 / 18 / 16$ & Sediment & $\mathbf{0 . 0 2 4}$ & $<0.02$ & No \\
\hline SD-24 & $7 / 18 / 16$ & Sediment & $<0.02$ & $<0.02$ & No \\
\hline & & & & & \\
\hline
\end{tabular}


Table 2.4 Detections of glyphosate and AMPA in field soils. Detections above the MDL are indicated in bold.

\begin{tabular}{|l|l|l|l|l|}
\hline Sample Name & Date Collected & Sample Type & $\begin{array}{l}\text { Glyphosate } \\
\text { Result (ug/kg) }\end{array}$ & $\begin{array}{l}\text { AMPA Result } \\
\text { (ug/kg) }\end{array}$ \\
\hline S1 & $7 / 16 / 16$ & Soil & $<0.02$ & $<0.02$ \\
\hline S2 & $7 / 16 / 16$ & Soil & $<0.02$ & $<0.02$ \\
\hline S3 & $7 / 16 / 16$ & Soil & $\mathbf{0 . 0 2 4}$ & $<0.02$ \\
\hline S4 & $7 / 16 / 16$ & Soil & $\mathbf{0 . 0 4 2}$ & $\mathbf{0 . 0 7 6}$ \\
\hline S5 & $7 / 16 / 16$ & Soil & $<0.02$ & $\mathbf{0 . 0 3 4}$ \\
\hline S6 & $7 / 16 / 16$ & Soil & $\mathbf{0 . 0 3 1}$ & $\mathbf{0 . 0 4 2}$ \\
\hline S7 & $7 / 17 / 16$ & Soil & $<0.02$ & $\mathbf{0 . 0 4}$ \\
\hline S8 & $7 / 17 / 16$ & Soil & $\mathbf{0 . 0 2}$ & $\mathbf{0 . 0 4 3}$ \\
\hline S9 & $7 / 17 / 16$ & Soil & $<0.02$ & $\mathbf{0 . 0 3 8}$ \\
\hline S10 & $7 / 18 / 16$ & Soil & $<0.02$ & $\mathbf{0 . 0 3 3}$ \\
\hline S11 & $7 / 18 / 16$ & Soil & $\mathbf{0 . 0 3 8}$ & $<0.02$ \\
\hline S12 & $7 / 18 / 16$ & Soil & $<0.02$ & $\mathbf{0 . 0 3 4}$ \\
\hline S13 & $8 / 22 / 16$ & Soil & $\mathbf{0 . 0 2 2}$ & $\mathbf{0 . 0 3 1}$ \\
\hline S14 & $8 / 22 / 17$ & Soil & $\mathbf{0 . 0 2 1}$ & $<0.02$ \\
\hline S15 & $8 / 22 / 18$ & Soil & $\mathbf{0 . 0 2 6}$ & $\mathbf{0 . 0 2 2}$ \\
\hline & & & & \\
\hline
\end{tabular}

The highest concentrations of glyphosate and AMPA were found in sediment samples taken during the months of October 2015 and May 2016. These samples, SD-5 and SD12, contained concentrations of glyphosate at $240 \mu \mathrm{g} / \mathrm{L}$ and $170 \mu \mathrm{g} / \mathrm{L}$ and AMPA concentrations of $290 \mu \mathrm{g} / \mathrm{L}$ and $160 \mu \mathrm{g} / \mathrm{L}$, which were orders of magnitude above the rest of the other samples collected. In general, sediment samples collected during these months had higher concentrations of both glyphosate and AMPA and may be somewhat explained by timing of the year when the samples were collected. While farmers spray during several months of the year to keep weeds down in fallow fields, spraying is particularly prevalent during the month of May when weeds become abundant in the spring and in late September right before farmers plant their seed in the ground. It is likely that spray concentrations during these collection months were high because of the proximity in time to which these spray events occurred. 
Figures 2.18 and 2.19 show months of spray against concentrations of glyphosate and AMPA in the watershed. Figure 2.18 shows that concentrations of glyphosate and AMPA are relatively consistent in water during all months when glyphosate is most frequently sprayed. However, during May and October when applicators have recently sprayed glyphosate, concentrations of glyphosate and AMPA increase substantially in sediment (Figure 2.19). In late September and early October, farmers also disturb soils more during planting activities. This increased disturbance likely contributes to additional sediment runoff to streams and would explain why concentrations of glyphosate and AMPA in sediment are elevated during these times.

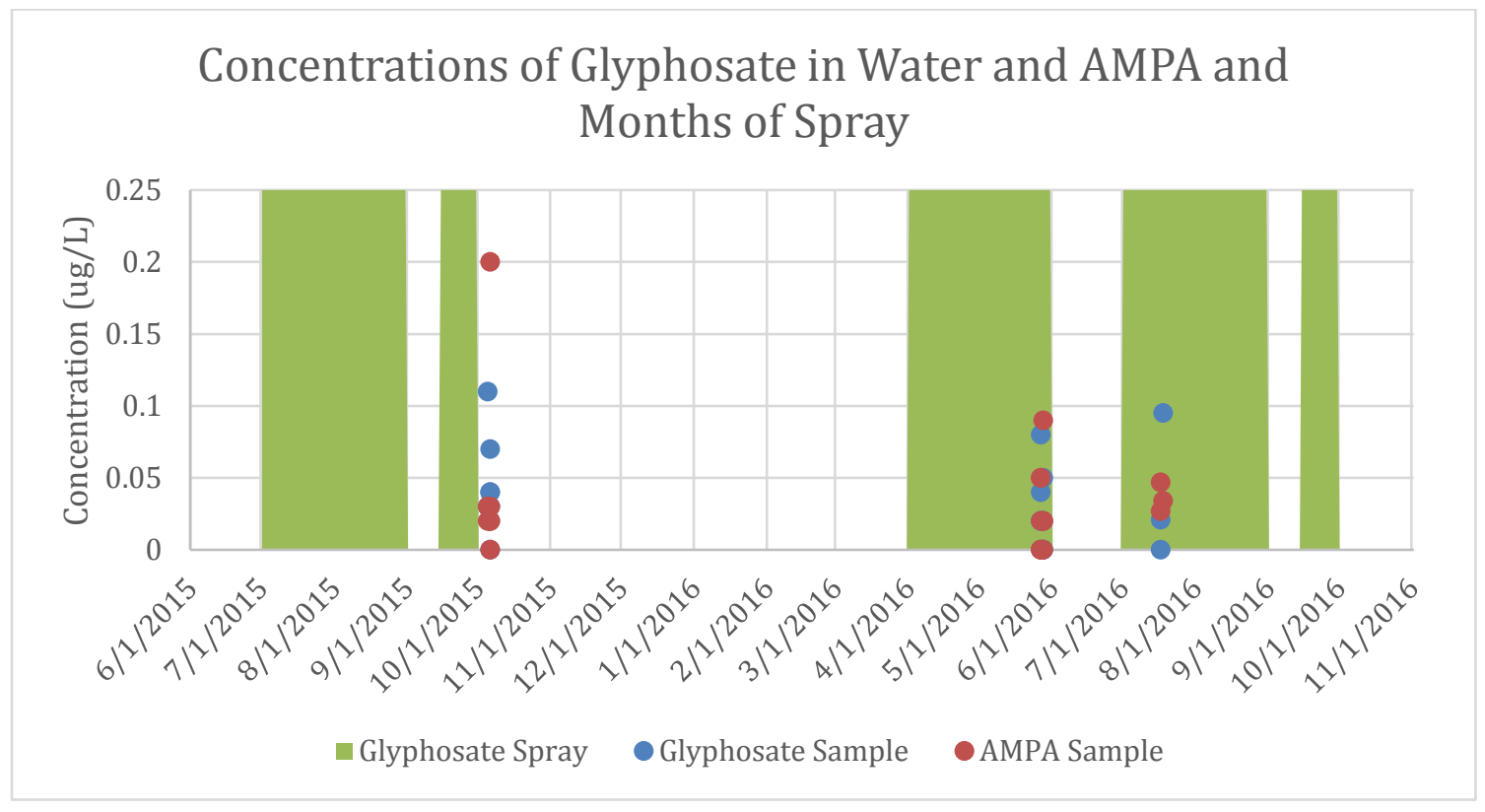

Figure 2.18 Months of herbicide spraying and concentrations of glyphosate and AMPA detected in water samples. 


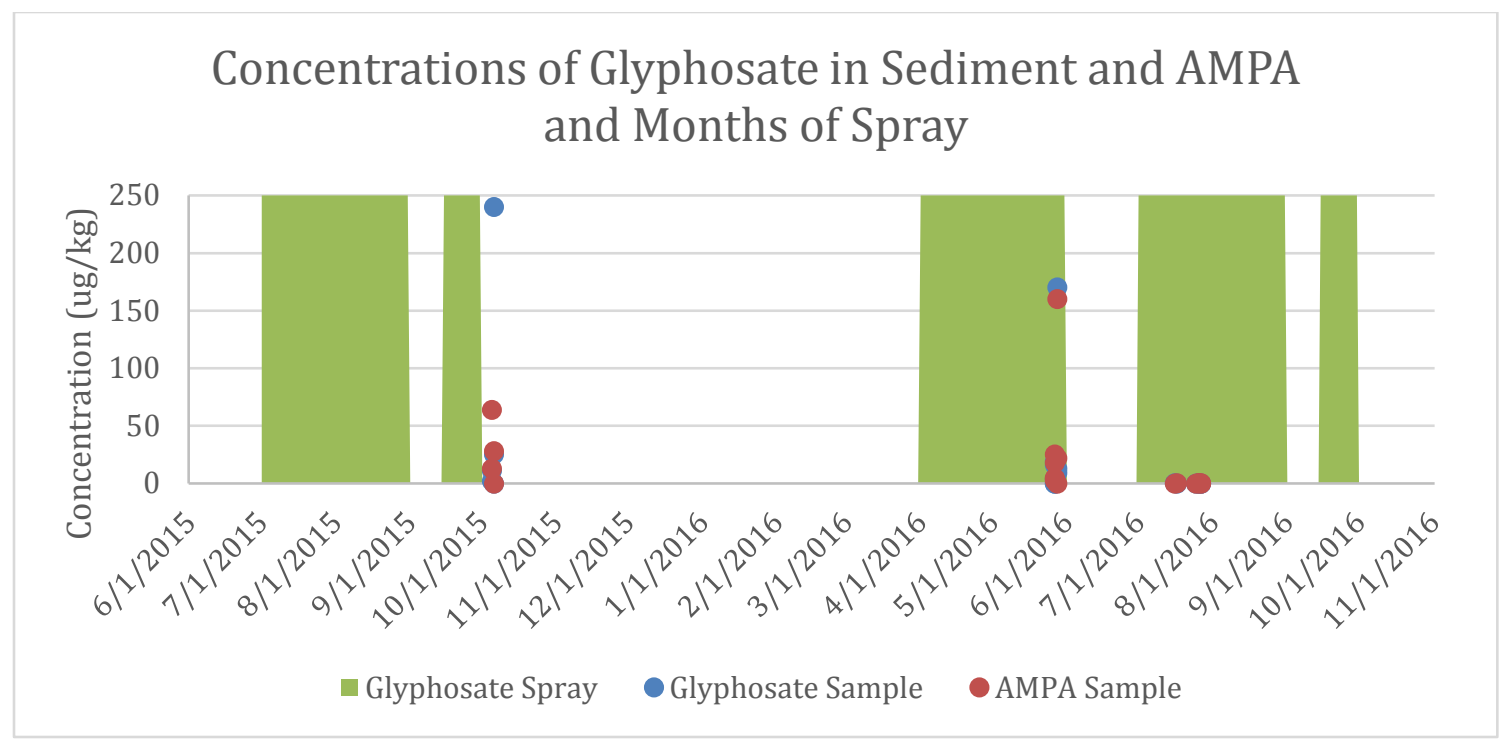

Figure 2.19 Months of herbicide spraying and concentrations of glyphosate and AMPA detected in sediment samples.

The samples with the highest concentrations of glyphosate and AMPA detections were located in streams where riparian buffer areas were not particularly wide. For example, sample SD-5 was collected just downstream (approximately 15 feet) of an area between two adjacent farm fields where vegetation had been pushed down over the stream for access between fields (Figure 2.20). Based on the topography of the local area, much of the drainage from both fields would naturally drain into the stream from fields on either side of the stream. Sample SD-12 was also located in an area where the crop field was within 10 feet of a small surface water pond connected to a small tributary stream (Figure 2.21). Although both samples were collected within CREP riparian areas or in land adjacent to CRP land, the lack of vegetation buffering the area between farm field and surface water likely contributed to the high concentrations of both glyphosate and AMPA. 


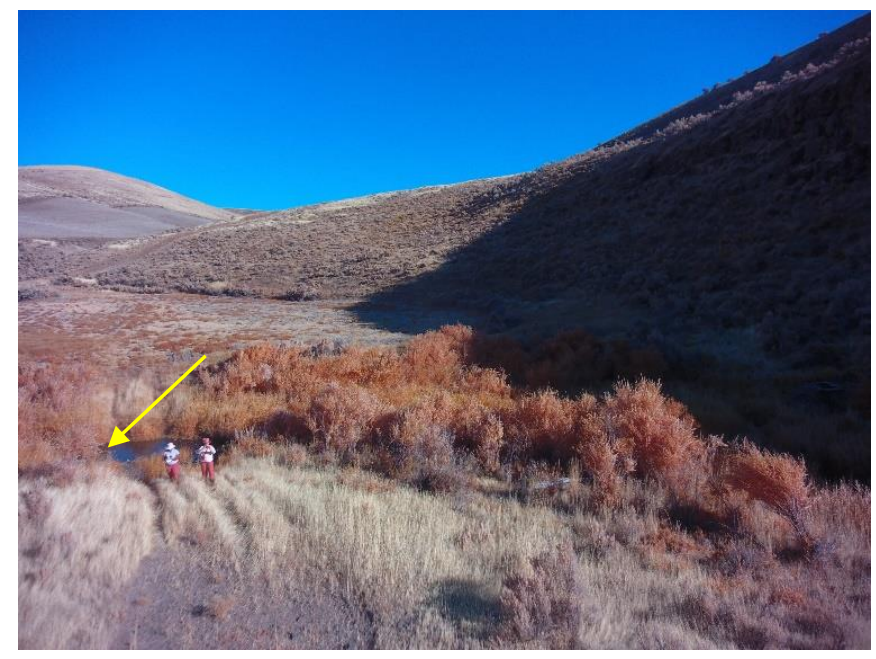

Figure 2.20 NDVI drone image of area near sample location SD-5. The sample was collected within $C R E P$, but less vegetation in the vicinity of the sample location likely contributed to the high concentration of glyphosate and AMPA in the stream. The sample was collected approximately 15 feet downstream of the opening in the vegetation. The yellow arrow indicates the downstream direction of the stream.

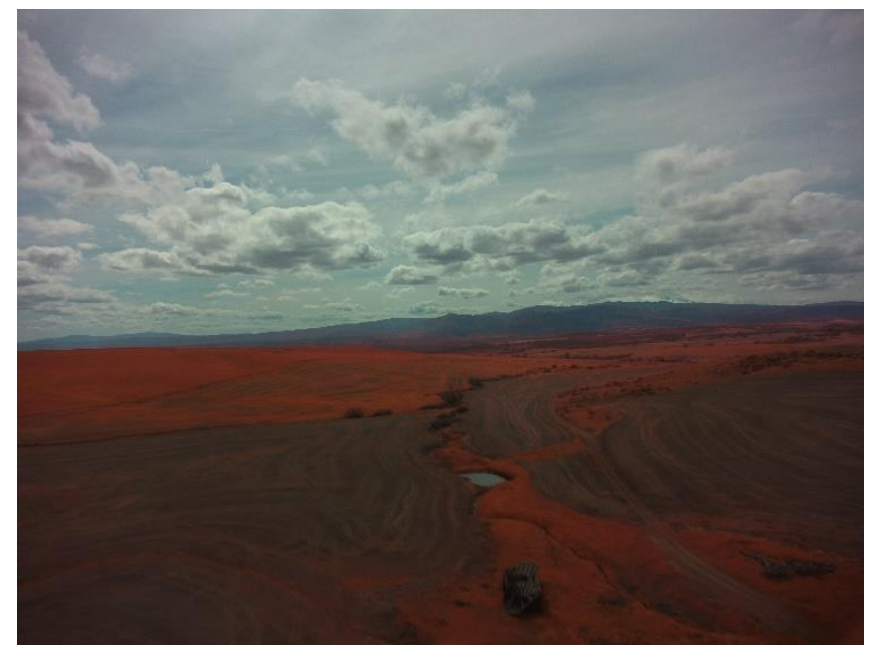

Figure 2.21 NDVI drone image of sample location SD-12. The distance between surface water in the pond and the farm field in CRP land was less than 10 feet. Sample SD-12 contained the second highest concentration of glyphosate and AMPA in the study area.

There is abundant literature on how herbicide persistence and concentration varies by soil type and properties, but simple linear regressions showed that there were no correlations between glyphosate, AMPA, and any of the soil properties that were tested in the lab in this study. Figure 2.22 shows concentrations of glyphosate and AMPA in sediment collected in months when detections of herbicide were highest during the 
October 2015 and May 2016 sampling events and during the months when detections of herbicide were much lower in the July and August 2016 sampling event. In all months, no observable patterns could be detected between soil or sediment texture and concentration of herbicide, as shown in the figure.
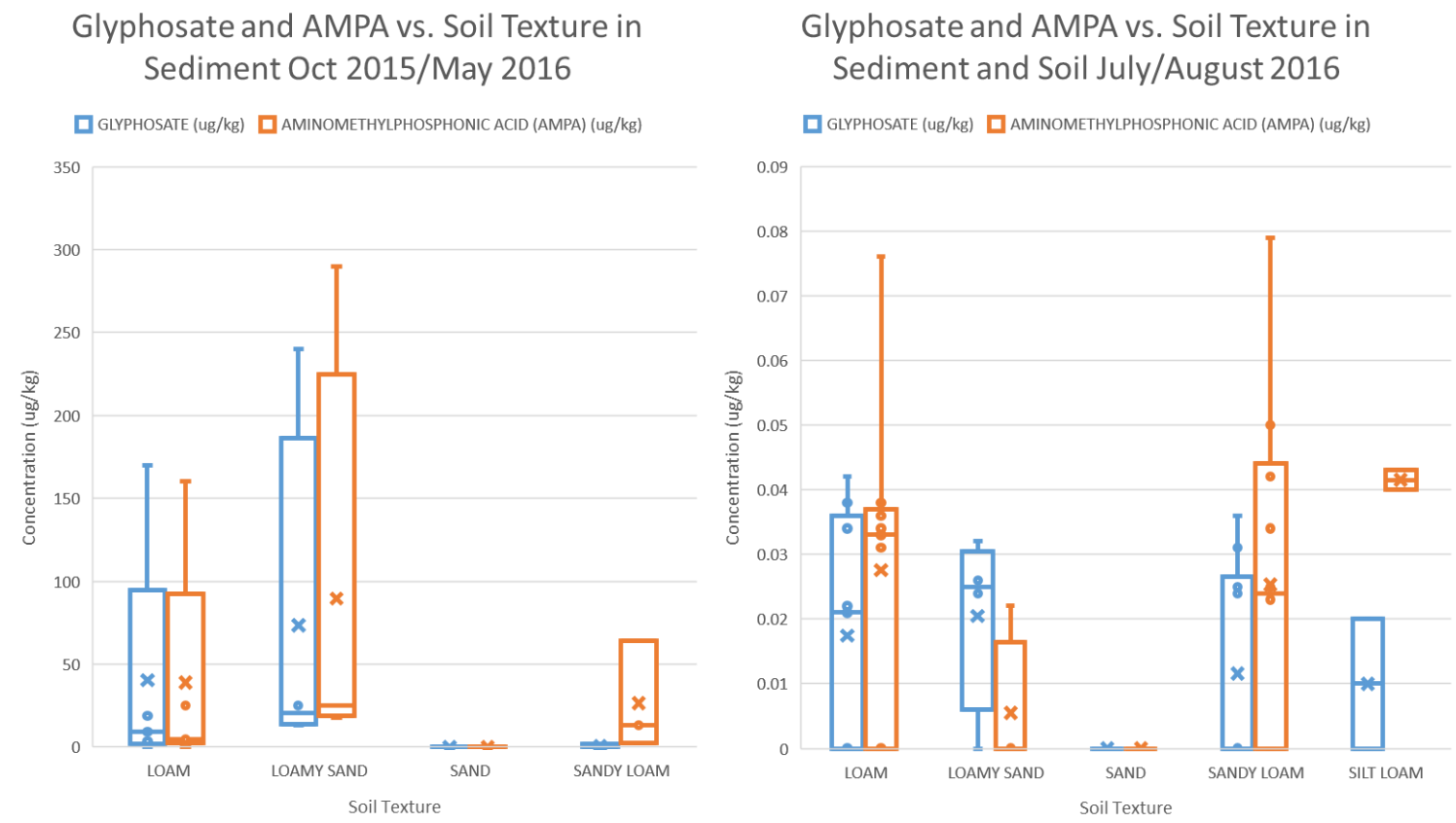

Figure 2.22 Concentrations of glyphosate and AMPA versus soil texture in sediment and soil. No correlation was found between samples taken during months when detections were high (October 2015/2016) or during months when detections were low (July/August 2016).

To determine if any other management practice could contribute to variable concentrations of glyphosate and AMPA, I reviewed NASS Cropland Data Layers. These data layers have been available since 2006 and show how much fallow land is present in the watershed each year. I inspected these layers to determine if increases in fallow land (that is sprayed often with glyphosate) increased during 2015 or 2016. The cropland data layers for the study area indicated that between 35 to 40 percent of land was classified as fallow in the study area between 2006 and 2015 (USDA NASS CDL, 2017). Therefore, amounts of glyphosate and AMPA in soil, sediment, and water (Figure 2.23) should not 
have varied with the amount of fallow land in 2015 or 2016, since fallow land acreage remained relatively consistent during all years examined. No other discernible patterns were found between glyphosate and AMPA and soil and sediment $\mathrm{pH}$, total exchange capacity, phosphorous, organic matter, or soluble salts using linear regression.

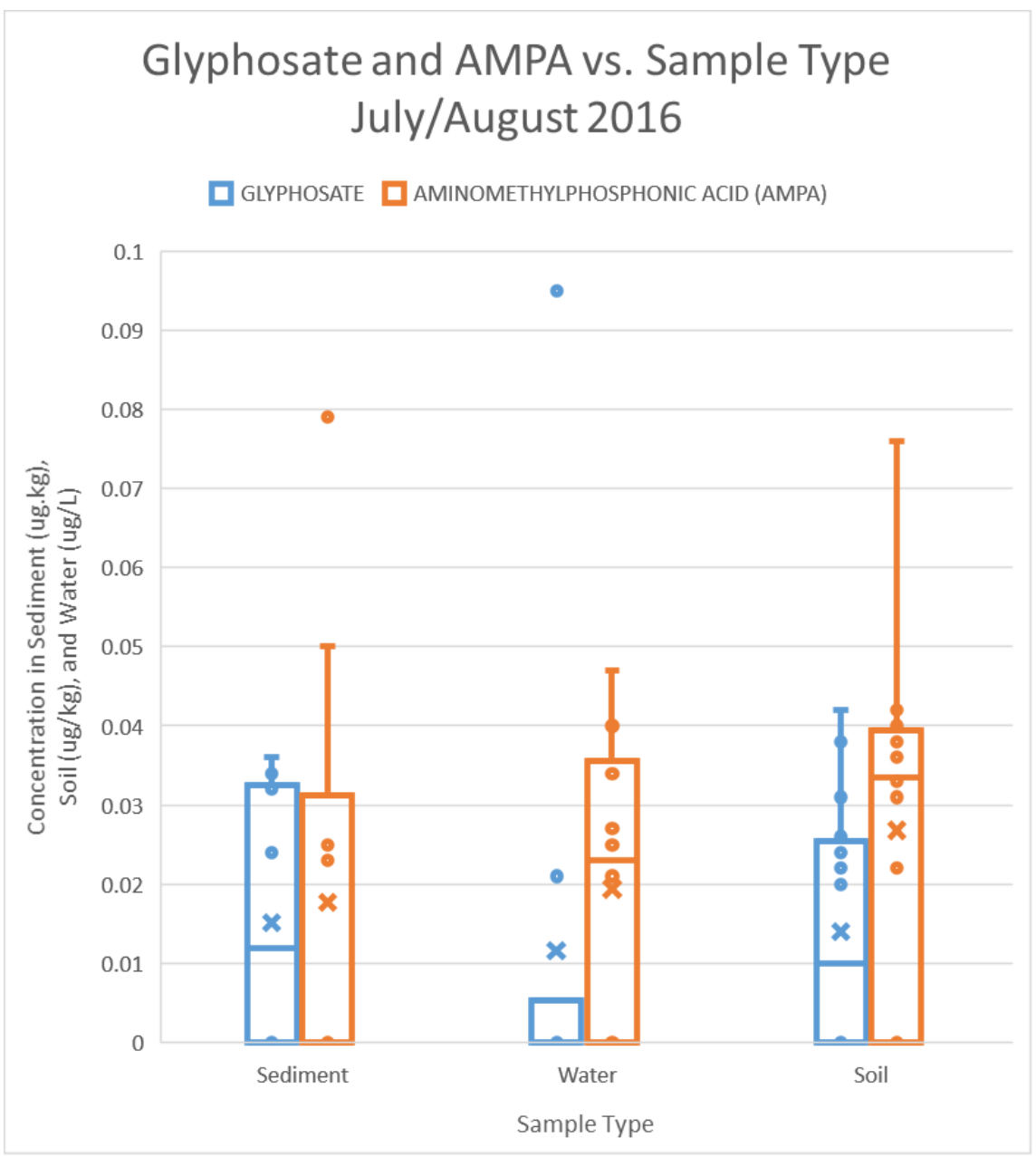

Figure 2.23 Sediment, water, and soil concentrations of glyphosate and AMPA in July and August 2016. Concentrations of glyphosate and AMPA were similar in each sample type during these months.

Regulatory and Toxicological Values of Concern

No regulatory screening criteria is available for glyphosate or AMPA, but the EPA's maximum contaminant level (MCL), which is the level of a contaminant in drinking water below which there is no known or expected risk to health, is currently set at 700 
$\mu \mathrm{g} / \mathrm{L}$ (EPA, 2016). A number of countries have also established a range of "acceptable" daily intake levels of glyphosate-herbicide exposures for humans, generally referred to in the U.S. as the chronic Reference Dose (cRfD), or in the E.U. as the Acceptable Daily Intake (ADI). An EPA cRfD of $1.75 \mathrm{mg}$ of glyphosate per kilogram body weight per day (mg/kg/day) has been established in the U.S. (NPIC, 2015). In the E.U, the current ADI was originally adopted in 2002 and is significantly lower at $0.3 \mathrm{mg} / \mathrm{kg} / \mathrm{day}$. The data upon which these exposure thresholds are based were supplied by manufacturers during the registration process, are considered proprietary and are typically not available for independent review (Myers et al., 2016; Mesnage et al., 2015).

In reviewing the literature on glyphosate levels, it is difficult to overstate how much concern there is about the amount that it is increasing in the environment and concerns about the levels which are currently allowed and considered acceptable in regulatory literature (Battaglin, 2016; Benbrook, 2012; Benbrook, 2016; Grandjean and Landrigan, 2014; Porter, 2010; Kremer, 2009; Mesnage et al., 2015, Myers et al., 2016 Relyea, 2005). Although the concentration values of glyphosate and AMPA detected in this study are far below the $700 \mu \mathrm{g} / \mathrm{L}$ or the $1.75 \mathrm{mg} / \mathrm{kg} / \mathrm{day}$ cRfD established by the EPA, detected concentration levels of both have been found to be harmful to human and ecological health in numerous studies.

In a comprehensive review of publications focused on toxicity and glyphosate-based herbicides, Mesnage et al. (2015) identified numerous peer-reviewed studies where the toxicological effects of glyphosate-based herbicides and adjuvants (chemicals mixed with glyphosate to make it more effective) were found to have toxicological effects well below regulatory screening levels. In this study on the Fifteenmile Watershed, the concentration 
values of glyphosate found in surface water $(0.02$ to $0.11 \mu \mathrm{g} / \mathrm{L})$ have been found to have endocrine disrupting and chronic effects (Figure 2.24).

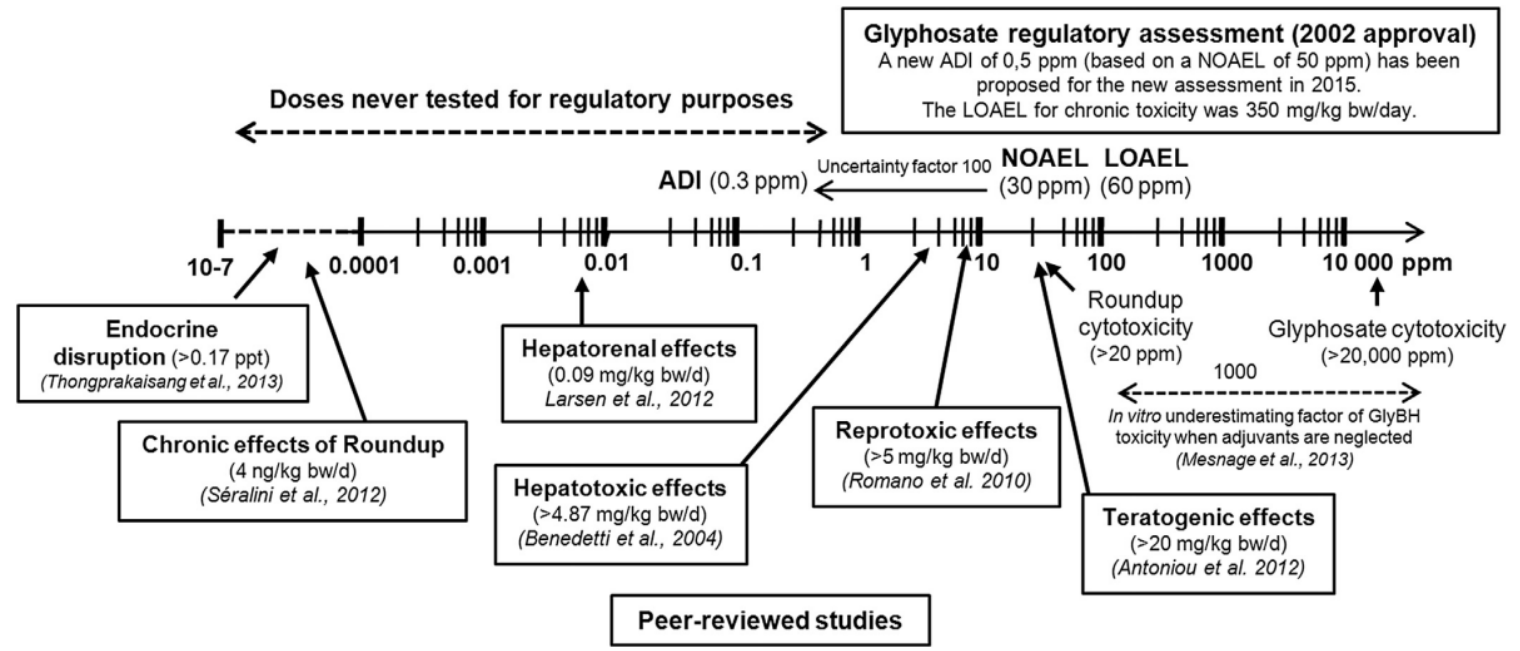

Figure 2.24 Figure of glyphosate human and ecological health impacts from Mesnage et al., 2015. The figure shows the ranges of values for which toxicological effects of glyphosate based herbicides and adjuvants (chemicals added to glyphosate to make it more effective) have been found harmful to human or ecological health. The concentrations of glyphosate in the samples collected for this study lie within the range that goes up to teratogenic effects.

In the Fifteenmile Watershed, farmers would likely be most vulnerable to exposure through ingestion of surface water and ground water intakes used for private domestic wells, irrigation, and water contact recreation. The designated beneficial uses listed for the waters in the watershed are: public and private domestic water supply, industrial water supply, irrigation, livestock watering, anadromous fish passage, salmonid fish rearing, salmonid fish spawning, water contact recreation, aesthetic quality, and hydro power (Clark, 2003).

Farmers in the watershed and county use surface water and groundwater extensively for irrigation and private water supply (Nelson, 2000; Clark, 2003; WCPD, 2017). Glyphosate based herbicides contaminate drinking water via rainwater, surface runoff and leaching into groundwater, thereby adding drinking water, bathing, and washing 
water as possible routine exposure pathways (Battaglin et al., 2014; Majewski et al., 2014; Coupe et al., 2012). Multiple studies have determined that groundwater wells are susceptible to glyphosate leaching from soils (Battaglin et al., 2014; Jayasumana, 2015; Myers et al., 2016). Further, this study has shown that surface water (which feeds groundwater supplies in much of the watershed) is already impacted by glyphosate concentrations that have been found to have endocrine disrupting and chronic effects.

Numerous studies (De Roos et al., 2005; Garry, 2002; Harrison, 2008; Jayasumana et al., 2015; Larsen et al., 2012; Mesnage et al, 2015; Mesnage et al., 2013; Rull et al., 2006; Schinasi and Leon, 2014) have also shown that farmers are exposed to herbicides, including glyphosate, in a variety of other ways. These exposure routes include pesticide drift and exposure to glyphosate during application of herbicides. Farmers in the Fifteenmile Watershed are likely exposed to glyphosate and other herbicides through both of these exposure routes, as high levels of wind and herbicide drift are frequent problems in the watershed. The contact between continental and maritime air masses produces strong wind patterns in Wasco County and the watershed, and the area receives high winds over fifty percent of the time (WCPD, 2017). Residents in the watershed have reported incidents of herbicide drift more frequently as new orchards and vineyards that border wheat land farms are increasingly planted (personal communication with extension agents, NRCS conservation district manager, and SWCD). This drift can cause inhalation or ingestion of herbicide when herbicides are volatilized or carried on soil particles in the wind (ODA, 2017).

Concentrations of glyphosate found in soil in this study ( 0.02 to $0.042 \mu \mathrm{g} / \mathrm{kg}$ ) have been found to have endocrine disrupting and chronic effects (Mesnage et al., 2015) and 
soil particles that have adsorbed glyphosate could be carried on the wind during application times, but even during times when application is not occurring. Low levels of glyphosate have frequently been detected in the urine of farm workers and their families shortly after glyphosate application in other studies (Acquavella, 2004; Mesnage, 2012).

Glyphosate and AMPA concentrations in sediment $(0.024$ to $25 \mathrm{ug} / \mathrm{kg})$ and water (0.02 to $0.11 \mu \mathrm{g} / \mathrm{L}$ ) pose ecological health risks as well. Several rare, endangered, or threatened species are listed in the Fifteenmile Watershed's streams and tributaries that are already impacted by sediment and temperature Total Maximum Daily Loads (TMDLs). These species may be vulnerable to effects of glyphosate. Species that are listed include native runs of winter steelhead (Onchorhynchus mykiss gairderi), which has been listed as a threatened species by the National Marine Fisheries Service. Other native species in the watershed include Coho salmon (Onchorhynchus kisutch), Pacific lamprey (Lampetra tridentata), Western brook lamprey (Lampetra richardsonii) resident redband trout (Onchorhynchus mykiss gairderi), cutthroat trout (Oncorhynchus clarkii) sculpins (cottid family), dace (Rhinichthys spp), redside shiner, chiselmouths, northern pike minnow (last four are members of the cyprid family), mountain suckers and largescale suckers (catastomid spp) (Clark, 2003).

Glyphosate concentrations in sediment and water have been shown to be harmful to aquatic life in a number of studies at the concentration levels found in this study on the Fifteemile Watershed. For example, changes in fish ovary development have been observed after 15 days exposure to glyphosate at only 65 ppb (Armiliato et al., 2014). Concentrations of $50 \mathrm{ppb}$ have been shown to produce toxic effects on the aquatic invertebrate Daphnia magna during chronic toxicity tests spanning its whole life-cycle 
(Cuhra et al., 2013). Tsui and Chui (2004) found that glyphosate based herbicides in the range of $240-340 \mu \mathrm{g} / \mathrm{kg}$ in sediment were found to be toxic to benthic organisms, which various fish species can feed on.

Temperature concerns in Fifteenmile Watershed further complicate the impact that glyphosate could have on fish species, as the toxicity of glyphosate increases with higher temperatures in fish. One study found that the toxicity of glyphosate doubled in bluegill and in rainbow trout (in the species onchorhynchus mykiss) when the temperature of the water was increased from 45 to 63 degrees F (Folmar et al., 1979 and Austin et al., 1991). Much of the Fifteenmile Watershed reaches temperatures of over 70 degrees F (Clark, 2003).

It should also be noted that glyphosate based herbicide product formulations, many of which are used in the study area, pose greater toxicity risks to a large number of nontarget organisms than glyphosate alone (Mesnage et al., 2015; Battaglin et al., 2014). These organisms include mammals (Mesnage et al., 2013; Tsui and Chu, 2004), aquatic insects, and fish (Folmar, 1979). Risk assessments of glyphosate based herbicides that are based on studies quantifying the impacts of glyphosate alone underestimate both toxicity and exposure, and thus risk (Myers et al., 2016). This oversight has led regulators to set inappropriately high exposure thresholds (cRfDs, ADIs) (Mesnage et al., 2015; Myers et al., 2016).

\section{Conclusions}

This study provides several methods to evaluate how herbicide use has been affected by the widespread adoption of no-till and conservation programs intended to protect stream health. While NDVI values of Landsat satellite imagery over the years of 1986 to 
2016 revealed that vegetation health in streams appears to have improved overall with the increase in conservation management programs and techniques, concentrations of glyphosate and AMPA were found in the majority of surface water, sediment, and soils in the watersheds of the study area, regardless of whether or not the samples were collected inside or outside of CRP/CREP riparian buffer areas. The detections of glyphosate and AMPA in streams, especially during times when spraying is increased (October and May) indicates that the herbicide is still reaching streams even with improvements in conservation agricultural practices. Further, certain locations within the watershed appear to be affected by persistent herbicide runoff or drift.

In addition, concentrations of glyphosate in water and soil samples collected for this study are within range of those that have been found to have human health impacts. Concentrations of glyphosate/AMPA in all media types is likely the result of not only increased amounts of glyphosate use, but also the number of months in which it must be sprayed in order to keep weeds in fallow fields under control. The presence of glyphosate and/or AMPA in the majority of samples during all months that were sampled is indicative of the persistence of glyphosate and AMPA in the environment and should be addressed for potential effects to human health. 


\title{
Chapter 3: Impacts of Farming Practices and Conservation Management Programs and Techniques on Sediment Cascades
}

\begin{abstract}
Agricultural conservation management techniques and programs are used nationwide to prevent soil erosion and preserve water quality. Yet, the U.S. Environmental Protection Agency (EPA) lists sediment among the top pollutants in U.S. waterways (EPA, 2012), and agriculture is frequently listed as a major source of sediment in streams (Walling and Fang, 2003; Blake et al., 2012). Distinguishing between sediment derived from naturally caused geophysical processes and those instigated by anthropogenic activity has remained challenging; therefore methods to distinguish the sources of sediment in streams are warranted. This study examines an agricultural watershed in Oregon where various forms of no-till agriculture have been practiced since the late 1990s and early 2000s in the majority of the watershed. Erosion analysis using RUSLE2 by the local NRCS office has shown that erosion has been significantly reduced in the watershed since the onset of no-till practices, but impairments to streams caused by sediment loading remain in much of the watershed. Using a combination of historic aerial imagery analysis, LiDAR, cesium-137 analysis for sediment source tracing, and interviews and surveys, this research identifies what proportions of sediment are from upland versus near-channel erosion and distinguishes between what processes are likely influenced by human activity in contrast to those by naturally occurring geomorphic processes. Identifying which processes are likely influenced by human activities provides an understanding of how sediment cascades are being affected in the watershed as well as the implications for conservation farming practices that affect current erosional processes
\end{abstract}


and sediment runoff into the streams of the watershed. Further, this study highlights the importance of incorporating methods that assess human activity into research on sediment cascades. Many geomorphological studies neglect the significant impacts that human activity has on geomorphological processes and do not provide a way for human activity to be incorporated into research methodology. By incorporating these methods, this study found that there are large disparities between the erosion that is currently estimated in the watershed and that a large amount of sediment is still generated from cultivated sources.

\section{Introduction}

Agricultural conservation management techniques and programs are used nationwide to prevent soil erosion and preserve water quality. Yet, the U.S. Environmental Protection Agency (EPA) lists sediment among the top pollutants in U.S. waterways (EPA, 2012), and agriculture is frequently listed as a major source of sediment in streams (Walling and Fang, 2003 and Blake et al., 2012). Distinguishing between sediment derived from naturally caused geophysical processes and those instigated by anthropogenic activity has remained challenging. This issue is especially true as the lines between what constitutes natural and anthropogenic sediment sinks and sources blur over time, as globally, humans have greatly increased terrestrial erosion through a variety of mechanisms that influence the way sediment is increased or reduced through river networks (Trimble, 1999; Syvitski et al., 2005; Montgomery, 2007). Further, these changes are happening more frequently on decadal rather than millennial time spans (Richter, 2007).

In much of the recent literature on sediment cascades (flux) many geomorphologists (Brierley, 2006; Fryirs 2007; Fryirs, 2013, Reid, 2007) argue that we now have a 
substantial understanding of sediment delivery and storage mechanisms in catchments, and that there are well established methods for modeling them. However, how these processes are coupled or decoupled in various types of catchment cascades is not well understood. This challenge arises from a need for developing frameworks and models that can enhance spatiotemporal resolution and specify provenance, timing, changes in the rates of erosion, deposition and yield along the sediment cascade (Houben et al., 2009; Wainwright et al., 2010). Fryirs et al. (2013) argue that a more sophisticated approach is required to fully account for both spatial and temporal connectivity so that the functioning of the sediment cascade is explained and alterations to internal dynamics is understood or forecasted.

The need to incorporate humans as major geomorphological agents is also highlighted more frequently in this literature. The basis for predicting the consequences of future climate change is dependent on sediment cascade operation over the Quaternary (e.g. Church and Slaymaker, 1989; Chiverrell et al., 2008; Brown et al., 2009; Houben et al., 2009; Dosseto et al., 2010). Therefore, understanding paleo-sediment cascade dynamics and responses to human disturbance will be important for the future (Fryirs, 2013). In some landscape settings, variability in sediment yield associated with natural spatial patterning and local human impacts are likely to exceed the impacts of moderate global warming (Evans and Slaymaker, 2004).

This study examines how agricultural farming practices, particularly those intended for conservation, have influenced sediment cascades. In doing so, this study contributes to the literature by providing a mixed-methods approach to explore how much human influence can alter the course of sediment cascades through various spatio-temporal 
scales, and by quantifying the percentage of stream sediment sourced from land under current conservation management. The specific location of study is in the Fifteenmile Watershed of Wasco County, Oregon where a variety of conservation management programs and techniques have been used with the goal of protecting soil and water quality, with varying impacts to sediment flux in streams.

\section{Background}

The Fifteenmile Watershed is an ideal place to study the effects of conservation management on sediment cascades, because the majority of the watershed (and the county it is in) has converted to various forms of no-till, and there is a long history of various conservation management techniques that have altered sediment flux into stream systems. During the 1940s to 1980s, land managers used structural practices, sediment basins, and terraces for the majority of their conservation efforts (SWCD, 2015). From 1985 to 1995, conservation efforts to reduce erosion were focused on crop residue management transitioning to strip-cropping and divided slope systems (SWCD, 2015). Yet, even with all of these management systems in place, the majority of the county's streams and tributaries have been on the U.S. Environmental Protection Agency's (EPA's) water quality limited list for sedimentation since 1988 (EPA, 2015). Conservation methods in the county intensified after a July 1995 flash flood followed by regional flooding in February 1996 in the Fifteenmile Watershed portion of the county. Heavy runoff and erosion from these events damaged cropland and did significant damage to roads and bridges, earning the attention of landowners and agencies alike (SWCD, 2015). The 1996 Farm Bill established the Environmental Quality Incentives Program (EQIP) administered by the Natural Resources Conservation Service (NRCS) 
(NRCS, 2015a). The bill's educational element was adopted by the Wasco County Soil and Water Conservation District (SWCD), which began to promote and provide education to farmers about no-till farming systems. By 1997, what was known as the transition to no-till agriculture began (SWCD, 2015). The educational effort coupled with numerous grants from the Oregon Department of Environmental Quality (DEQ) and Oregon Watershed Enhancement Board (OWEB), along with EQIP cost shares, enabled more and more farms to make the transition from conventional tillage to direct seed / notill systems. By 2012, 93\% of Wasco County's farmland had been converted to what were referred to as no-till systems, with most farmers and agencies claiming that runoff and erosion from that land had been greatly reduced (SWCD, 2015).

\section{The Contribution of Past Farming Practices to Sediment Cascades}

Various farm practices have been used in the study area, with most centered on weed control, retention of soil moisture, and prevention of erosion. Most of the cropland in the study area and throughout much of the Columbia basin where wheat is grown has been and continues to be used for summer-fallow dryland farming (dryfarming). In summerfallow dryfarming, no crops are grown during one crop season in order to store additional moisture for the growth and yield of a crop the following season. This practice also helps to control weeds and conserves plant nutrients. Farmers practice fallowing by leaving crop stubble on the field during the winter. Under conventional tillage, prior to the switch to no-till and direct seed, the soil was tilled with disks, sweeps, or chisels in February, March, and April, before weeds removed much of the soil moisture and the soil surface became dessicated (NRCS, 1982). Rod weeders were also commonly used in spring when the soil is cultivated from one to four times a season (Williams and Wuest, 2001). 
Comprised of cultivator blades and a square rod that turns counter to the direction of travel, these implements are dragged approximately $25-50 \mathrm{~mm}$ below the loose soil surface, uprooting weeds and sealing the soil surface by creating a dust mulch and trapping soil moisture.

In addition to disks, sweep, or chisels, equipment commonly used for conventional tillage included harrows, moldboard plows, slickers, and drills. Depending on the type of equipment used for tillage and weed control, the soil could be disturbed anywhere from 2 inches to 2 feet deep (Hunter, 1907; conversations with local farmers). All of the various forms of tillage therefore had an impact on hydrology in the watershed, albeit to varying degrees.

\section{Conservation Practices Contribution to Sediment Cascades}

Depending on the capability class of the soil, a variety of conservation measures were used in the past to prevent erosion. Abundant runoff and soil erosion have long been associated with unique regional weather patterns and dryland wheat production on loessial soils developed on steep slopes (McCool et al. 2006; McGregor 1982). In some locations where dryland wheat is grown, susceptibility to soil loss is so great that unprotected soil moves downslope in the absence of rainfall when the top 3 to $4 \mathrm{~cm}(1.2$ to 1.6 in) of soil thaws and becomes a viscous, flowing slurry (Zuzel and Pikul 1987). Under conventional tillage, it was common for crops to utilize only about a third of the precipitation occurring during a 2- year period (NRCS, 1982). Water losses through evaporation from fallow soils were high, and in certain years runoff was rapid because of slow infiltration on finely tilled seedbeds or frozen ground (NRCS, 1982, Williams and Wuest, 2001; Williams, 2014). Further, past conventional farming practices made the 
land susceptible to large rills and ephemeral gullies, leading to major sediment delivery into streams (Clark, 2003).

To counteract these extreme conditions, efforts to reduce soil erosion on steep slopes in the region have relied heavily upon conservation practices that leave crop residues on the surface and promote infiltration of winter rain and snow melt when crop cover is minimal (McCool et al. 1995). Combinations of straw scattering at harvest, cloddy fallow and minimum tillage, diversion terraces, contour farming, and several hundred to over a thousand pounds of crop residue per acre were commonly left on the soil surface during winter to keep soil erosion losses to less than about 4 or 5 tons per acre per year (NRCS, 1982). In straw scattering, when the grain was cut and harvested, straw was scattered or dumped in bulk and left upon the ground to preserve soil moisture and to prevent wind erosion (NRCS, 1982). In cloddy fallow the land was plowed as late in the spring as possible, and no further cultivation was given. This practice would cause the soil to break up in a cloddy form and become so dry before it was plowed that no weed seeds would germinate (Hunter, 1907).

No-till farming has gained the most popularity for prevention of erosion and retention of moisture over approximately the past 15 years in the Columbia Basin upland region and is practiced on the majority of the farmland in the study area. The term "no-till" has been used somewhat loosely in the region and sometimes refers to what is actually known as direct seed. It may also refer to some form of minimum or reduced tillage that falls into the category of conservation tillage, which require at least $30 \%$ of residue cover to remain on the ground and causes less than 30\% disturbance (NRCS, 2006;WSU Extension, 2017). However, depending on whether true direct seed or some other form of 
conservation tillage is practiced, disturbance and/or reductions in erosion can vary widely (Huggins and Reganold, 2008). Variations in the way no-till is practiced and the range in the amount of disturbance caused by no-till practices has generated interest because of the potential impact to overland erosion and runoff into streams.

\section{Objectives}

Based on a recent NRCS erosion study on the Fifteenmile Watershed, NRCS estimates that 11.6 million tons of soil has been conserved since 1975 (NRCS, 2015b) and that sediment delivery to streams has been greatly reduced. However, before the streams in the watershed can be removed from the impaired streams list, several key questions need to be answered for regulating agencies: Where is the sediment that is still in the streams coming from? What proportions of the sediment are from upland sources versus near-channel erosion? How much of the excessive sediment loading is caused by modern land use and water management versus the legacy of past land use? These can be summarized in the primary research question of this paper: What are the sources of stream sediment in the study area and what influences are conservation management techniques having on them?

To answer the primary research question and related questions, I examine past and current farming practices, human modifications to streams, and geomorphological processes. The goals of this study are to: 1) identify potential sources of sediment throughout the watershed and constrain contributions from source areas; 2) understand how previous and current human activity has influenced sediment cascades in the Fifteenmile Watershed; and 3) determine what the implications are of localized human impacts on erosional processes, particularly those associated with conservation 
management techniques. In the following sections, I describe relevant characteristics of the study area and the range of methods employed.

\section{Study Area}

The research was conducted in wheat field farmlands of Wasco County, Oregon (Figure 3.1). The county is bordered to the north by the Columbia River, to the east by the Deschutes River, to the west by Mount Hood National Forest, and to the south by the Warm Springs Reservation. The county has 670 farms, most of them wheat, which account for the largest land use in Wasco County and approximately 81,130 acres are actively cultivated (NRCS, 2015b). The particular focus of this study is on the Fifteenmile Watershed of Wasco County, where the majority of wheat is grown in the county, and where many impaired streams are listed for sediment. 


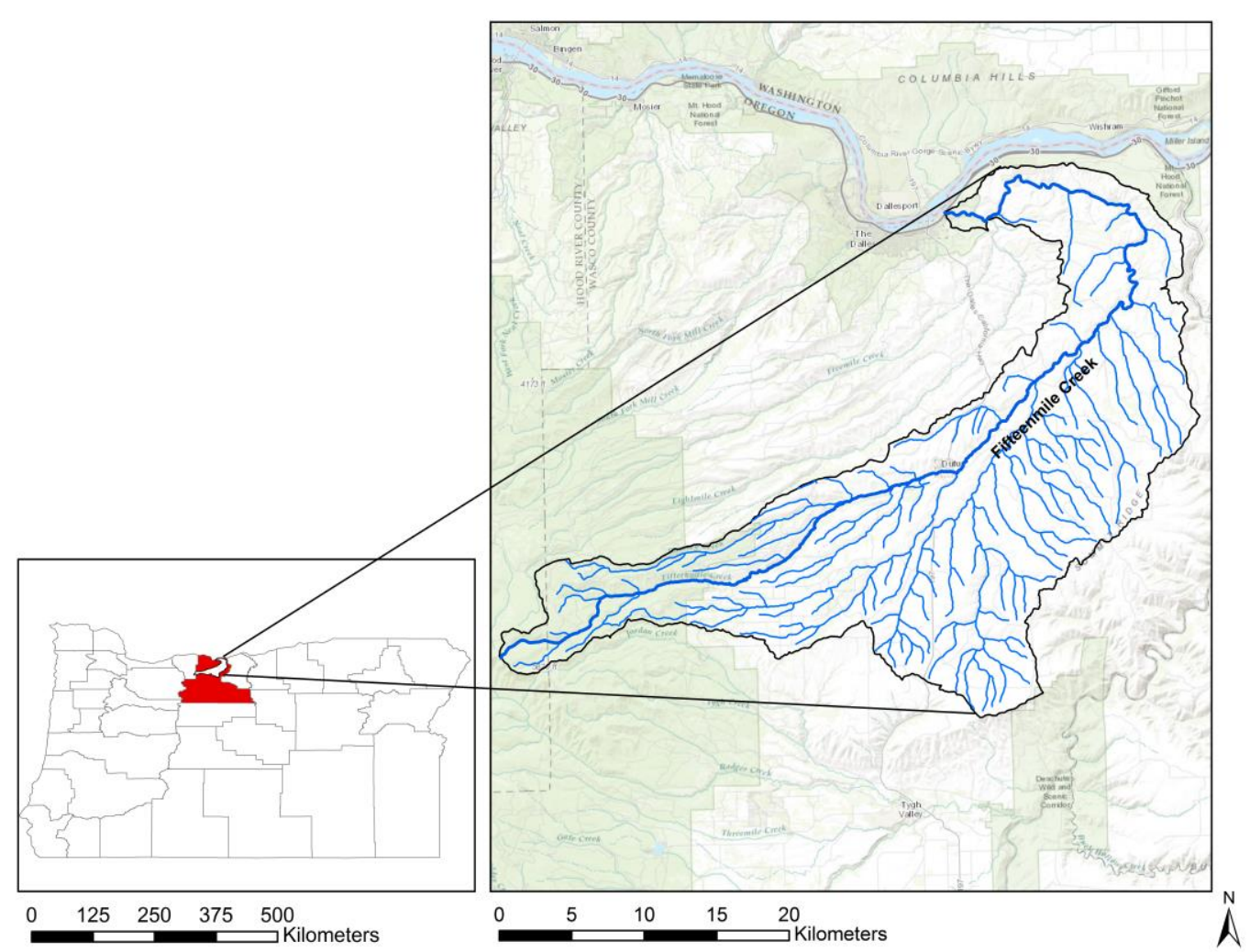

Figure 3.1. Study Area. Wasco County is shown in red and Fifteenmile Watershed is shown on the right hand-side with the main stream, Fifteemile Creek and its tributaries shown.

The Fifteenmile Watershed and Wasco County is located within the Columbia Plateau physiographic province and partly on the Eastern Cascade Mountain provinces. The Eastern Cascade province is comprised of wide and high upland eroded terraces consisting of mostly coarse alluvial and pyroclastic materials interspersed amongst deep V-shaped canyons. The Columbia Plateau is comprised of an uplifted lava plain with elevation ranging from 1,000 feet along the northern boundary to about 3,500 feet in the southwestern and western parts of the study area. The Columbia River demarcates the northern boundary of the study area and has an average elevation of 97 feet. Escarpments and steep slopes bordering the Columbia River rise abruptly to the upland terraces. In some places narrow sandy terraces parallel the river; in others, vertical basalt 
escarpments rise from 800 to 1,000 feet. Fifteenmile Creek is the main river within the Fifteenmile Watershed where most dryland wheat farming occurs, and it terminates into the Columbia River. Many of the tributary streams associated with Fifteenmile Creek have steep gradients and flow through deep canyons. Its tributaries: Eightmile, Fivemile, and Ramsey Creeks originate in the Mt. Hood National Forest and flow northeasterly, discharging into the Columbia River just downstream of The Dalles Dam (SWCD, 2015). The Deschutes Riverbasin borders the eastern edge of the watershed. The Columbia River Basalt flow has preserved the major ridges adjacent to the Deschutes and Columbia Rivers. The basalt is commonly more than 1,000 feet thick. The Dalles Formation has been deposited over older formations in the western part of the survey area and was built up slowly, as evidenced by buried soils in the regolith (Hodge, 1932).

There are two general types of soils in the Columbia Basin: residual and sedimentary (NRCS, 1982). The residual soil occupies practically the entire wheat-producing portion of the region. It is mainly the result of the weathering and disintegration of the Columbia basalt River B, and is a very fertile soil (Hunter, 1907). These soils, comprised of a mixture of clay, silt and gravel deposits transported by water, are also combined with ash and pumice from former volcanic activity and loess transported by wind from other areas. In many locations throughout the study area, the soils are now so intermixed that alluvial and aeolian materials are no longer distinct (NRCS, 1982). However, some patterns are present. For example, the soils on uplands are generally shallow over bedrock and are stony. Soils that formed in material on alluvial fans and terraces generally are somewhat gravelly or cobbly and in places are high in content of pumice. Soils formed in loess are high in silt and are shallow to deep over bedrock. 
During recent geologic times a mantle of loess was laid down over the entire survey area, but now it is thickest on north facing slopes, mostly as a result of preferential erosion (Hodge, 1932). It is a nonstratified and unconsolidated deposit by the wind. Along road cuts in the survey area, the loess stands in vertical banks as much as 10 feet thick (NRCS, 1982).

\section{Methods}

This study employed a mixed-methods approach to understand the geomorphic evolution of the landscape and to identify potential sediment sources. The methods, which account for both the human and geophysical influences on geomorphology, are described herein:

\section{Determining Source Contributions with Cesium-137}

Cesium-137 sampling and analysis was used to determine what source areas were contributing to sediment in streams. During the 1950s and 1960s, atmospheric nuclear tests distributed radioactive fallout of cesium-137 around the world where it was deposited onto and adsorbed by soil (Nagle and Ritchie, 2003). Because of its widespread distribution, multiple studies have used cesium-137 for tracing sediment sources in agricultural lands (e.g. Nagle and Ritchie, 2003; Stout et al., 2014; Zhang et al., 2016). The range of topics involving cesium-137 are vast, including everything from addressing how soil characteristics contribute to likelihood of erosion; how some heavy metals can be correlated with cesium-137 radionuclides; and for using cesium-137 for making a complete sediment budget in a watershed (Dragović, et al., 2008; Li et al, 2007; Polyakov, 2004). For this study, cesium-137 was used to identify eroding sediment 
sources in the watershed, and to assess how the identified contributing sources reflected on conservation programs used in the watershed.

Five different properties under no-till management were sampled for cesium-137. On each property, one or two different hillslopes were chosen for sampling that were representative of the landscape in the watershed. Each hillslope was sampled at the top, midslope, toeslope, and stream/ephemeral stream below using a standard shovel. In some cases, toeslopes were not sampled when the stream below would have amounted to the toeslope position. Between four and five discrete sampling points were taken along each transect on the hillslopes spaced between 15 and 20 meters apart depending on the size of the slope. At each point, samples were taken at 10,20, and $30 \mathrm{~cm}$ intervals to ascertain where cesium concentrations were highest. In some locations, particularly where channel walls were exposed, a $50 \mathrm{~cm}$ and $1 \mathrm{~m}$ sample were also collected to determine if cesium137 was present at those depths, and to determine if disturbance had occurred in those locations. Each of the sample intervals were composited into one sample that was representative of that transect. For example, a sample along the top of a slope at the 0 to $10 \mathrm{~cm}$ interval was actually comprised of four or five individual samples that were composited into one sample bag for analysis for the $10 \mathrm{~cm}$ depth along that transect. This was also done for the 10 to $20 \mathrm{~cm}$ interval, and 20 to $30 \mathrm{~cm}$ interval for each transect on each field. Interval sampling was conducted at the suggestion of an Oregon Department of Agriculture (ODA) employee who had previously sampled cesium-137 in the area for another study and found that it provided more consistent detections in the laboratory when the samples were analyzed. 
In streams or channels, samples collected were discrete and not composited. The number of samples collected for streams/channels varied by the size of the slope above it, but on average, three to four samples were collected from each channel and stream below a hillslope that captured the runoff from above. When both channel and stream conditions were ideal for sampling, the channel sample was collected within $2 \mathrm{~m}$ of the stream sample. Depths of channel and stream measurements were variable due to less than ideal substrate for sampling, but typically stream samples were collected between 10 to $20 \mathrm{~cm}$, with most stream samples collected from a depth of $10 \mathrm{~cm}$. Only two stream samples taken were collected from a depth of $30 \mathrm{~cm}$. Samples in streams were collected with a 2 inch PVC pipe that was driven into the bottom sediment of the stream bed when possible. Sediment was also sometimes extracted via hand shovel to a depth of $10 \mathrm{~cm}$. A Trimble Juno GPS unit was used to log geographic coordinates for each transect, channel, and stream sample location.

After collection, samples were dried in an oven at 105 degrees Celsius for 24 hours and then sieved with a $2 \mathrm{~mm}$ sieve and broken into two portions. One portion of the sample was submitted to the USDA ARS Southwest Watershed Research Center in Tucson, AZ for cesium-137 analysis. The analysis was performed using a spectrometry system consisting of four high-purity germanium detectors (Canberra GC4019) with $>30 \%$ relative efficiency and multi-channel analyzers (DSA-2000). The system was calibrated using mixed radionuclide reference material IAEA-327 and IAEA-447 certified by International Atomic Energy Agency (Strachnov et al., 1996). Measurement and spectrum analysis was conducted using Genie-2000 Spectroscopy software (Canberra, 2000). Activity of cesium-137 was calculated from the $661.6 \mathrm{keV}$ photopeak 
with $0.24 \mathrm{keV}$ resolution. The samples were counted for at least $80,000 \mathrm{sec}$ or until $<10 \%$ peak area uncertainty was achieved. The analysis included correction for self-attenuation due to variation of sample density (Quindos et al., 2006).

Standard gamma spectroscopy was used for the analysis of samples and cesium-137 concentrations were input into a spreadsheet for use in a conversion model. The mean values of cesium-137 analysis were input into a simple mixing model (Peart and Walling, 1988; Wallbrink et al., 1996), which allows for comparison of radioactivity among the samples. This model provides a reliable estimate of the change in erosion between the reduced tillage systems and other potential sources of soil. The equation for the model is as follows:

$$
C_{s}=\frac{P_{r}-P_{b}}{P_{S}-P_{b}} * 100
$$

Where

$C_{s}=$ contribution from cultivated surface sources $(\%)$

$P_{r}=$ mean value of property for stream bottom sediment

$P_{S}=$ mean value of property for cultivated soil

$P_{b}=$ mean value of property for bank material

The other portion of the sample was analyzed for texture to measure particle size by Hydrometer Method ASTM D422, 2007 at Portland State University and by Brookside Lab. Cesium-137 is strongly adsorbed to or fixed by fine soil particles and organic matter, which are generally transported as suspended loads or wash loads in streams (Zhang et al., 2016). To circumvent the enrichment of suspended sediment in fines, many studies measure only the fine fractions of $<63 \mu \mathrm{m}$ (representing the silt and clay 
fractions) in order to preserve the conservativeness assumption (Wallbrink et al., 1998; Walling, 2005; Koiter et al., 2013, Motha et al., 2002). In keeping with this rationale, the measured cesium-137 activity on the whole soil was divided by the silt and clay fraction of the sample to obtain the activity on that portion, which was used in the aforementioned mixing model and is shown in the equation below.

$$
C^{\prime}{ }_{s}=C_{s} * \frac{1}{f_{\text {clay }}+f_{\text {silt }}}
$$

Where

$C^{\prime}{ }_{s}=$ contribution from cultivated surface sources adjusted for particle size $(\%)$

$f_{\text {clay }}=$ fraction of clay in sample

$f_{\text {silt }}=$ fraction of silt in sample

Determining Human and Geophysical Impacts on Sediment Cascades

In the Fifteenmile Watershed, human influence has significantly affected sediment cascades in the landscape, primarily through varying forms of intensive to less intensive agriculture, which have created varying landscape sensitivities over recent decades. In addition, extensive channel modifications to stream channels throughout the watershed have resulted in a number of changes to erosional events. These activities are common at many catchment and landscape scales, where human disturbance can affect the effective catchment area and timescales of connectivity (Harvey, 2002; Lane et al., 2008). For this study, the processes and changes that affected the landscape were analyzed through analysis of historical aerial imagery, interviews and survey, and light detection and ranging (LiDAR) analysis. 


\section{Analysis of Historical Imagery}

Information about conservation management techniques used on farm fields was provided by the local SWCD, NRCS, DEQ, Oregon Department of Fish and Wildlife (ODFW) and farmers in the area. This information was used in conjunction with aerial imagery from 1939 forward obtained from the University of Oregon historical aerial photograph archive. Analysis of sequential aerial photographs is of particular value in determining frequencies and recovery times for different processes (Florsheim et al., 2011). This process helped to quantify the temporal and spatial scales of sediment cascades working on the landforms managed with different agricultural practices, particularly in areas susceptible to farm practices, such as ephemeral gullies and rills.

Stream channels in aerial photographs were also examined. Stream channelization and straightening of streams occurred with settlement of the Columbia Plateau and streams were regularly cleaned of vegetation to facilitate the efficient removal of water and soil from adjacent roads and fields (Williams and Wuest, 2001). More locally in the Fifteenmile Watershed, some of the more significant human alterations to the streams of the watershed include the Army Corps of Engineers' modification of stream channels throughout the watershed by installing rip-rap, dikes, and dams, particularly during the 1964 and 1996 floods (personal communication ODFW; Clark, 2003). Analysis of historical aerial imagery as well as information from a watershed assessment conducted in 2003 (Clark, 2003) was used to highlight changes between former and current forms of agricultural drainage system configurations and sediment pathways. 


\section{Interviews and Surveys}

To supplement the aerial photography analysis, I sent a survey to farmers who have been farming in the study area over several decades. The survey inquired about the history of various agricultural practices in the watershed. According to the local SWCD, much of this knowledge had been informally communicated before but had never been formally recorded. The local SWCD distributed the survey to farmers in the Fifteenmile Watershed and released the records for this study. These surveys were useful for constraining the years during which various types of agriculture had an influence on the movement of sediment in the watershed to gather the following information:

1. How long the property has been in no-till or direct seed and specification for which form of agriculture was used, and starting date/years for using no-till/direct seed.

2. Other forms of agriculture that have been used on the property in the past (e.g. straw/mulch till, conventional till, etc.) and years that the property was used for each agricultural management technique.

3. Known plow depths for the property and the type of equipment used on the tract, and the size of equipment and plows use and types of plows used.

4. Modifications to, or dredging of, streams downslope and adjacent to managed tracts, and the years that modifications and clearing of sediment occurred.

5. Any major erosion on properties from wind, rain, overland flow or gullies or rills and, if known, any years when erosion occurred on a frequent basis and/or years of erosional events that were more severe than others.

Semi-formal interviews with six farmers in the study area were conducted, as well. During the interviews, farmers were asked about the different farming practices they have 
used, equipment details, erosion concerns, and events or modifications to streams that had occurred on their properties. These interviews were useful for obtaining more details about how no-till is practiced in the area and for obtaining definitions about commonly occurring practices.

\section{Mapping of Floodplains and Terraces with LiDAR}

Floodplains and terraces are numerous throughout the study area, and can be sources of sediment when there is significant difference in elevation between the surface being eroded and the floodplain and point bar being constructed on the opposite bank (Lauer and Parker, 2008) (Figure 3.2). Terraces and floodplains in the Fifteenmile Watershed were delineated using the TerEx tool in ArcMap, which extracts and maps terraces and floodplains from a LiDAR derived DEM and measures the absolute elevation and height relative to the nearby stream channel (Stout and Belmont, 2013). LiDAR of the study area was provided by the Wasco County SWCD. In the Fifteenmile River, the TerEx tool was used to extract terraces based on three user-specified attributes based on the recommendations of the tool developers (Stout et al., 2014): 1) local relief of the terrace did not exceed $0.5 \mathrm{~m}$ within a $500 \mathrm{~m}^{2}$ area; 2 ) the terrace was located within $100 \mathrm{~m}$ of the channel centerline; and 3) the area of the surface terrace, once identified, was not less than $500 \mathrm{~m}^{2}$. Terrace surfaces selected for this tool were ground-truthed to verify that they were alluvial deposits. Floodplains were also extracted and were defined as surfaces that were less than 2.0 vertical meters above the channel. Alluvial surfaces higher than that elevation were considered terraces. 

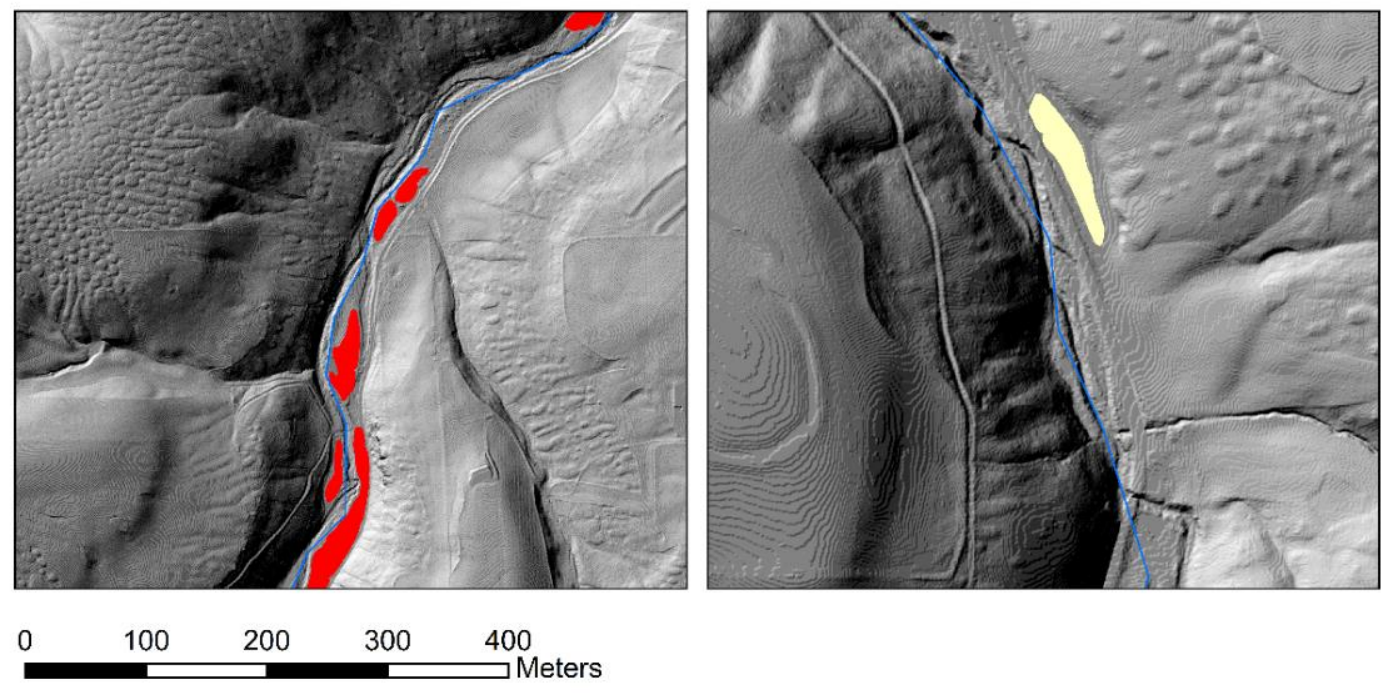

Floodplains

Terraces

Streams

Figure 3.2. Examples of floodplains and terraces mapped using the TerEX Tool.

(https://qcnr.usu.edu/labs/belmont_lab/resources). Figure on left shows floodplains mapped in red. Figure on right shows mapped terrace in yellow.

\section{Results and Discussion}

\section{Sediment Source Contributions Determined by Cesium-137 Analysis}

Given the variations in the way that no-till or other conservation management techniques are practiced in the present day and the modifications to streams in the watershed, it was necessary to determine what proportions of sediment were still being generated from land in conservation management programs as well as modified stream banks that have been altered to prevent channel erosion. Figure 3.3 shows the locations where cesium-137 samples were collected throughout the watershed. 


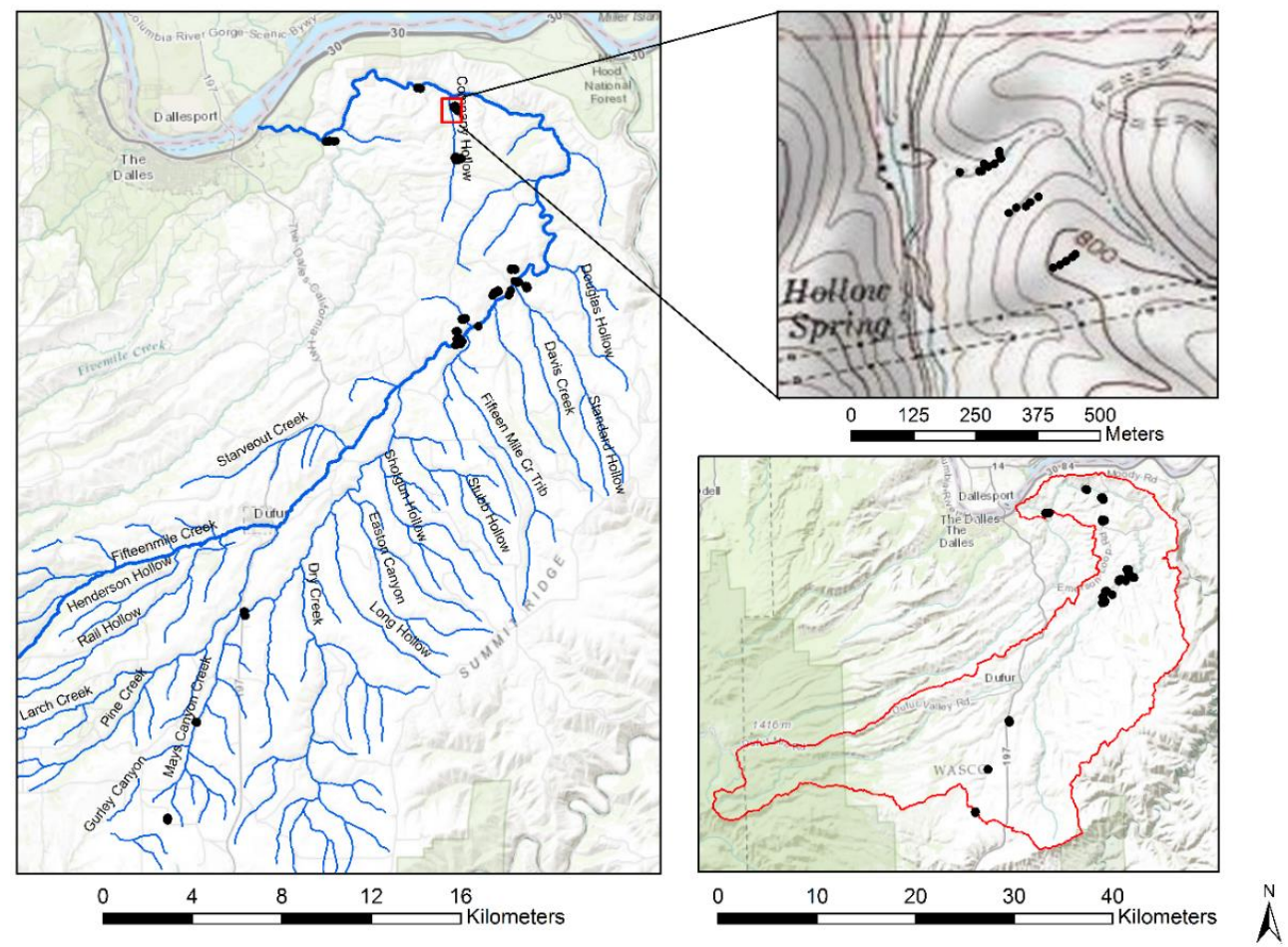

Figure 3.2. Locations of cesium-137 sampling. Figure on bottom right-hand corner shows the distribution of sampling locations, with the Fifteenmile Watershed outlined in red. The figure on the left shows the sampling locations in relations the main streams and tributaries of the watershed. Inset on upper right-hand side shows an example of the sampling scheme, where samples across three transects on the upper, middle, and toeslope positions of a hillside were located above a stream channel that was also sampled.

Although agencies and farmers in the area have noted substantial improvements in the amount of runoff that has been generated in farm fields that flows directly to streams, the cesium-137 analysis conducted for this study determined that approximately $49 \%$ of sediment in streams is still sourced from cultivated fields in the watershed (Table 3.1). The other $51 \%$ is generated from eroding channel banks. The percentage of cultivated source materials $\left(\mathrm{C}_{\mathrm{s}}\right)$ is calculated by taking the difference between the stream sediment $\left(\mathrm{P}_{\mathrm{r}}=5.21\right)$ and bank soil $\left(\mathrm{P}_{\mathrm{b}}=5.45\right)$. This number is divided by the difference between the cultivated soil $\left(\mathrm{P}_{\mathrm{s}}=4.97\right)$ and the bank soil $\left(\mathrm{P}_{\mathrm{b}}=5.45\right)$. The standard deviation and standard error of the mean were calculated for the watershed to demonstrate the range of the 
concentration values on the $<63 \mu \mathrm{m}$ fraction of sediment in each sample, as shown in the previously discussed equations. Although the high standard deviation indicates highly varied sample values, the low standard error of the mean reflects a number that is representative of the true mean value of the watershed as a whole and the large number of collected samples.

Table 3.1. Mean contributions of sediment from different source areas with calculated standard deviations and standard errors of the mean.

\begin{tabular}{llll}
\hline & Cultivated & Bank & Stream \\
\hline Number of Samples & 90 & 47 & 29 \\
Mean of Activity Bq kg & 4.97 & 5.45 & 5.21 \\
Standard Deviation & 5.02 & 5.60 & 7.31 \\
Standard Error of the Mean & 0.53 & 0.82 & 1.36 \\
Mean Contribution to Stream & $49 \%$ & $51 \%$ & \\
\hline
\end{tabular}

As mentioned previously, some samples were taken between $50 \mathrm{~cm}$ to $1 \mathrm{~m}$ to assess the depth to which cesium-137 was found across cultivated surfaces and to assess potential disturbance of bank deposits near streams. These samples were limited to areas where the $50 \mathrm{~cm}$ depth could be reached in farm fields and to locations where channel banks were thick enough to be sampled to $1 \mathrm{~m}$. In total, twelve samples from between 50 $\mathrm{cm}$ to 1 meter were collected, with seven of these samples collected from exposed channel bank faces that appeared to be actively eroding. In each of the channel bank locations, cesium-137 was detected, with an average concentration of $4.3 \mathrm{~Bq} \mathrm{~kg}^{-1}$. The concentration of cesium-137 at this depth was surprising given that cesium-137 does not usually penetrate to this depth level (Nagle and Ritchie, 2003). However, in the locations where the samples were taken, it appeared that the channel banks had been accumulating deposits from overland runoff. Materials in the soil horizon (generally what would be considered a weakly formed A-horizon) where the samples were taken from were often 
loosely consolidated without a strongly defined transition to the next soil horizon. These channel characteristics indicated that the channel bank likely received overland flow deposits from uphill, cultivated sources during precipitation and storm events.

In the five locations where samples were taken from cultivated fields, samples were collected from a depth of $50 \mathrm{~cm}$ and only one sample had any concentration of cesium137 at $1.67 \mathrm{~Bq} \mathrm{~kg}^{-1}$, which is appropriate given the amount of soil disturbance that occurred during conventional tillage and the large amount of runoff during that same time. More attempts were made to reach $50 \mathrm{~cm}$ at each field, but the conditions of the soils at depth (e.g. hard pan layers) made it difficult to reach $50 \mathrm{~cm}$ in most locations. Nonetheless, samples were collected at the $50 \mathrm{~cm}$ depth at three out of five farm properties, and the absence of cesium-137 at this depth (and the presence of the hardpan layer) would indicate that cesium-137 it is not likely present at lower depths in most cultivated areas, especially given that farmers did not disturb soil greater than 50 to 60 $\mathrm{cm}$, even during times of conventional tillage.

It should also be noted that some of the cultivated surfaces where sampling occurred are likely influenced by road surfaces with fine particles. Although the majority of roads throughout the watershed are paved or graveled, there are some extensive roads that consist of fine, loamy soils as well as exposed roadcuts across from cultivated lands. However, the amount of sediment supplied to cultivated areas and streams in the watershed as a whole is likely low, given the number of roads that are in this condition were not present at the majority of the field site locations. Roads would also not be expected to contribute as much to stream sedimentation as cultivated surfaces or eroding 
channels banks, since roadcuts are generally not subjected to as high of turbulent flows as channel banks (Nagle and Ritchie, 2003).

\section{How Humans Practices and Environmental Conditions Have Influenced Sediment Cascades}

Upon determining that nearly $50 \%$ of stream sediment is still generated from cultivated surfaces after the onset of conservation management practices, and over $50 \%$ is still generated from channel banks even after extensive modifications to streams, it was necessary to find out why. Further, it was necessary to determine what practices and events over both spatial and temporal scales are likely influencing the sediment cascades in the watershed.

Ten farmers, who represents about one-third of the farmers in the watershed (personal communications with SWCD), responded to surveys with varying levels of detail provided about past farm practices and known modifications to streams. The level of detail supplied in the surveys varied, with most farmers noting general trends of land use, as opposed to specific locations of management practices. However, more detailed information was provided by the informal semi-structured interviews that were conducted with six farmers who, cumulatively, are amongst the highest recipients of subsidy and conservation payments in the watershed related to no-till practices (EWG, 2017a; EWG, 2017b) and who have also managed a large percentage of the Fifteenmile Watershed for at least several decades (personal communication with SWCD). The combination of these methods along with aerial imagery and LiDAR analysis provided information that helped to constrain the time frame and temporal scales over which sediment likely contributed to streams in the watershed. 


\section{Past Farm Practices that Likely Influence Sediment Cascades}

Most farmers practiced conventional tillage until at least 1985 when the first conservation programs payments associated with the 1985 Farm Bill became available. Answers to questions 1 through 3 of the surveys and interviews concerning past practices, equipment used, and known plow depths were found to be consistent with the information summarized in Background section of this paper.

During interviews, all farmers indicated that the number of passes over a field for harvesting and planting had been reduced since the onset of no-till on their properties. Interviewees indicated that the number of passes over a field ranged from anywhere between four to six times prior to even seeding for preparatory work that was necessary under conventional tillage. This preparatory work involved disking and chisel plowing from anywhere between 2 inches to 2 feet deep, followed by a pass with a rod weeder. These practices seemed to have exacerbated two main issues in the watershed: ephemeral gullies and wind erosion. The erosional processes and their temporal and spatial component of their effects are discussed below.

\section{Ephemeral Gullies Related to Farming Practices}

All surveyed or interviewed farmers and agency employees indicated that ephemeral gullies in the watershed used to be a significant concern when conventional tillage was widely practiced in the watershed. These gullies provided steep drainage pathways to streams adjacent to farm lands and were often exacerbated during years of conventional tillage. All farmers indicated that they had not had problems with erosion occurring in ephemeral gullies since converting to-no-till, and some of them noted that they have been able to rework some of the former gullied areas into level surfaces with farm equipment 
by filling in the gullies with surrounding soil. This practice previously had to be conducted every year, but has not been as frequent since the onset of no-till.

Aerial imagery analysis shows that while many gullies have improved over time, the scars of the majority of the gullies remain. Figure 3.4 shows an example of an ephemeral gully that has remained from 1939 to the present. Many of the gullies seem to narrow in width and depth, but the scars of the gullies remain in aerial photos of majority of the landscape at present. Runoff from gullies was often exacerbated during extreme storm events that are common to the region, especially during the winter months when the majority of rainfall occurs.

While farmers indicated gully conditions had improved, two farmers and an agency employee indicated that new pest concerns have arisen since the onset of no-till that may also affect older gully areas, namely gopher holes and burrows that channel floodwaters and erode large quantities of subsurface soil in cropland. Rodent populations can thrive under no-till conditions, as burrow systems are undisturbed and plant residues able to build-up on the surface, providing cover and insulation (Witmer et al., 2004). Many of the burrows on sampled properties are even visible in widely accessible satellite imagery provided by Google, and may be contributing to erosion from cultivated surfaces into streams presently. Burrows from pests have been shown to exacerbate gullied areas in other dryland wheat farm environments in Oregon, as well (Nagle and Ritchie, 2003). Farmers have been attempting to combat these issues by placing nesting boxes near wheat fields that encourage birds of prey to manage rodent populations. 

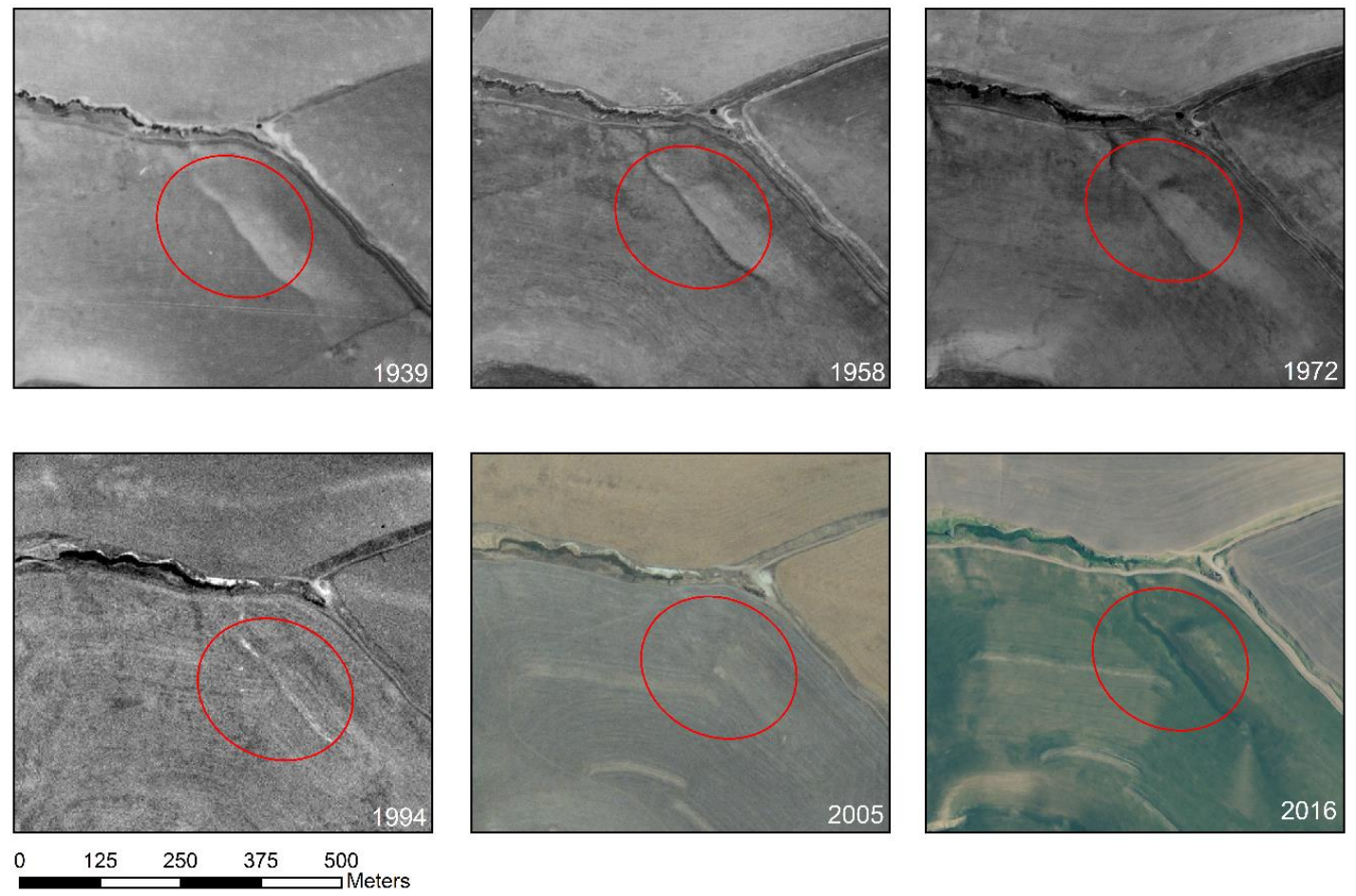

Figure 3.3. An example of an ephemeral gully from the years 1939 to present. As in the pictures shown above, although runoff from many of the gullies improve over time and may narrow in width and shallow in depth, the majority of gullies left impressions on the landscape that persist to the present day.

\section{Wind Erosion Related to Past Farming Practices}

Wind erosion was also significant during times of conventional tillage. The

Fifteenmile Creek subbasin lies in the transition zone between western and eastern

Oregon, and both summer and winter air temperatures can be somewhat extreme in the eastern portion of the subbasin where the majority of the Fifteenmile Watershed is located (Nelson, 2000). Prevailing winds are from the west, although easterly Fifteenmile Creek Subbasin winds occur along the Columbia River in December and January. In this area, even many flat, low lying floodplain areas without slope and converted into farmland are classified as highly erodible land (HEL) because of the wind. All farmers interviewed indicated that wind erosion and dust storms have not been as frequent since 
no-till became widespread. Wind erosion was likely more severe during drought years and years of lower precipitation, and was exacerbated by conventional plowing practices that reduced organic matter.

While all farmers interviewed indicated that wind erosion was much worse during times of conventional tillage, one farmer also stated that there were dust storms in 2016 that were comparable to the wind storms experienced when farms were under conventional tillage. Another farmer stated that his land continues to erode from wind erosion, even though the majority of his property is on flat land adjacent to a floodplain and is categorized in the HEL category.

When asked how they managed land to avoid erosion from wind, two of the farmers interviewed indicated that when wind was an issue under conventional tillage, farmers plowed in directions that would help to reduce topsoil loss. They also indicated that they would avoid working areas of the fields with gullies and rills in order to prevent wind erosion and dust storms from occurring. However, even with these practices, dust storms often occurred during conventional tillage.

\section{Current Farm Practices that Likely Influence Sediment Cascades}

\section{Equipment Variations in Equipment, Tillage Practices and Soil Disturbance}

Although conventional tillage clearly exacerbated the normal environmental conditions of the region, variation in the way no-till currently is practiced also appear to be having an effect on runoff into streams. There is a high amount of variability in the way that farmers practice no-till in the Fifteenmile Watershed. Indeed, even the definition about what constitutes no-till farming varies. After the last major flood of 1996, many farmers upgraded their equipment to various types of direct seed equipment that was 
authorized under various government contracts that they had access to during the late 1990s and early 2000s. According to the farmers interviewed and local NRCS employees, as long as farmers purchased equipment that met the criteria for direct seed, then farmers who enrolled in conservation contracts and converted their land to no-till were considered to be in compliance with the amount of disturbance allowed and would receive payments for the duration of their contracts (usually 3 to 5 years). However, the transition to no-till took place over several years; most farmers interviewed gradually converted acreage from conventional tillage to some sort of reduced tillage or what is often referred to as minimum tillage (see Table 3.2). In addition, true no-till practices, as defined by literature provided by the NRCS office (NRCS, 2006), have a soil tillage intensity rating (STIR) of $<10$, which translates to approximately $15 \%$ disturbance of row width during planting. However, NRCS also noted that equipment that has been accepted for contracts for enrolling into no-till programs in the watershed has included equipment that contains hoe/chisel openers and drills, which can cause as much as $30 \%$ disturbance to row widths during planting and is in the moderate range of tillage intensity (NRCS, 2006). Four of the six the interviewees indicated that they used air drills and knives with their direct seed equipment, keeping disturbance closer to $15 \%$. The other two farmers indicated that they use other types of hoe openers that fall within the acceptable range of disturbance but are not true no-till. Farmers who submitted surveys did not indicate the specific type of equipment they used.

Most farmers have bought direct seed equipment that generates a STIR value equivalent to 15 to $30 \%$ disturbance, within the range of conservation tillage, but higher than that allowed by true no-till or direct seed as defined by NRCS employees (personal 
communication with NRCS and NRCS presentation on Erosion in Watershed). Initially, when farmers signed up for no-till contracts, some farms were checked for compliance with this STIR value on their properties. However, limited resources and labor restricted the government's ability to confirm that the amount of disturbance occurring across the watershed actually met the STIR value criteria. Further, since most farms are now out of contract for these conversions to no-till and overseeing agencies assume that most farmers have direct seed equipment, the actual percentage of disturbance on each tract of land is unknown on a watershed scale, leading to some confusion over what type of notill practices are occurring, if at all.

Table 3.2. Table showing categories of conservation tillage and residue. Large differences between residue conserved, soil disturbance, and erosion occur due to equipment differences used for each method. Source Washington State University Extension Service (2017).

\begin{tabular}{|c|c|c|c|c|}
\hline \multicolumn{2}{|l|}{ Classification } & Primary Tool(s) & Tillage Intensity & Residue Coverage \\
\hline \multicolumn{2}{|l|}{ Clean-till } & Moldboard plow & High, soil inversion & $<30 \%$ \\
\hline \multicolumn{2}{|l|}{ Clean-till } & Heavy offset disk & High & $<30 \%$ \\
\hline \multicolumn{2}{|l|}{ Reduced-till } & Chisel plow, disk & High & $<30 \%$ \\
\hline $\begin{array}{l}\text { Reduced-till Minimum-till, } \\
\text { Mulch-till }\end{array}$ & \multirow{5}{*}{ 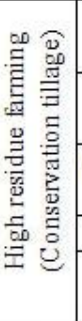 } & Chisel plow & Moderate & $>30 \%$ \\
\hline Strip-till & & Strip-till implement & $\begin{array}{c}\text { Non-uniform, moderate-none, } 6 \text { - } \\
12^{\prime \prime} \text { deep } \\
\end{array}$ & $\begin{array}{c}60-80 \% \text {, bare soil in planted } \\
\text { strip }\end{array}$ \\
\hline Zone-till & & $\begin{array}{c}\text { Gang of coulters on planter, } \\
\text { row cleaners }\end{array}$ & $\begin{array}{c}\text { Non-uniform, moderate-none, } 1 \text { - } \\
2^{\prime \prime} \text { deep }\end{array}$ & $\begin{array}{c}60-80 \% \text {, bare soil in planted } \\
\text { strip }\end{array}$ \\
\hline Direct seed, No-till* & & Planter with row cleaners & \begin{tabular}{|c|} 
None \\
\end{tabular} & $60-80 \%, 0-80 \%$ in planted strip \\
\hline Direct seed, No-till & & $\begin{array}{c}\text { Planter without row } \\
\text { cleaners }\end{array}$ & None & $80-100 \%$ \\
\hline
\end{tabular}

The number of farmers practicing true direct seed as opposed to some other form of conservation tillage is extremely important, because of the effect it can have on surface erosion in cultivated soils otherwise assumed to be minimally disturbed. Table 3.3 shows the erosion rates that NRCS determined using RUSLE 2 for the watershed in 2015 (NRCS, 2015b). Assuming that there are 81,130 cultivated acres in the watershed and that farmers are practicing no-till using true direct seed techniques, approximately 27,000 tons of soil erodes per year, which is significantly less than the amount of soil eroded 
under conservation tillage or conventional tillage. However, once variations in

disturbance are factored in, the amount of erosion occurring increases substantially, as

shown in Table 3.4.

Table 3.3. Differences between erosion rates based on type of tillage used. Erosion rates were calculated by NRCS in Wasco County using RUSLE2. The amount of tons of soil lost per year assumes that there are 81,130 acres of cultivated land in the watershed. If all users practice no-till/direct seed as defined with less than 15\% disturbance, only 27,584 tons are eroded per year. Erosion rates were supplied by NRCS Soil Conservationist in Wasco County.

\begin{tabular}{lccc}
\hline & $\begin{array}{c}\text { No-Till/ } \\
\text { Direct Seed }\end{array}$ & $\begin{array}{c}\text { Conservation Tillage (Rate for Reduced } \\
\text { Till, Minimum Till, Mulch Till) }\end{array}$ & $\begin{array}{c}\text { Conventional } \\
\text { Tillage Rate }\end{array}$ \\
\hline $\begin{array}{l}\text { Erosion Rate } \\
\text { (tons/acre/year) }\end{array}$ & 0.34 & 4.6 & 8.83 \\
Eroded Soil (tons/year) & 27584 & 373198 & 716378 \\
\hline
\end{tabular}

Table 3.4. Differences between erosion rates based on variations in the range of users of a particular method. The table shows a range of possibilities for erosion given the variability of farmers' responses during interviews and information supplied by agency employees with knowledge of the study area. If it is assumed that approximately $5 \%$ of users still practice conventional tillage (the mean value of those left over if it is assumed that between the 93 to $96 \%$ of users practice some form of no-till), then 171,468 tons of soil are eroded each year. This is much higher than the estimate shown in Table 7 if all users practice no-till/direct seed as technically defined.

\begin{tabular}{|c|c|c|c|c|}
\hline & $\begin{array}{l}\text { No-Till/ } \\
\text { Direct Seed }\end{array}$ & $\begin{array}{l}\text { Conservation Tillage (Rate for Reduced } \\
\text { Till, Minimum Till, Mulch Till) }\end{array}$ & $\begin{array}{c}\text { Conventional } \\
\text { Tillage Rate }\end{array}$ & Total \\
\hline $\begin{array}{l}\text { Percentage of } \\
\text { Users }\end{array}$ & $63 \%$ & 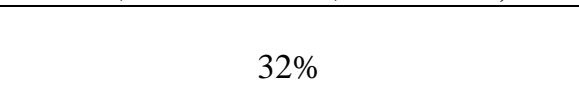 & $5 \%$ & \\
\hline $\begin{array}{l}\text { Eroded Soil } \\
\text { (tons/year) }\end{array}$ & 17470 & 118179 & 35819 & 171468 \\
\hline
\end{tabular}

According to the local SWCD and NRCS, there are 81,130 acres of actively cultivated land in the Fifteenmile Watershed and between 93 to $96 \%$ of farmers are practicing what they have reported to be no-till conservation practices. If the information supplied during informal interviews is applied to the watershed as a whole - a reasonable assumption given that they manage the majority of the watershed - and four out of six people (or 63\%) practice direct seed as it is technically defined, then approximately 17,000 tons of soil erosion per year can be attributed to the current version of no-till 
practices. The remaining $32 \%$ of users practicing some form of conservation tillage produces almost 120,000 tons of soil erosion, and those still practicing conventional tillage produce over 35,000 tons of soil erosion, with a total amount of over 170,000 tons of soil eroded per year. While this estimate is below what would be eroded if everyone practiced conventional till, it is still significantly higher than the estimated 27,000 acres of soil eroded per year were all farmers practicing true direct seed, and is likely a reason that higher sediment loads in streams persists.

Beyond interviews with farmers and NRCS, interviews with other agencies and extension agents with knowledge of the region corroborated much of the variability that is likely occurring in the watershed. One agency employee stated in an interview that every farmer has his own definition for what constitutes no-till and that this definition varies between farmers, with most farmers considering some form of high residue tillage (e.g., reduced till, strip till, mulch till, and zone till; see Table 3.2) as no-till. The agency also indicated that many farmers are able to practice no-till or direct seed that meet the requirements for maximum residues and minimal disturbance in two or three of their crop rotations, but also might have to incorporate a form of conservation tillage another year due to field conditions or other environmental factors that do not permit adherence to true no-till practices. For this reason, many farmers use the term "no-till" interchangeably with conservation tillage, even though they may not be consistently meeting the requirements of true no-till or direct seed practices.

Some extension agents noted that a small number of farmers in the county and the Fifteenmile Watershed had returned at least part of their land back into some form of conventional tillage or minimum tillage after practicing no-till. These conversions were 
due to a variety of issues related to difficulties with herbicide resistance, difficulties managing crop stubble, and changes in weather patterns that made predicting farming difficult. Under conventional tillage, farmers could "farm by the calendar," meaning that there was a set schedule and time by which preparatory work and ongoing management of farming occurred. With no-till, on the other hand, extension agents and several farmers noted that even though they were getting better at no-till practices, they were still trying to figure out the best timing for some practices. This trial-by-error approach has sometimes proven difficult, especially during times when changing weather patterns have been prevalent in the region and the state. Several farmers even brought up climate change as a contributing factor to their difficulties with management, but the majority indicated that conditions under no-till were better overall than when they practiced conventional tillage or other forms of conservation tillage as distinguished from their current definition of no-till practice.

\section{Stream Modifications and Unrecognized Sources of Sediment}

The streams of the Fifteenmile Watershed have undergone extensive modifications. Typical manmade channel modifications include dikes, riparian roads, stream crossings, dams, and rip rap in many areas (Clark, 2003). According to ODFW, which has been heavily involved in various stream modifications and improvements for the past several decades, all of Fifteenmile Creek has been altered or straightened at one time or another starting in the 1940s and after every flood since then. Flooding is a natural factor that modifies the channel of a stream, and most agencies and farmers indicated the most extensive floods occurred in 1964 and 1996. 
The prevalent modifications to streams that occurred throughout the watershed were corroborated by investigation of aerial imagery of streams in the watershed from 1939 forward. Historical images in various parts of the watershed and for all of the properties sampled were available for the years 1939, 1947, 1958, 1965, and 1972 from the University of Oregon's historical imagery collection. The most apparent changes to streams occurred during the years of the aforementioned floods in 1964 and 1996. Imagery from the year 1964 was not available, but aerial imagery from 1965 that showed changes in stream configurations post-1964 flood were reviewed.

Figure 3.5 shows an example of a stream that has had major changes within its channel configuration from 1947 to 2011 . Although it was impossible to avoid sampling in channel areas that have been modified, locations where channels have been modified extensively, as shown in the figure, were not chosen for sampling. These locations included areas where intentional channel modifications had been made after the 1960s (when cesium-137 would have been deposited) and areas where the 1964 and 1996 floods changed channel morphology. 

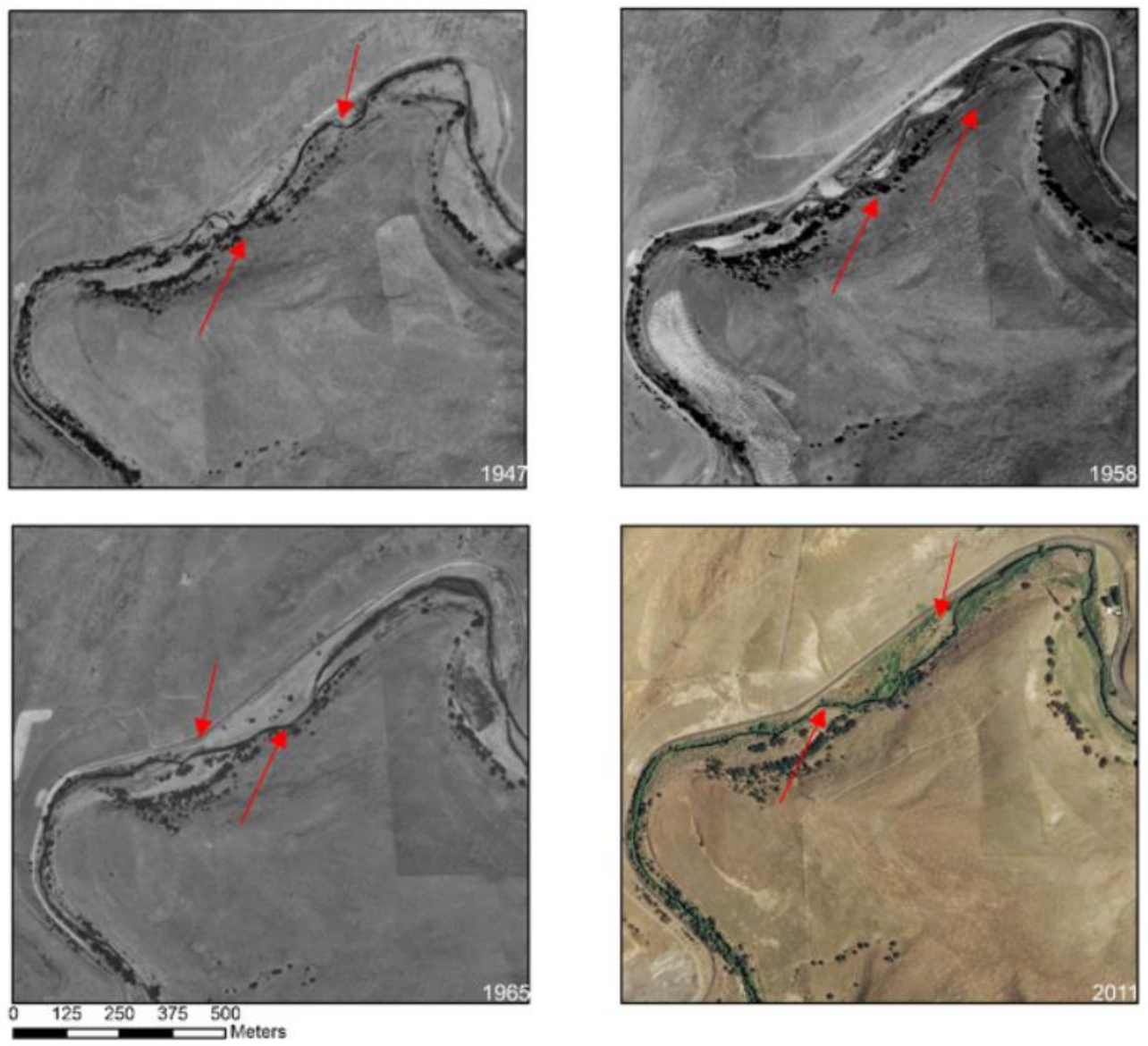

Figure 3.4. Figure showing an example of a highly modified stream in the watershed. The red arrows draw attention to areas that were modified extensively over several decades. Many channel modifications like those shown above are prevalent throughout the Fifteenmile Watershed. Streams that showed significant channel modification were avoided during cesium-137 sampling for this study.

Aerial photograph inspection and review of watershed assessments demonstrate that floodplains have been extensively used for agriculture and residence. Stream channels have been manipulated in order to consolidate farm fields, protect infrastructure, and accommodate roads (Clark, 2003). However, consensus on whether or not the floodplain currently interacts with streams in the Fifteenmile Creek varied amongst farmers and agency employees. Conversations with ODFW indicated that the main Fifteenmile Creek no longer interacts with floodplains anywhere in the Fifteenmile Watershed, while other agencies have identified locations in the watershed that still interact with the floodplain. 
Three farmers out of the six interviewed indicated that stream erosion had occurred on their properties prior to the planting of vegetation in Conservation Reserve Enhancement Program (CREP) corridors. The other three interviewed farmers were not confident about the ways in which stream channels interacted with floodplain areas or eroding terraces that crossed their properties. According to the SWCD, since the late 1990s, CREP has been implemented in the majority of the watershed through contracts with farmers to improve stream habitat and prevent erosion to streams. In addition, ODFW constructed approximately 1000 in-stream fish habitat structures using rock and logs in addition to constructing 209 miles of riparian protection fences for over 100 miles of stream from intensive livestock grazing funded by BPA from 1986 to 1994 ODFW.

Given the continued exceedances of sediment TMDLs, the USFS, DEQ, and ODA have attempted to determine how much sediment is still in streams and if it has improved over time since no-till practices were implemented. Pebble counts conducted by USFS have been replicated by DEQ since the early 2000s. Relative Bed Stability (RBS) measurements were conducted by ODA in 2005 and 2006 and again in 2015 and 2016. Although DEQ, ODA, and USFS have admitted that variations in methods have occurred from year to year, all of these analyses have indicated that sediment in streams has not improved (Jessup, 2016). A recent report prepared for DEQ evaluating all of these methods specifically notes that data from 2000 to 2015/2016 using pebble count measures and data from 2005/06 to 2015/16 using RBS methods indicates that no improvements in substrate conditions were detected using t-tests watershed-wide (Jessup, 2016). 
To assist with constraining the local sources of sediment from channel banks, this study employed the use of the TereX tool (Stout et al., 2014) and 1 meter LiDAR, to identify floodplains and eroding terraces that are likely contributing sediment to streams. It should be noted that the tool is capable of identifying, and did identify, many locations throughout the watershed that were likely cultivated terrace source areas, but these areas are not included in this analysis. Permission to access these cultivated surfaces was not granted for verification, so at this time it is not reasonable to include those areas in this study. However, a future study should include analysis of the cultivated surfaces if access is permitted.

The LiDAR analysis identified floodplains and upland terraces (excluding cultivated surfaces) that are likely contributing sediment to streams (Figure 3.6). Many of the floodplain areas are adjacent to, or border, farmland that is located in floodplain areas. Cumulatively 0.92 square kilometers of surfaces have been identified as contributing to the watershed. While, the TerEx tool itself does not give a value for the amount of sediment generated at each location, the surface area of likely surfaces that are eroding into streams, coupled with the information from the cesium-137 analysis revealing that $51 \%$ of sediment is generated from locations along channel banks is cause for concern. 


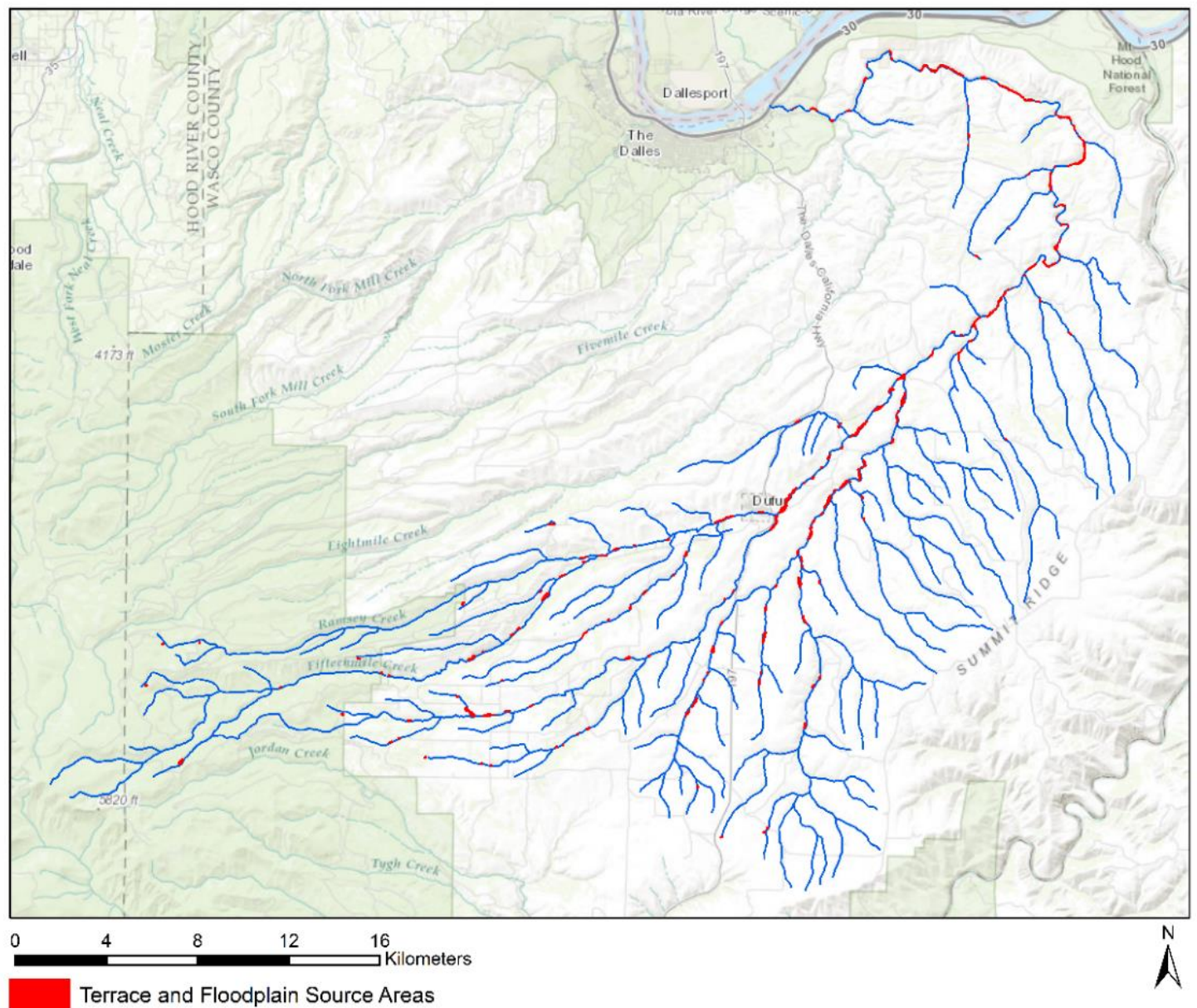

Figure 3.5 Locations where the TerEx tool identified likely floodplain and eroding terraces throughout the watershed.

The source areas along channel banks identified by the TerEx tool were overlaid with RBS sites that were found to be in poor or fair condition from the 2016 report prepared for DEQ (Figure 3.7). At these locations, an exceedance of fine particles were found in relation to the rest of the watershed. By combining the RBS sites with the map of contributing floodplains and terraces, it was deduced that three of the five sites that were in these conditions were also located in areas identified as source areas. One contributing floodplain identified by TerEx was identified as being 60 meters downstream of another RBS site in poor condition (24567). Another site (28337) does not appear to be impacted 
by floodplains or terraces in the vicinity, as it is located across a roadway from these features. RBS sites located in the watershed, but in forested area were not included in this map, as the processes affecting sediment in streams in forested areas were not assessed in this study and are likely driven by different forces than those that occur in the agricultural regions of the watershed. Nonetheless, using the map could prove useful for future assessments in the watershed to determine sediment source contributions and to assess the conditions of substrate in those locations. This information would assist in decisions on how stream management could be improved. In the most conservative estimate that takes into account variability of no-till practices where two-thirds of farmers are practicing no-till with minimal disturbance, 118,179 tons of soil are being eroded into streams without accounting for channel bank erosion. With additional sediment generated from floodplains and terraces near streams, it becomes clear that erosion estimates in the watershed are likely substantially lower than they should be, and the additional information provided by investigating source areas in and near streams could be useful in efforts to quantify the amount of sediment being generated. 


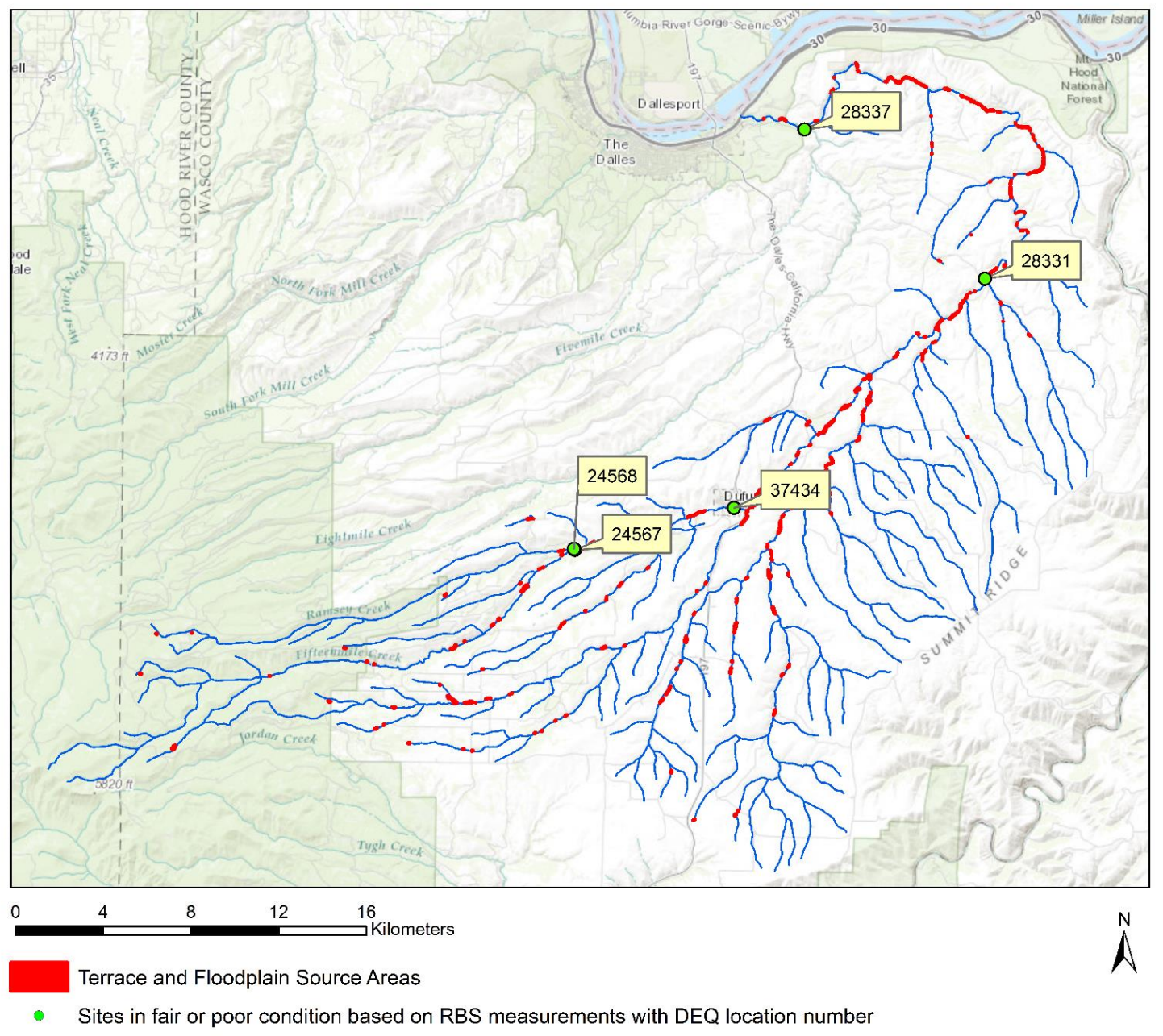

Figure 3.6 RBS sites in fair or poor conditions (locations with an excess of fine particles) combined with terraces and floodplains identified as likely sediment sources.

\section{Conclusions}

This study provides valuable information about the likely sources of sediment in the Fifteenmile Watershed. By incorporating a mixed-methods approach, this study found that there are large disparities between the erosion that is currently estimated in the watershed with RUSLE2 and what is more likely occurring. The mixed-methods approach used allowed for a greater investigation into the complexity of why sediment was likely still coming from cultivated fields and revealed that current conservation 
practices are still likely contributing large amounts of sediment to streams. The study also demonstrated that current erosion estimates do not take into consideration erosion from channel banks, which accounted for just over half of sediment in the watershed.

This study also highlighted the need for input of methods that allow for engagement with farming communities, as the variations in practices in no-till would likely not have been factored into this analysis unless interviews and surveys had been conducted. By combining these methods with measurable quantitative data produced by cesium-137 analysis and LiDAR analysis, this study showed that lands that are largely managed with conservation management techniques are contributing far more sediment than previously thought and that streams modified to not interact with watershed floodplains actually do in many locations. Conventional Universal Soil Loss Equations (USLE) based estimates, such as RUSLE2, are useful for identifying local erosional hotspots, but USLE-based approaches are inherently limited at the larger watershed scale by the a priori assumption that the contemporary sediment yield is directly attributable to erosion ongoing in the upland environment (hillslopes and agricultural fields) (Stout et al., 2014). Given that over half of the sediment in the streams is generated from channel bank locations in the watershed and that sediment conditions have not improved since no-till was implemented in the watershed, it is clear that additional considerations for these source areas need to be factored into methods for reducing sediment in the watershed.

It should also be noted that this study's findings do not indicate that no-till farming is doing more harm than good for the watershed. It has been well documented that no-till practices reduce erosion rates from dryland agricultural watersheds (e.g., FernandezCornejo, J. and Hallahan, 2013; Fu et al. 2006; Schreiber et al. 2001). As discussed 
previously, prior to no-till practices, farmers faced severe consequences in the form of wind and gully erosion when conventional till was practiced. Rather, this study finds that the amount of disturbance and amount of erosion varies widely by the way no-till is practiced in the watershed, and that more effort should be put into finding out what practices are causing different amounts of erosion in the watershed. This could be done by a more detailed engagement with farmers in the community to assess how much disturbance their machinery causes to the landscape and working on practices that could improve and minimize erosion on the landscape. This would be beneficial for the entire community, as many of the farmers involved in this study expressed their pride in being involved in conservation programs and were genuinely interested and engaged in practices that would improve stream conditions. As mentioned previously, between 93 to $96 \%$ of farmers in the area at least attempt to use no-till on their property, and the farmers that participated in this study are likely among the most engaged and dedicated to practicing conservation with a goal of improving the watershed.

Further, it should also be noted that the farmers in this study and throughout the watershed were encouraged to participate in no-till through a variety of programs and contracts that were made available to them. The information supplied to them by NRCS about no-till and how much it improves farming conditions and what their practices should be should have significantly improved stream quality, but has not for the following reasons: 1) conservation programs associated with farm bills often have loosely defined requirements in how to improve environmental conditions 2) lack of resources (both in labor and time) available to government employees who are instructing farmers how to use no-till limit the amount of critical evaluation of how effectively a given 
conservation is being practiced and 3) continued misinformation provided to farmers and the community perpetuate the idea that environmental conditions are improving when they are not. This last point is most damaging and frustrating for farmers that are engaged in conservation practices as, on the one hand, they are encouraged to practice a method that is said to improve their environment, while on the other, they are regulated when the methods they think they are using correctly do not work as intended. When one makes these observations, it is clear that the persistence of sediment in the watershed is more a reflection of inadequate policies and instruction derived from an institutional level than any one practice that a farmer may be practicing on his property, and strategies to identify how conservation methods could be improved should be discussed. 


\section{Chapter 4: A Critical Physical Geographical Analysis of Conservation Management Practices: Implications for Soil Quality, Water Quality, and Farm Bill Policies}

Affecting No-Till Agriculture

\section{Introduction}

A variety of conservation trends have gained and lost favor throughout the years in agriculture, with U.S. Farm Bills often influencing what conservation practices are implemented by farming communities throughout the U.S. (Lehrer, 2010; Rigdon, 2011). This paper focuses on the unintended consequences of conservation management techniques and programs in the Fifteenmile Watershed of Wasco County, Oregon. Farmer enrollment in various conservation management agricultural techniques, loosely referred to as no-till agriculture in the study area, has affected soil and water quality through the increased use of herbicide and variations in the way no-till agriculture is practiced. As a result, glyphosate, the most used herbicide in the world (Benbrook 2016), has been detected in soil, sediment, and water at concentrations below regulatory standard levels, but above levels that have been shown to have negative impacts to human and ecological health in numerous peer-reviewed studies. Soil erosion processes have also been affected by uneven implementation of best management practices (BMPs) associated with conservation management techniques, and these variations have failed to reduce sedimentation in streams as much as is needed for many of the county's streams to be taken off the state's regulatory impaired water quality list (EPA, 2015). Given that participation rates in conservation programs is high among farmers in the county, many practitioners wonder why the practices have failed to produce the desired results and if the conservation practices are as effective as they should be. This paper will discuss the 
contributing physical and social factors that have led to the current environmental issues in the watershed.

\section{Background}

The specific focus of this study is the Fifteenmile Watershed portion of Wasco County, Oregon. The watershed experiences extreme precipitation and wind events, and is comprised of a landscape of steep slopes and hills prone to erosion even in the absence of weather-related events. As such, farmers in the watershed have always had to implement a wide variety of conservation methods in an effort to combat soil erosion, even since the 1940s when conservation practices were not widely practiced across the U.S. (Rigdon, 2011). The implementation of the 1985 Farm Bill encouraged many farmers to engage in more conservation practices such as the Conservation Reserve Program (CRP) (Hall, 1998; Rigdon, 2011). However, substantial changes in conservation management techniques in most of the Fifteenmile Watershed did not occur until severe flooding in the years 1995 and 1996 resulted in mass erosion events that caused most farmers to consider no-till farming as an alternative to conventional farming practices. Farm subsidies and grants associated with the 1996 and 2002 farm bills incentivized farmers to buy the equipment needed to make the conversion to no-till. Educational programs hosted by the Natural Resource and Conservation Service (NRCS) and local Wasco Soil and Water Conservation District (SWCD) further assisted in the transition from conventional tillage to conservation management techniques associated with no-till. By 2012, $93 \%$ of farmland was managed under some form of no-till agriculture in the Fifteenmile Watershed (SWCD, 2015). 
Although herbicide use, particularly glyphosate, is known to be on the rise because of the switch to no-till, most of the concern in the study area has been on soil erosion issues because they are directly related to sedimentation issues in streams. These issues were supposed to be remedied by wide scale conversion to no-till conservation practices and have gained the attention of regulatory and non-regulatory managing agencies alike, as they have not been resolved. Given that sediment remains a problem in streams throughout the watershed and that additional problems associated with no-till and herbicide have arisen, I ask the following questions: Why have sedimentation issues related to soil erosion persisted in the presence of conservation programs that are supposed to improve water quality? How and why has the focus on soil erosion obscured the impacts that herbicide use has had on soil quality and its potential impacts to human and ecological health? Are farmers being encouraged through quasi-state actors and government subsidies to engage in conservation programs in ways that do not support programs goals or result in contradictory outcomes and unintended consequences?

\section{Critical Physical Geography}

To answer the research questions of this paper, I engage with a Critical Physical Geography (CPG) framework. CPG has largely arisen out of the need to expand political ecology's horizons and has sought to rework the relationship between human and physical geography (Lave et al., 2013). As several authors of the emerging field have noted (Lave et al., 2013; Rhoads, 1999; Tadaki, 2015), studies of the environment often become polarized as purely social or purely biophysical problems (depending on the lens of the researcher) and CPG seeks to integrate the two. At the center of CPG is an integration of the links between and causes for the social and biophysical causes of 
environmental problems. As Lave et al. describe it, CPG promotes an integration of "the power relations and social processes at the heart of critical human geographic inquiry and the material processes at the heart of physical geographic inquiry in a wider project of social and environmental transformation" (Lave, 2013). A CPG framework assumes that human-environmental problems can only be well understood through a mixture of social and environmental change and seeks to provide an interdisciplinary synthesis of causation.

CPG has been used in conjunction with a wide variety of disciplines and has been built on a transdisciplinary approach (Bridge 2008; Castree 2012; Clifford 2002; Goudie 1986; Harrison et al. 2006; Lane 2001; Rhoads 1999). CPG integrates particularly well with biogeography, soil science, and geomorphology, because researchers in these fields generally "share an intellectual world-view centered on complexity, uncertainty, the importance of process, and the particularity of local systems" (Lave, 2014). Even though it is a relatively new field, several articles and books that have served as inspiration to the integration of CPG and soil science (Richter, 2007; Richter, 2001; Swidler, 2009) have been published and there have already been exemplary articles and books published that integrate CPG and soils analysis (Engel-Di Mauro, 2014; McClintock; 2015) since its emergence in 2013.

With conservation management in mind, CPG is useful for determining how land management decisions are made that affect soils, which are at the center of much of this research. A CPG approach enables the study of soils in a way that promotes an open discussion on political positions (e.g. about land use), the scope of science, and the role of scientists relative to the state and the rest of society, among many other unspoken, yet 
underlying issues (Engel-Di Mauro, 2014). It has also opened the door to the incorporation of relations of power and social context into soil science (Lave, 2013; Engel Di-Mauro, 2014; McClintock, 2015). Understanding these power relations in a complex of nonhuman and human processes, all of which operate on varying spatiotemporal scales (Richter, 2007), provides insight into a variety of environmental problems on both regional and global scales.

\section{Overview}

I begin the paper with overviews of how farm bills have influenced conservation practices, with particular emphasis on bills created after 1985. The farm bill of 1985 , known as the Food Security Act of 1985, was the first true conservation farm bill, because it imposed financial penalties in the form of subsidy revocation on farmers who failed to meet minimum standards of eco-conduct (Rigdon, 2011). Every bill since the 1985 farm bill has mandated that farmers incorporate conservation practices as part of requirements for receiving subsidies. The types of mandates associated with the bills offer substantial explanation as to why it is that no-till became the preferred conservation method for much of the U.S. to prevent soil erosion. I then discuss the history of the most widely used herbicide in the world, glyphosate, and how its rise coincided with - and in many cases, increased in use because of - conservation practices associated with no-till. In examining this, I point to how loose interpretations of conservation practices, influence from agrochemical companies, and the rise of neoliberalism have all contributed to environmental issues associated with no-till agriculture. To illustrate an example of how these larger phenomena work in tandem on a local scale, I present the current environmental impacts of no-till agriculture in The Fifteenmile Watershed of Wasco 
County, Oregon. Numerous authors have discussed how social forces such as economics or policy have influenced conversions to no-till (e.g. Lerher, 2010; Hall, 1998; Rigdon, 2011), while other studies have focused on the biophysical effects of no-till (e.g. Fernandez-Conejo, 2013; Montgomery, 2007; Williams and Wuest, 2011). While these studies may briefly allude to the social or biophysical causes of environmental issues associated with no-till, they focus on one or the other, and do not explain how these processes in combination translate to actual environmental change. By using a CPG approach, this study will illuminate how these processes work in tandem to alter the social and physical environments.

In line with a CPG framework, I used a mixed-methods approach to address both the biophysical, quantitative aspects of this research as well as the social, qualitative aspects. The methods had to identify: 1) Where sediment in the watershed originated to determine if sediment in streams was sourced from cultivated landscapes under no-till management in the watershed and/or from other sources in the watershed; 2) What concentrations of herbicide were present in soil, sediment, and water in the watershed to verify if concentrations of herbicide were persisting and terminating in stream waters and sediment where they should not be present; and 3) How management practices were affecting the geomorphological processes in the watershed as well as the concentrations and persistence of herbicides. I describe the methods used to derive this information in detail in Chapters 2 and 3 of this dissertation, and I will not discuss them further in this chapter. 


\section{Farm Bills Lay the Groundwork for No-Till}

Much has been written on farm bills and the reasons that certain subsidies and commodities were included or excluded over time (e.g. Hall, 1998; Lehrer, 2010; Rigdon, 2011; Lenihan and Brasier, 2010). Briefly, farm bills establish federal agricultural food policies, and historically have focused on farm income objectives, international trade, and decreasing soil erosion. Farm subsidies associated with farm bills have a large influence on what farmers do with their land - from what they decide to plant to how much they irrigate - as well as determining what effort they put into protecting the environment (Keeney, 2010). Farmers widely participate in subsidy programs, and therefore, also widely participate in the management practices that are associated with the subsidies. For example, from 1997 to 2006, producers in the U.S. received an average of $30 \%$ of their net farm income from direct government payments (Service, 2007). The largest subsidies are provided for corn, wheat, rice, soy and cotton (Gale, 2013). Early farm bills, like those implemented between 1933 and the early 1970s, did not take into account environmental problems that could potentially result from certain farm practices. These farm bills were largely implemented with subsidies and commodities that were put into place for the survival of the American Farmer (Lehrer, 2010; Rigdon, 2011). In many instances, this set up led to the subsidy system rewarding unsustainable farm practices (de Rugy, 2012). While policy makers and regulators encouraged farmers to use conservation practices to combat erosion issues (like those experienced during the Dust Bowl era), farmers were not formally required to use them in order to receive subsidies.

By including requirements that all farmers on highly erodible land file an erosion plan within ten years, The Food Security Act of 1985 marked a major transition - from farm 
bills focused on farmers' survival to farm bills mandating conservation. The events that catalyzed this transition, can actually be traced to an earlier farm bill, the Agriculture and Consumer Protection Act of 1973. The 1973 farm bill prompted the era of large farms and "fence row to fence row" planting practices and "get big or get out" policies encouraged by Nixon's Secretary of Agriculture Earl Butz (Lehrer, 2010). While the policies associated with these practices eased worries about potential food shortages at the time, intensive tillage associated with these operations caused numerous environmental concerns, with the major one being increased soil erosion (Hall 1998, Lehrer, 2010; Rigdon, 2011). Hence, in the 1970s and 1980s, recognition that soil erosion was outpacing soil production led to warnings that society could "run out of soil before oil” (Brown, 1981). Further, farmers and researchers began to report that substantial losses of soil were leading to the need for more and more expensive inputs to sustain high crop yields (Milham, 1994).

Many of the practices that followed the 1973 farm bill also ultimately led to the farm profitability crisis of the 1980s (Rigdon, 2011), which further propounded these issues. This time period was marked by declining farm commodity prices, increased farm loan interest rates, declines in land prices, and increased global competition and trade wars that made farm profitability increasingly difficult (Basran and Hay, 1988; Goodman and Redclift, 1991; Winson, 1992). As a result, many farmers were forced to seek out new techniques and technologies.

It is within this context that the search for a more sustainable, soil conserving form of agriculture began to take hold, and is best described as the result of several processes of neoliberalization discussed herein. While many forms of neoliberalization shape the 
biophysical environment (Bakker 2010; Castree, 2010; Harrison, 2008) the most pertinent to this study are based on those described by Noel Castree (2010): market-friendly reregulation; state rollback and deregulation; and creation of self-sufficient individuals and communities. These processes drove the need for newer technologies, greater quantities of agrochemicals, and decreased regulatory involvement that led to the eventual rise of no-till as the conservation method of choice.

Market-Friendly Reregulation: Why No-till Became the Conservation Method of Choice on the National Level

While the market has always been an influence and driver of economic policy related to farm bills, the late 1970s to early 1980s marked a widespread transition to neoliberal ideology and policy in the United States, which led to the aforementioned processes of neoliberalization (Hall, 1998; Harrison, 2008; Lehrer, 2010; Rigdon, 2011). By the 1980s, the public felt that support for farmers through subsidies seemed too close to socialism (Lehrer, 2010). Environmental concerns rose, and farmers' worries about losing soil made policymakers realize that farm bills would not pass without some form of conservation implemented (Rigdon, 2011). The variegated mixture of concerns resulted in the rise in neoliberal regulatory reform and ideology throughout the 1980s, where sustainable agriculture came to focus largely on developing market-based alternatives to conventional agriculture - to focus, in short, on "politics via markets" (Harrison, 2008; Lipschutz and Rowe, 2005). The odd combination of growing concern for the environment and embrace of neoliberal ideology resulted in the neoliberalization of many agricultural policies friendly to agrochemical companies. Castree (2010) refers to these as market-friendly reregulation practices, where 
the state in its various forms becomes 'market manager' or 'night watchman', and less of a 'provider' to the citizenry or special interests therein: it intervenes for the economy not, as it were, in it... to enable 'free' movements of money capital and also other less 'fluid' commodities (Castree, 2010, p. 1728).

In the case of agricultural policy, this reregulation ultimately had consequences for the environment. For example, soil conservation problems were known to be serious issues that were largely a result of the 1970 s era policies that encouraged intensive tillage and high yields. However, the conversation surrounding conservation measures that led to the 1985 farm bill asserted that, with good management and best management practices (BMPs), farmers could produce more productive soils with minimal adverse effect on the environment, while still using intensive farm practices. Hall (1998) and Higgins and Lockie (2002) have argued that by controlling and framing the discussion in this way, both industry and the government were able to assert that a major shift away from the intensive use of soil resources or the focus on high yields of a limited range of crops was not required. Rather, the focus stayed on providing high yields even though the conversation was actually supposed to be about conservation practices that preserved soil. This framing of the discussion was a huge benefit to agribusiness. The conversation seemingly discussed conservation practices that could help with erosion, and did address some of the problems caused by erosion (Langdale, Leonard, and Thomas, 1985), but it still allowed for continued exploitation of productive soils at the same basic rate, and with a continued reliance on chemical fertilizers (Hall, 1998).

By the early 1990s, it was clear that conservation requirements would likely be a permanent fixture of new farm bills. Agribusiness and state interests had clearly aligned. No-till agriculture was gaining popularity as a conservation method that would have high production yields while mitigating the soil erosion issues that were so prominent and at 
the forefront of environmental conversation efforts (Adkin, 1992; Buttell, 1993). As Marshall (2000) notes, agribusiness interests at the time maintained strong relationships with the USDA and became more involved in the 1996 farm bill than they had ever been previously. Congress and agribusiness interests aligned to champion farm policy that was driven by a liberalized trade agenda. Their goals were to increase efficiency and competitiveness, while maintaining a balanced federal budget that minimized the needs for social welfare programs (Sorenson, 1994).

An additional perk to agribusiness was that no-till often required higher inputs of chemicals to manage weeds that were becoming more prolific (Glenna, 1999). This boost in chemical usage would bolster sales of chemical inputs in agribusiness that had been in decline since the early 1980s (Osteen and Fernandez-Conejo, 2013; Robbins and Sharp, 2003). With advances in technology and new formulations of chemicals available, agribusiness enabled farmers to increase farm size acreage, which meant greater sales of chemical inputs to control weeds. These financial incentives appealed to farmers, as well, because no-till had the potential to provide production efficiencies through cost savings and greater concentration of land by large farm operators (Glenna, 1999; Lehrer, 2010). No-till was attractive to farmers because larger equipment and reliance on chemicals meant reductions in labor costs and more farm acreage; overall, farmers could become more "efficient" (Hall, 1998; Rigdon, 2011). In summary, no-till agriculture was so successfully championed as the conservation method of choice because it had ideologically aligned the interests of farmers, the state, and agribusiness. The state seemingly mitigated erosion issues through improved conservation programs; farmers 
benefited by becoming more productive, efficient, and profitable; and agribusiness saw an increase in sales of equipment and chemical inputs.

The alignment of state, agribusiness, and farm group interests via the market-friendly practices that drove farming regulations and policy paved the way for advances in technology that supported the transition to no-till in the late 1980s to 1990s. Figure 4.1 shows a timeline of key farm bills, economic, regulatory, and environmental trends that have influenced farm policies, along with the eventual technological innovations that contributed to the rise of no-till. Even though there have been events that could have steered farm policy away from no-till and towards less chemically intensive forms of conservation agriculture - the release of Rachel Carson's Silent Spring in 1962, the founding of the EPA in 1972, or the rising concern over chemicals and their effects on the environment in the 1980s (Hall, 1998) - these events were often countered by market forces that were bolstered by limits to regulatory authority. For example, the EPA was only a few years old before its budget plummeted throughout the late 1970s, a budget that has not recovered since (US OMB, 2006). The Toxic Substances Control Act (TSCA) was implemented in 1976 to regulate the introduction of new chemicals and some existing chemicals. However, it was largely limited in its authority from the outset because chemicals that were already released on the market (of which there were 60,000 released prior to 1976) were grandfathered into the act and deemed safe (EPA, 2017). As of 2015 , only 250 of the original 60,000 chemicals that were grandfathered in have been tested for safety, and since 1976, more than 80,000 new chemicals have been released (EPA, 2017). Many of these have been agrochemicals, which have become more potent in their chemical formulations over time (Harrison, 2008; USDA, 2017). Therefore, by 
the early to mid-1990s, much of the path had been paved for no-till technologies that would support sales of large agribusiness chemical inputs.

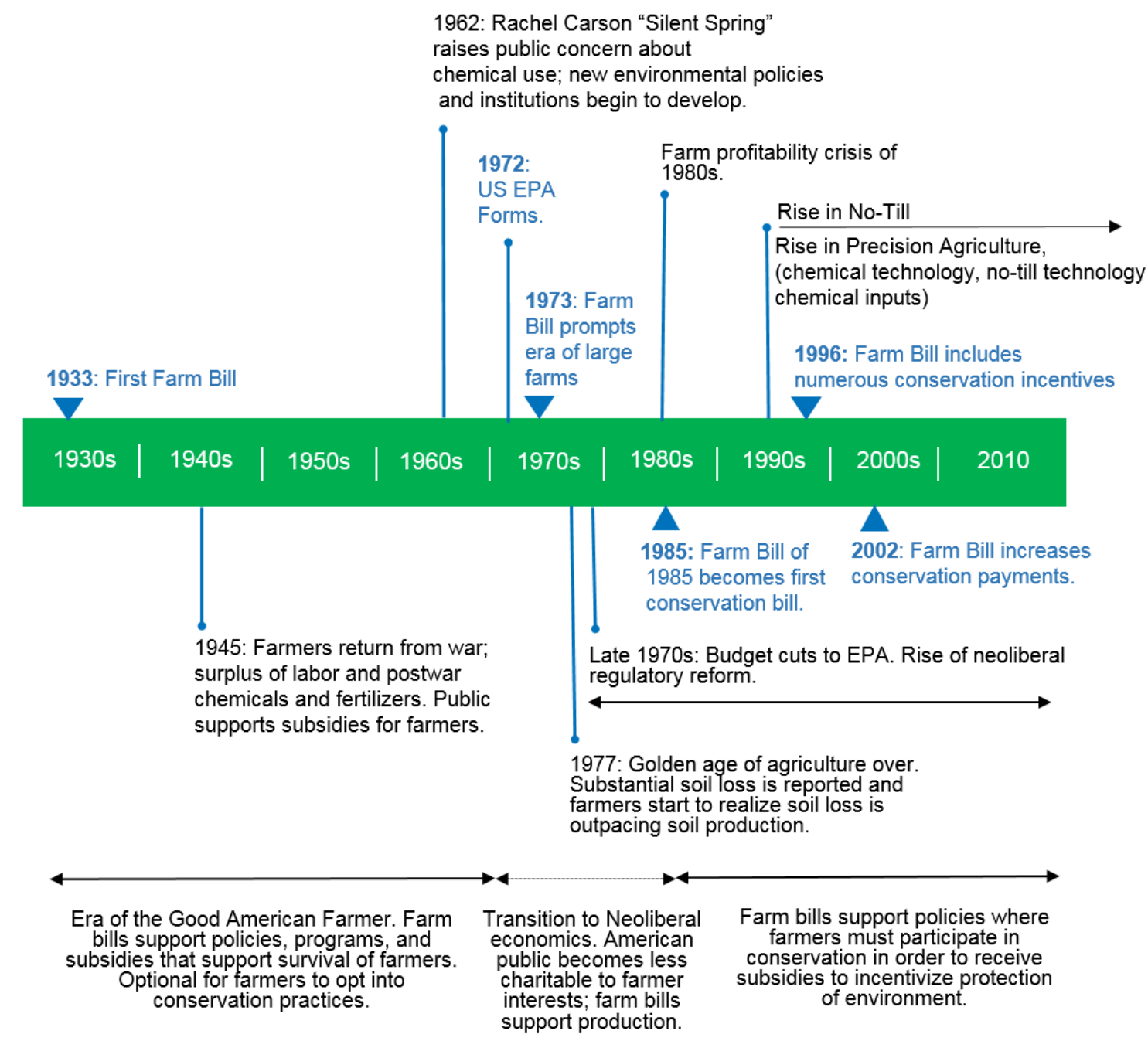

Figure 4.1 Economic, regulatory, and environmental trends that have influenced conservation farm bills.

The rise of precision agriculture was particularly important for the success of no-till agriculture during this time. Precision agriculture uses proximal and remote sensor surveys to delineate and monitor within-field variations in soil and crop attributes, guiding variable rate control of inputs, so that in-season management can be responsive (Hedley, 2014). Its rise during the 1980s was made largely possible by the emergence of 
affordable geographic positioning systems (GPS) technology, numerous affordable soil and crop sensors, and improved computer technologies and software that made precision application of various chemicals and sprays possible. Since precision agriculture came about, it has been praised for its increases to efficiencies for farming (e.g.Gonzalez-deSoto et al., 2016) and its potential to reduce chemical and fertilizer use overall for most farms (Hedley, 2014). However, given that rates of herbicide use have increased over the same time period as developments in precision agriculture (USDA, 2017), and increases in chemical potency have also occurred during that time, it is clear that it has not mitigated increased amounts of agrochemicals in the environment completely, and cannot solve the entire problem of increased chemical use on its own.

Hence, by the 1996 and 2002 farm bills, which allotted major payments to farmers who practiced conservation tillage, the technologies to make no-till successful were already available. Farmers across the U.S. were able to buy larger, expensive equipment in the name of conservation. Prior to these farm bills, farmers had not had access to, and would not have access to, this equipment without programs like the Environmental Quality Incentives Program (EQIP) and Conservation Security Program (CSP) funded by these farm bills. These programs provided farmers and ranchers with financial cost-share assistance and technical assistance to implement conservation practices on working agricultural land and allowed them to buy no-till equipment and technologies needed for chemical sprays.

Not surprisingly, the increases in conservation practices also coincided with the increase of glyphosate, commonly referred to as Roundup (Figure 4.2). Between 1995 and 2015, when farm bills increased payments for no-till and other conservation-related 
methods, glyphosate application in the U.S. increased from 28 million pounds to 300 million pounds (Benbrook, 2016; USDA, 2015). As genetically engineered and herbicide resistant crops gained market share from 1996 to 2000 - 1996 being the year of the Freedom to Farm bill, and 2000 when glyphosate lost its patent on the market glyphosate rates rose by 70 million pounds and accounted for $80 \%$ of national use (Benbrook, 2016). By 2010, over 90\% of farmers used glyphosate (Benbrook, 2016; NASS, 2017). Much of the increase in glyphosate is due to the rise of "Roundup Ready" crops that are resistant to glyphosate damage, but the increase in glyphosate is also due to the rise of conservation tillage practices, such as no-till (Service, 2007). 


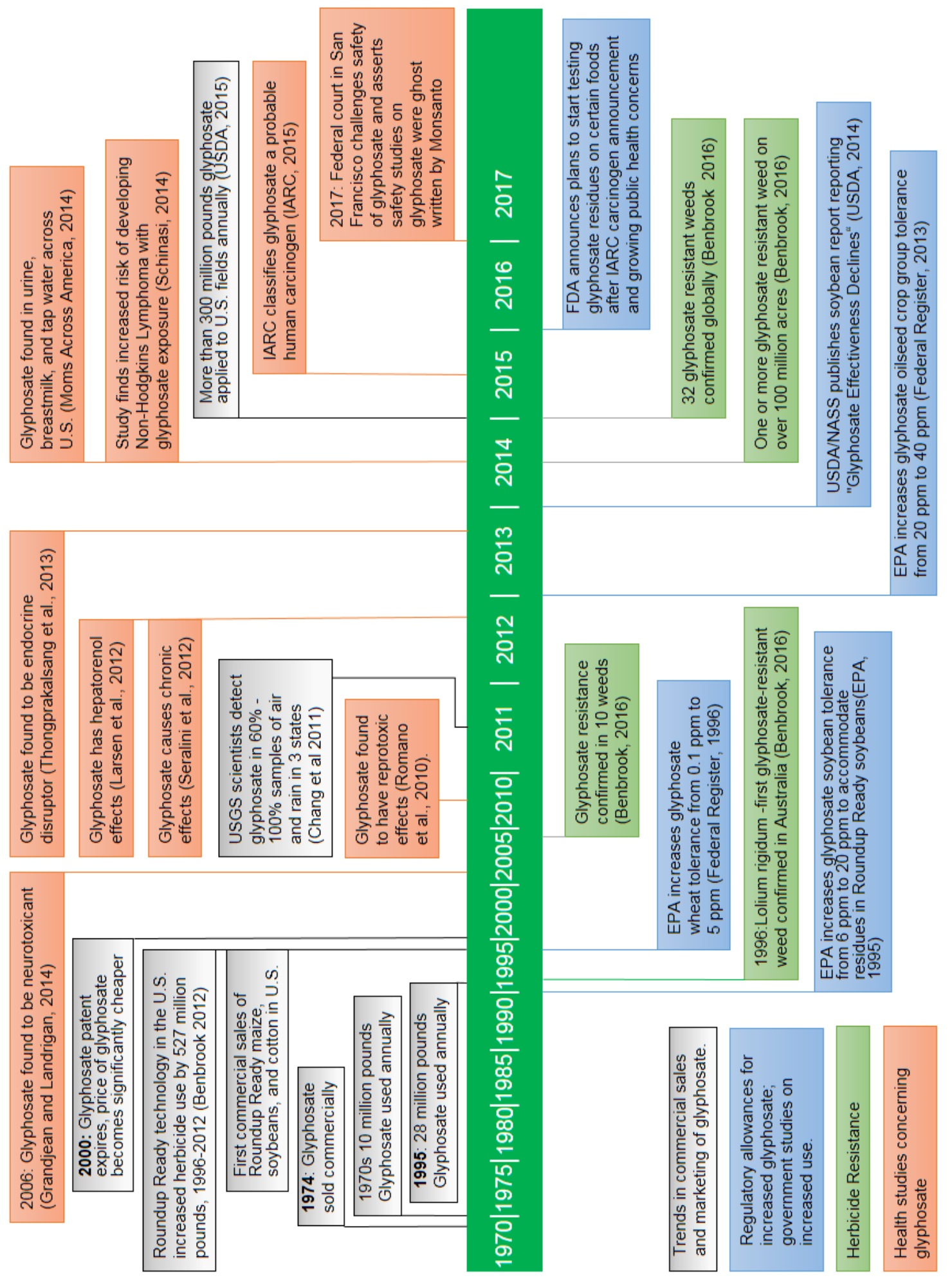

Figure 4.2, Herbicide resistance, trends in commercial sales, and regulatory trends influencing increased glyphosate use and human and environmental health concerns. Adapted from Benbrook (2016) and Mesnage et al. (2015). 
The timeline above draws from timelines by Benbrook (2016) and Mesnage et al. (2015) and highlights glyphosate trends in human and environmental health, herbicide resistance, and regulatory trends, with additions from other peer-reviewed sources and regulatory sources (Grandjean and Landrigan, 2014; Chang et al., 2011; USDA, 2014; USDA 2015; IARC, 2015) as well as public interest health groups like Moms Across America. The timeline shows that while regulatory allowances for glyphosate residue in various crops increased from the mid- to late-1990s forward, there was also an increase in the following: general glyphosate use, an increase in where glyphosate is found in the environment, increases in herbicide resistant weeds, and increases in human and ecological health concerns. For instance, in 1996, only one glyphosate resistant weed had been confirmed globally. By 2014, over 100 million acres were infested with glyphosate resistant weeds, and by the following year, 32 species of glyphosate had been identified worldwide (Benbrook, 2016). As time went on, and glyphosate lost its patent in 2000, the EPA made more exceptions to allow higher levels of glyphosate residue in food crops. More genetically altered Roundup Ready crops and crop technologies were developed that would support conservation tillage techniques (such as no-till) as well. During this time, glyphosate use increased approximately 15-fold from 1996 to 2015 (Benbrook, 2016).

Many of the farm bill trends that allowed for increases in payments to farmers for technologies coincided with these developments, and now glyphosate is detected in the majority of air, water, soil, and sediment in the U.S. (Battaglin, 2014; Chang et al, 2011); it is even found in our bodies (see Schinasi and Leon, 2014; Gandjean and Landrigan, 2014; Mesnage et al., 2015). The widespread presence of glyphosate is of growing 
concern. The International Agency for Research in Cancer (IARC), a division of the World Health Organization (WHO), has classified glyphosate as a probable carcinogen, and scholars have published a growing number of studies on endocrine disruption concerning glyphosate. In the timeline, it is also important to note that many of the human health studies have been reviewed as part of a larger group of several metaanalysis studies (e.g. Mesnage et al., 2015), and only represent a subset of a much larger number of cases where glyphosate has been found to have carcinogenic or endocrine disrupting effects.

\section{Market Friendly Reregulation in the Fifteenmile Watershed}

The story of how no-till came about in Wasco County parallels many of the larger national trends of the 1980s and 1990s, with technological advances and economic incentives for farmers and agribusiness often driving conversion to no-till more than environmental issues. In the late 1980s, when it became clear that participation in some form of conservation would be necessary to continue to receive subsidy payments, some farmers in neighboring Sherman County (directly east of Wasco County) decided to try no-till. Interviews with extension agents, several members of the SWCD, and various agency officials indicated that this attempt to switch to no-till was largely unsuccessful because the equipment necessary to do no-till was prohibitively expensive and not actually designed for the landscape in the area. Others noted that the chemicals needed for no-till were not yet available. Influenced by their neighbors in the adjacent county, a handful of farmers in Wasco County's Fifteenmile Watershed also tried to convert to notill at that time, but encountered the same issues as the farmers in Sherman County. With little success, farmers still participated in programs like Conservation Reserve Programs 
(CRP) that were associated with the 1985 farm bill, where environmentally sensitive land prone to erosion was taken out of production. In large part, however, most people continued to use various forms of conservation tillage that fell into reduced tillage categories. The problems associated with no-till farming in the 1980s came up often during interviews, as reflected in the quote below:

The problem is that it became apparent that after the fact that it really wasn't sustainable because the mechanical technology was sort of one-size-fits-all and didn't really fit the varying topographies at the time ... It was such a huge and heavy drill the no-till drill or yielder drill, you call it - it took so much horsepower. It didn't really fit the topography at all. The yielder drill was technology that was available but it really wasn't very adaptable to the very physical landscapes and the changes in the landscapes around. When you are on a hillside, with the yielder drill, it's like, "Oh my gosh!" you know, it's a little scary. You get to Wasco County and there's some really steep slopes. The other problem was that there wasn't the chemical technology to support it and I think that you probably get that problem from everybody. I mean things like Roundup - and you really need help to control the weeds. So we noticed a hugely massive problem for no-till early on and I think what probably one of the biggest, my take on it, one of the biggest reasons it didn't really take off very well. It got started, people thought it was a really great idea, it made sense economically, but there just wasn't any way to make it sustainable, and so things kind of died down, and in the process some of the bigger companies started looking at drills and Monsanto and others looking at weed controls, weed sprays. So it kind of sort of cooled down and then came back. In the process, people, like in Sherman County, really, they got burned. You might find some of the old equipment in the draws down there. (extension agent, personal interview)

Even though there were environmental concerns in the watershed, what actually provided much of the incentive and means for farmers to move to no-till was the number of grants that were available through the 1996 and 2002 farm bills. These grants, along with improvements in technology, made the equipment feasible for use in the county. During an interview, the former NRCS district conservationist related the effect that grant money had on farmers' accessibility to no-till equipment: 
There were concerns and a lot of people were wanting to try it but the costs were prohibitive if you tried to do it on your own, so there was a lot of interest on how can you help us do this, give us some financial help. With no-till, there was quite a lot of unproven chemical so there was a lot of train wrecks. Every time we tried no-till we would lose our yields ... later, we had 300-and-some applicants and we ended up funding 290. Close to 26 million dollars went into that project and that would include all tillage systems, it wasn't just no-till, but quite a bit went into no-till. (former NRCS district conservationist, personal interview)

Once the technology and money were available, the idea of switching to no-till was considered an actual possibility and farmers in the area took the opportunity to convert.

One no-till farmer reflects,

Then historically, you know, in the ' 80 's a lot of farmers went broke and the joke was you would go to one of those auction sales and there would be a no-till drill there and to a certain extent it was true. But it was a different no-till technology to what we have now. I mean, what really made no-till work is inexpensive Roundup. Really, in a nutshell, if you didn't have inexpensive Roundup, you couldn't afford to do it. (no-till farmer, personal interview)

A non-regulatory agency employee also described how the cost of no-till equipment created barriers to purchasing the equipment before grant money was available:

The big thing was investment of the equipment and that's what most of the money ended up going for. No-till drills are expensive and when you get one of those you have to have a bigger tractor, it was a real expensive proposition moving into that. (non-regulatory employee, personal interview)

Changes in technology led to bigger farms using very different equipment in the Fifteenmile Watershed. It also led to more chemical equipment and higher rates of chemical use. Just as it did nationally, the transition to no-till had an effect on labor and perceptions of herbicide use. Much of the ideology of improved efficiency and costsavings were expressed during interviews. One extension agent discussed how advances 
in technology changed farm practices in the watershed and drove farmers to increase their

acreage:

I just don't know. But right now those guys are struggling, and they're kind of looking back, which I hate to see. You've got to stay in business, you've got to cover costs. A combine cost half a million dollars now. So it's serious money for these guys and, that's the reason - when I started, the average farm size was 1,500 acres, now its 4,000 plus acres, for a family farm, a husband and wife and maybe one employee or one family member, a son or daughter that's helping them and that's what they run the place on. It's just like McDonald's. You have to get bigger and bigger to be sustainable. So when you look at this equipment, like at the Wasco county fair they had this - I've seen this before but - it's a self-propelled sprayer. That thing must be 50 or 60 feet long. You could not see it out of both sides of your eyes. It sort of feeds on itself. As the costs rise - what is the wheat price now? If you look over the decades, guys don't really make a lot of money, you know. So they got to produce more, so they need bigger equipment, so they need bigger farms. It's just like an arms race, you know. You got to keep getting bigger, so you need bigger equipment. Bigger acres, just less people. People cost so much money, so you can't afford it. It's like there's just no winning in this world. (extension agent, personal interview)

In another interview, the former NRCS district conservationist talked about how the

decline in Roundup's price, coupled with better no-till equipment, incentivized farmers'

conversions to no-till practices throughout the watershed.

I can't remember how much Roundup [used to] cost per gallon. So once it became more affordable and effective, the equipment became more specific for no-till and direct seed, better built, more reliable, but still expensive. More and more people started looking at it as an alternative practice, so with those cost share programs we really started seeing a huge change and people were adapting. And it was a little strange because it wasn't just the cost share. It was a lot of peer pressure, looking over the fence of the neighbors and seeing that they were doing it and it was successful. People weren't seeing huge declines in their yield, they were still able to raise good wheat, they were able to cover more acreage, they were more efficient, the labor cost went down and it was kind of a win-win for a lot of people. Some of the big growers here in Wasco County made the switch without any cost share. Then we saw the writing on the wall that we can save $15 \%$ on our overall inputs, it just made sense for us to do it, we didn't care if we got cost share on not. One man can cover a lot of acreage so unfortunately a lot of hired men lost their jobs. So if you are farming a thousand acres a year maybe it's not such a big deal but if you're farming 5,000 
acres per years you've got to be able to get over all that in a timely manner. So spraying is one important part to that. Controlling your weeds because that was one of the biggest hang-ups why no-till was not successful; it was not able to control the weeds. But with Roundup and other chemicals they were able to do a better job of controlling the weeds and to do it relatively quickly. They are applying it more often, the chemicals are probably more effective, they are not relying on tillage to control their weeds, they basically have to rely on chemicals to control their weeds. (former NRCS district conservationist, personal interview)

These interviews illuminate how market-friendly practices driven by agribusiness influenced the conversion to no-till in the Fifteenmile Watershed. However, the reader should also consider how the actual physical environment of the Fifteenmile Watershed contributed to the widespread conversion to no-till as well. Much of the conversion to notill was driven by market forces and incentives that were influenced by farm bill policy, but the conditions specific to the landscape (e.g., steep slopes and mass erosion events) also made it necessary for farmers to find a technology that had been proven to prevent erosion and stabilize the literal foundations of their economy. Even in the absence of notill, it is likely that farmers would have eventually tried different methods and technologies in order to mitigate some of the effects that unsustainable farming practices were having on the watershed. However, the timing of market-driven no-till technologies and their capacity to mitigate erosion concerns experienced by farmers in the watershed, which are more severe than in other places in the U.S, made no-till more of an obvious choice for farmers in the Fifteenmile Watershed. These specific concerns coupled with larger agri-environmental policies caused the watershed to participate in and experience many of the trends that affected agricultural communities across the U.S., as will be discussed shortly. 


\section{The Environmental Impacts of Market Friendly Reregulation}

The data collected for this study indicates that glyphosate is affecting the environment in multiple ways in the Fifteenmile Watershed. The most traceable effects are herbicide resistance in no-till fields, and glyphosate contamination of soil, sediment, and water at levels that have been found to impact human and ecological health throughout the watershed. During interviews, farmers - as well as almost every regulatory and nonregulatory agency employee working in the area - named a number of herbicide resistant weeds. Most interviewees noted that weed problems were worse at the beginning of the watershed's conversion to no-till than they are currently. Over time, some of the weed issues were mitigated as members of the community became more familiar with no-till practices and newer technologies became available. Chemical representatives were also brought in to advise users of no-till about chemical use, and additional money associated with farm bill grants helped to fight some of the weeds associated with herbicide resistance. The initial concerns about herbicide were widespread and considerable effort was put into fighting weeds. One extension agent explains,

Cheat grass and the goat grass and all this other stuff and the weeds became - the notill fields were just weeds - "Oh, there's wheat out there, right?" You couldn't see it for the weeds. Annual weeds have always been the bane for no-till, cheat grass, goat grass, the basic winter annuals, it's just been a huge problem, so that it's obvious we've got a number of different things. Now, so I think, once those came on board some of the new technologies - then some of the more progressive growers picked up on the technology, some of the younger fellows, as well, saw the potential for reducing cost and improving efficiencies. They picked up on it, to their huge credit. They supported themselves. So we actually would have meetings every other week and we'd bring in speakers and it was kind of a self-help kind of a thing and guys would share ideas, and were like, "Okay, we tried this and this didn't work." We'd get some of the chemical reps coming in, some of the local guys, and then just to try to talk out issues. Like, "Okay, here's a problem we're all facing." It really was supportive. Ironically, we're not doing that lately, but people get so busy. That lasted 
for a number of years. You have a really strong network of growers in Wasco County,C and part of that we owe to when all the agencies were working together, like us and NRCS and SWCD and FSA. NRCS and SWCD folks had grant money to offset some of the costs for the equipment and to try new things. We were doing a lot of work, still doing a lot of work on rotational crops and stuff, but there was money to be creative and look at new options ... They've got millions of dollars into the county that supported this change over and it took the edge off. (extension agent, personal interview)

However, meetings with herbicide representatives, technological advances, and chemicals did not resolve all weed problems. The majority of people interviewed indicated that they are still fighting herbicide resistant species, a number of which had not been present prior to their dedicated switch to no-till. Further, many of the interviewees noted that the herbicide resistance problems were often associated with increased glyphosate use: "Russian thistles and other broad leafs are becoming Roundup resistant, even the orchard is becoming like that, when they spray their trees with Roundup they run into mallow and different weeds that they can't kill with Roundup anymore" (former NRCS district conservationist, personal interview). Another farmer also discussed his struggles with herbicide resistant weeds and the chemical methods he used to manage the weeds:

Some of the ones that give me problems - I would say, Pigweed Lettuce, that's a big one. Russian thistle is another bad one. Some of those are worse because I can't use 2,4-D-like products and so I have to use a higher rate of glyphosate and it will cost me more money and it's expensive and plants are becoming resistant to it. (no-till farmer, personal interview)

Based on fieldwork and interviews with farmers and agency workers in the watershed, I was able to identify nine weeds in the Fifteenmile Watershed that have become herbicide resistant, all of which are listed in the International Survey of Herbicide Resistant Weeds (2017) for Oregon. Unfortunately, the majority of 
recommendations for mitigating herbicide resistance have been to either rotate the chemicals used, or to use more chemical to kill the herbicide resistant plant. Generally, this has led to increased use of glyphosate, as well as more applications of glyphosate, since it is one of the cheapest herbicides to use. A former NRCS district conservationist explains,

Trying to rotate chemicals is the best way to do it. The other good way to avoid herbicide resistance is to make sure that you use proper labeled rates, maximum rates, nothing worse than a wounded cheat grass. It will grow and survive and the problem with that is that it won't take in the next chemical application. It kind of hunkers down. It will grow and make seed, but it won't take another round of Roundup application. If you are going to kill it, kill it. It's like that saying, don't just shoot it, shoot it in the head. That happened earlier on with some of the guys who were inexperienced and with different grades of Roundup they were using. They would say, "I was able to get by with only six ounces." But if you kill $75 \%$ of your cheat grass but $25 \%$ survives, then it will get resistant to Roundup because it learns that "you dinged me with this chemical before so I'm going to produce a seed that is resistant to it" instead of killing everything that's out there. (former NRCS district conservationist, personal interview)

Beyond impacts to herbicide resistance, this study also found that glyphosate and/or AMPA is already found throughout the Fifteenmile Watershed at concentrations that have been found to have human and ecological health impacts (see Chapter 2). Glyphosate and/or AMPA was also detected in the majority of samples collected in all media (e.g. soil, sediment, water). Although the concentration values of glyphosate and its derivative product AMPA detected in this study for the Fifteenmile Watershed are far below the $700 \mu \mathrm{g} / \mathrm{L}$ or the $1.75 \mathrm{mg} / \mathrm{kg} /$ day chronic reference dose (cRfD) established by the EPA, agrochemicals have a long history of being regulated at standards which are far too high to be protective of either human or ecological health. Examples of chemicals that have had minimal (and not protective) regulatory standards in the past include the compound DDT, which is now a known carcinogen, and is known to be harmful to bird 
populations (Grandjean and Landrigan, 2014; Harrison, 2008); or atrazine, which has been shown to have a number of reproductive effects on amphibians (Boone et al., 2014; Fagin, 2012).

\section{State Rollback and Deregulation National Level and in the Fifteenmile Watershed}

The process of the "state roll back or deregulation," defined by Castree (2010) is

the withdrawal or diminution of government intervention in certain areas of social and environmental life in order to enable firms and consumers to exercise 'freedom of choice'; and the subsequent creation of new quasi-state or state-sanctioned actors to take on functions that states themselves could otherwise perform in theory or practice (Castree, 2010, p. 1728)

Peck and Tickell (2002) argue that through neoliberalization, the internal contradictions and glaring social externalities produced by 'roll-back' neoliberal deregulation have prompted the 'deepening' of the neoliberal project and associated policies, like those that govern agriculture. These translate to the "meaner and leaner" (Brenner and Theodore, 2002) policies that affect much of agri-environmental policy and which coerce market-based "voluntary" agreements between industry and civil society to develop. Lenihan and Brasier (2010) further expound upon this idea by arguing that much of U.S. agri-environmental policy is voluntary and incentive based because agricultural production and environmental quality are considered contradictory rather than complementary goals. Hence, a voluntary approach to agri-environmentalism is borne out of primary productive interests in the U.S. that are driven by a desire to minimize government regulation (Buttel, 2006). This approach translates to federal emphasis on reducing soil erosion and land retirement as opposed to dealing with the harmful effects of chemically intensive farming. The approach also helps perpetuate the hegemony of powerful agribusiness interests by promoting a corporate friendly version of sustainable 
agriculture that maintains farmer dependence on purchased inputs, while legitimizing the system in the eyes of primary producers and consumers (Lenihan and Brasier, 2010; Hall, 1998; Glenna, 1999).

Both voluntary compliance and state rollbacks and deregulation have contributed to sediment issues related to no-till practices and the increases in herbicide use in the Fifteenmile Watershed. Yet, this outcome seems counterintuitive given the number of agencies that work on issues related to soil erosion and water quality. Much of Wasco County and the Fifteenmile Watershed is managed by the Wasco Watershed Pesticide Stewardship Program (PSP) which is made up of the SWCD, Oregon State Extension Service, Columbia Gorge Fruit Growers, Department of Environmental Quality (DEQ), Oregon Department of Agriculture (ODA), The Dalles Watershed Council, Fifteenmile Creek Watershed Council, and US EPA (through grant funds). While some of these agencies have legal authority to implement best management practices concerning herbicide use and farming practices that would affect erosion and water quality, many of these agencies do not have formal enforcement power and act as "quasi-state" actors.

For example, for decades the ODA (an agency with enforcement power) has had a strategy for compliance with the federal Clean Water Act on farmland that was largely complaint-driven (Perkowski, 2014). However, complaint-driven enforcement in the area was only partially effective because some water quality problems were never reported. In 2012, ODA decided to "self-initiate" compliance with water quality rules, relying on publicly available information like aerial photographs and topographical maps to identify potential problem areas and notify the landowners. Because the agency did not have the resources to conduct in-depth monitoring of the entire state, this new approach was first 
tested in Wasco and Clackamas counties. As stated in the Oregon Agriculture Water Quality Report (ODA, 2012, p. 2) "By law, ODA has authority to adopt and implement regulations as part of the program. Compliance with the regulations is required, but farmers and ranchers may choose the strategies they use to comply". While ODA has touted this approach as successful (ODA, 2012), it still represents the diminution of government that often leads to negative environmental consequences as a result of larger neoliberal processes.

The rollback in government affects the Fifteenmile Watershed significantly because there is not enough government power to oversee how no-till is actually practiced. The rollback also limits the ability of agencies to enforce penalties when no-till is not practiced correctly, thereby leading to variable results in farm fields that are supposedly managed using the same conservation management system. Further, the ways that conservation programs are monitored, or rather unmonitored, lead to questions of whether or not they are being practiced in the ways intended. Interviews with NRCS, ODA, and farmers practicing no-till have indicated that the way a farmer practices no-till is highly variable from farmer to farmer. In an inquiry to a NRCS employee working in the county, I asked how the agency knows if no-till is being practiced correctly (e.g. how much disturbance there is or how much residue there is on a crop). In response, the NRCS employee stated that farm fields are not usually visually inspected to make sure that residue percentage requirements are met or that a minimum amount of disturbance has occurred, even though these are explicitly stated as requirements in the conservation programs in which the farmers enroll. Instead, farmers are often required to state what types of equipment they use, and the NRCS assumes that the farmer will meet the criteria 
for the practice of no-till. However, as stated by Williams and Wuest (2001), "the no-till drills disturb the soil to varying degrees" and significant variability from farm to farm and community to community exists using this conservation management technique, which has significant implications for how well soil and water quality are protected.

Several farmers that were interviewed indicated that when they received money for switching to no-till through EQIP or CSP programs, they were initially checked for compliance with no-till practices, which requires more than $30 \%$ residue coverage and somewhere in the range of 15 to $30 \%$ disturbance of a row in a crop (according to the current NRCS district conservationist). However, these checks were usually only performed at the time of the farmer's original conversion to no-till and infrequently during the time the farmer was in contract, which generally ranged between two to three years. Most farmers, as well as the NRCS district conservationist, noted that it was only equipment that was checked for compliance, not the actual fields. As one farmer said during an interview, "If that's part of your program - if that's what you signed up for [notill farming] - they will come and verify it, but a lot is like, just you have this model and drill, and you know what it does". In a different interview, a no-till farmer said, "When you got an EQIP contract they would check what the equipment is doing and what it's supposed to do". Finally, another farmer reiterated these comments, but also indicated that compliance checks became less frequent over time. He said, "Oh yeah, they monitored. When we were getting money, they did. Oh yeah, they were required to ... but not as much anymore since everybody switched over”.

Since compliance checks were only conducted at the beginning of (and periodically during) contracts, and because equipment was the primary focus of the compliance check, 
the amount of disturbance and the actual practice of no-till is, and was, highly varied across the watershed. Information such as how much disturbance occurred, the number of passes over fields, and other information that lends itself to describing how no-till was being practiced was often not recorded and is still not available from any agency when inquiries are made. The variation in techniques used for what everyone refers to as "notill" has even led to confusion as to whether farmers are even practicing no-till in much of the area. Definitions of what constitutes no-till farming varies from farmer to farmer. A regulatory agency official discusses just how confusing it is,

Everybody does it different, everybody has their own definition or range of definitions. I have talked to people - it's everything from what I would call high residue tillage, which is still definitely tillage, but they're calling it no-till because there's so much stuff that isn't raked up. It's not the pristine clean field. I have heard people that have called everything from high residue tillage to drilling with no-till and strip till and everything in between, and in a lot of cases, it really depends on the rotation because there are folks that have a rotation that is defined that allows them to drill to actually do no-till practice, and then there's other folks that maybe two or three out of the different plant types in the sequence of their rotation they can do true no-till and they might have to do a strip till, they might have to do a high residue tillage in order to make that rotation work for them, but I think that most of the folks see no-till as the opposite of conventional tillage. "If I'm not doing conventional tillage, I'm doing no-till." And I would say that there is conventional tillage and there's conservation tillage and the conservation tillage includes high residue tillage. It includes strip till and no-till. It has a range of different options, but I think there's a lot of time when they use no-till interchangeably with conservation tillage. (regulatory agency employee, personal interview)

The confusion about what farmers are practicing is widespread amongst agency workers and farmers in the watershed. That is to say, all farmers interviewed know how much disturbance they are causing from year to year, how much residue they are leaving on the ground for cover, and how their equipment works at an individual level. However, there is no collective sense of whether or not a farmer is practicing true no-till, meaning 
no metal disturbs the ground (according to the local NRCS district conservationist); direct seed, which is what most people refer to casually as no-till in the watershed, and disturbs between 15 to $30 \%$ of a row in a crop; or some other form of conservation tillage, which, by definition, must leave at least 30\% residue on the ground but often disturbs the soil more than direct seed (NRCS, 2006; WSU Extension, 2017). The local SWCD and NRCS assume that most people are practicing what falls into the direct seed category, and NRCS has based its current erosion estimates using the Revised Universal Soil Loss 2 (RUSLE2) model on the assumption that virtually the entire watershed is being managed with this conservation technique.

Although many agencies are involved, no single agency has the capacity to check that everyone in the watershed is actually practicing no-till as intended. Further, it took so much effort to get no-till implemented (with all of the educational events about how to practice no-till, grant money, and getting over cultural inertia to switch to no-till after initial failures with equipment), agency members are often hesitant to actually enforce or to ask about whether or not what is being practiced actually qualifies as no-till. This problem is partially reflective of a larger problem experienced throughout the U.S. with state rollback and deregulation; states have reported having insufficient funds, inadequate monitoring programs, and limited staff to collect and analyze such data (GAO, 2011). According to the U.S. government General Accountability Office (GAO), only six states have enough data to fully assess the condition of their waterbodies, while only 18 have enough data to place their waterbodies on the list of impaired waters (303d list). Therefore, even in cases where agencies involved in the Fifteenmile Watershed want to check practices that affect water quality, the resources available to do so are often not 
available. Hence, some improvement in land practice is looked at more favorably than no improvement at all. Managing agencies try to exude support for the efforts that the farmers have made thus far, even while knowing that eventually the way no-till is practiced will have to be changed. In one interview a regulatory employee explained,

I look at it and I think what they are doing is definitely better. I'm not going to go out and slap their hand and say, "Wait, that's not no-till," because it's better, and I want to encourage them to do stuff better, but we definitely need to have that conversation, we need to get where they are on that scale as opposed to just lumping it all into notill because otherwise the way that we review the outcomes and the results is all going to be muddied up. (regulatory agency employee, personal interview)

In another interview, a regulatory employee explained how minimal state resources limit an agency's ability to monitor actual no-till practices. These limited resources often force agency employees to rely on somewhat of an honor system where farmers are responsible for truthfully reporting their practices, as demonstrated in the quote below:

We are working with folks in the watershed and we say, "What are you doing?" if they come in and they say, "We are doing this." Sometimes I get, or someone else in my capacity gets, the opportunity to go out to their property and really see what they are doing, but most cases we have to take their word for it. We don't - I mean, I'm not covering what I'm supposed to be covering now. I don't have the capacity to do that. (regulatory agency employee, personal interview)

Yet another regulatory employee described how state resources occasionally allow for verification of conservation practices, but the employee also indicated that in most cases verification is not feasible. The employee explained,

So that's why we are taking their word for it too in the cases where we don't have a direct financial input. If they tell me that they are doing X Y Z then I write it down that they are doing X Y Z. In those cases where I heard otherwise where every now and again somebody will say, "Wait a minute, why do you have that? Because I have a map that says this practice is going here and that practice is going there." So they will look at that and we will be in conversation, and they will say they are doing strip till and I think they are doing high residue, so there has been a few cases where we have gone out and talked to somebody about it, but for the most part, no. (regulatory agency employee, personal interview) 
The extent to which farmers are practicing no-till as defined by direct seed requirements, as opposed to some other form of conservation tillage in the Fifteenmile Watershed is extremely important, because of the effect it can have on surface erosion in cultivated soils assumed to be minimally disturbed at present. In Chapter 3 of this dissertation, I used radioisotope sampling and spatial analysis to source where sediment in streams is coming from and found that approximately $49 \%$ of sediment in streams is directly sourced from cultivated fields. In addition, I found that $51 \%$ is sourced from actively eroding channel banks that are not included in any erosion model that is, or has been used, for the Fifteenmile Watershed. This finding was surprising given that every single person interviewed noted how much more improved the streams are than they were prior to the conversion to no-till. Further, most reports on the Fifteenmile Watershed (e.g. the Fifteenmile Creek Subbasin Summary (2000), the Fifteenmile Watershed Assessment (2003), and the Fifteenmile Creek Basin Aquatic Habitat Restoration (2010)) indicate that streams do not interact with eroding channel banks or floodplains. In conversations with a local regulatory employee, I was specifically told that "the stream no longer interacts with the floodplain anywhere in the basin" (regulatory agency employee, personal interview).

Yet, I would argue that this literature and the dominant agency narrative have caused managing agencies to overlook floodplain and channel bank sources that are still contributing to streams. This oversight is likely due to limited resources caused by state rollback and deregulation. Further, the disconnect between what is published in reports about the Fifteenmile Watershed's channel bank and floodplain interaction in streams and what is actually occurring is leaving managing agencies with a gap in the data for 
estimates of how much sediment is coming from these locations. Even prior to no-till, sediment erosion in many streams classified as confined (meaning streams did not interact with channel banks or floodplains) was taking place. For example, even though many channel banks had been confined by the 1960s by various Army Corps of Engineer projects and Oregon Bonneville Power Authority (BPA) projects, channel bank erosion often occurred in riparian areas that were not yet been placed in CREP corridors, where vegetation helps to prevent soil eroding into streams until the late 1990s and mid-2000s. In other locations classified as confined, cattle were still let into streams, and sediment was often eroded into those locations from heavy animal foot traffic. These examples demonstrate that land managers and agencies often overlook localized management practices that have likely contributed to continued sediment erosion issues over time. This oversight is even highlighted in the Independent Multidisciplinary Science Team (IMST) report on DEQ's Draft Development and Selection of Bedded Sediment Benchmarks in Oregon (2009), which states that

Landscape erodibility is complex and highly variable, incorporating a greater range of erodibility than is captured in the landscape classification proposed in the draft. Likewise, local in-stream sediment deposits are inherently variable because of local variability in land use, stream slope, historical sediment deposits, local soils, beaver activity, and large wood ... Some discussion of those issues would help the reader understand the observed variability in the indicators. (IMST, 2009, p. 2)

These oversights are reflective of scarce budget and labor resources that are the results of state rollback and deregulation in the watershed. With only partially available information, regulatory agencies like DEQ have tried to use limited resources that are spread thin over the state of Oregon to determine why sediment problems persist in the Fifteenmile Watershed. DEQ has found that sediment in streams is higher than it should 
be by using a variety of methods such as the Wolman Pebble Count, Relative Bed Stability (RBS), and macroinvertebrate habitat studies that measure sediment particle sizes in streams. These problems should have been resolved given that other nonregulatory and regulatory agencies alike have indicated that streams should have improved with conservation farm practices and money spent on stream protection.

In some ways, it is easy to see why increasing detections of, and use of, glyphosate in the watershed have not been addressed by any agency thus far. There is a great deal of confusion surrounding how no-till is actually practiced. Sediment issues related to unresolved erosion issues persist and limited government resources make oversight of herbicide use exceedingly difficult in the county. Various agencies working in the watershed have implemented BMPs that should mitigate erosion issues that should also minimize the amount of glyphosate reaching streams. However, continued focus on erosion issues without considering increased herbicide use has obscured what Harrison (2008) refers to as the harmful effects of the neoliberalized and inadequate pesticide regulatory complex. Here, state rollback and deregulation have complicated the social and ecological processes by which glyphosate increases in the environment.

When I spoke with employees of regulatory and non-regulatory agencies, most indicated that they knew glyphosate use was on the rise, but had limited knowledge of how extensive problems associated with glyphosate are and/or had limited capacity to deal with it. In confidential interviews, several agency employees noted that they would like to test for glyphosate more often, because they realized that it is of growing ecotoxicological and human health concern. However, they also noted that funding and labor resources only allow them to test for the most restricted chemicals at present, such 
as Malathion, which is used in large quantities by orchard growers in the watershed and is known to be extremely toxic. Further, glyphosate is a costly herbicide to analyze for in sediment. Glyphosate analysis often cost nearly $\$ 400$ per sample in comparison to other herbicides that are more frequently analyzed across the U.S. such as chlorinated herbicides, which cost closer to $\$ 100$ per sample to analyze. In fact, many of the samples in this study would not have been analyzed if USGS had not volunteered to analyze some of the samples for free at the water quality testing lab in Kansas. The pattern of having limited resources to analyze glyphosate is a national one, since glyphosate is difficult and costly to measure and assessment efforts in the US have been "limited primarily to regional, targeted, or short-term studies" (Stone et al., 2014).

Interviews with local regulatory officials revealed that employees often experience growing frustration when they try to determine how much herbicide use is occurring and how it is affecting environmental health as well. Here again state rollback and deregulation creates additional environmental concerns, as herbicide regulation has become severely restricted because of increasing restrictions on regulatory scientists' and the public's access to research materials (see PEER, 2006; Urstadt, 2004; NYT, 2006). In addition, neoliberal policy reforms have resulted in reductions to regulatory funding that control herbicide regulations. These reforms have served the agricultural industry's economic interests more than public health for decades (Baker, 1988; Lake and Disch, 1992; Nash, 2004).

Most interviewees indicated that resources to monitor or find out about herbicide use were often limited. One regulatory employee, for example, reflects, 
When I talk to folks about pesticide use, there's sort of a general conclusion that it has changed pretty dramatically in those areas that have a large conversion to conservation tillage, but again, how its changed- it depends on the producer and the crop rotation and what's going on- and then you take that kind of low resolution data - when they report their pesticide use - it's sort of like an annual mass. It's not, "I put this on this field on this day and that on that day and then I come back and put some more later." At the end of the year they say, "I used 600 tons" - or you know, whatever it is. It's really high resolution reporting, so you take that kind of reporting and then you have this other overlay that - during the drought there was land that was fallow - and so they doubled up the water on another little piece of land and planted something completely different than they are used to planting because they didn't have the water that they needed for what they're used to planting, and you take all of that complexity and you just can't figure that out. It's impossible to say, "Oh well, Farmer $\mathrm{X}$ is using more because of conservation tillage." It's impossible right now. We have had too many perturbations in what used to be a pretty even data stream. You just can't figure it out right now. (regulatory employee, personal interview)

In addition, certain laws are specific to certain agencies, so while NRCS, for example, may have access to herbicide use from farmers, another agency, like DEQ, which regulates the effect of the chemical in the environment does not. Similarly, agencies like ODA can legally restrict the use of a chemical when it suspects that it is causing an environmental harm, while DEQ cannot. Beyond this, Oregon is unique in some ways because waterways are managed according to their dedicated beneficial use, which does not always align with ecological and human health standards. For example, if a water body in Oregon is used for drinking water, but its beneficial use is not designated for drinking water, it cannot be regulated for it by any managing agency. Some of these constraints are reflected below.

We probably don't have enough resources to do that [monitor pesticide levels]. In terms of just ... yeah, providing the most intensive outreach possible, we involve them, all the core partners at the local level working on watershed projects, identifying what their different needs are so they can be defined by these grants. Some of those are more general outreach efforts. Some are more specific activities, like spray optimization equipment that helps the blasters and the berries get their sprays and breathe but ... if an area's not used for drinking water, then we don't have 
a standard that's applicable. So we go back to the benchmark and the benchmarks are totally non-regulatory. (regulatory employee, personal interview)

In summary, state rollbacks and deregulation have largely been responsible for limitations that have made it difficult for local agencies to address new concerns, such as increased glyphosate use, and to evaluate the impacts of BMPs associated with conservation practices that have been put into place to improve environmental conditions. While agencies in the Fifteenmile Watershed should have been monitoring continually improving stream conditions, instead they have been preoccupied with trying to figure out why conservation programs designed to improve sediment conditions have not worked thus far. As this has transpired, increased glyphosate use associated with these conservation practices has posed new threats to human and ecological health in the watershed. These unintended consequences have all been driven by larger state rollbacks that have been responsible for many of the shortcomings of the government programs associated with no-till farming and U.S. farm bills. These consequences have manifested in the environment in various forms, including: unidentified sediment sources, which have not been incorporated into erosion estimates for the watershed; persistent sedimentation issues; and vegetation affected by persistent herbicide.

\section{Self Sufficient Individuals and Community in the Fifteenmile Watershed}

Castree (2010) defines the creation of self-sufficient individuals and communities as

the cultivation of an ethic among persons and communities that emphasizes less, and ultimately limited, reliance on state-provided services for life's necessities. For neoliberals this ethic is almost a 'natural' good. It encapsulates the individual's right to maximum freedom and their responsibility for their own affairs (Castree, 2010, p. 1728).

Evidence of the neoliberal self-sufficient individual is strong in The Wasco County Rural Living Handbook (2009), which states "Every farmer, rancher, grower, 
homeowner, and hobbyist is asked to do his/her part to help solve water pollution problems" (SWCD, 2009, p. 22). The list of what the individual is responsible for is large including: identifying sources of bacteria and nutrient runoff, soil erosion from crop and pasture lands, and identifying those practicing improper fertilizer and pesticide use. Further, the handbook written by the SWCD "quasi-actor" puts responsibility on the individual to carry out appropriate management on the landscape without claiming any authority to do so. It states, "While SWCDs are not regulatory nor enforcement agencies, they are often called upon to offer assistance when a complaint is filed with ODA. It is totally up to the individual whether or not to accept the assistance offered" (SWCD, 2009, p. 22).

This manual, the aforementioned 2012 rollback of the ODA, loose regulatory enforcement of NRCS on contractual obligations, laws and guidelines that hinder access to useful information, and limitations in resources needed to successfully implement conservation programs offer pieces of evidence that the creation of the self-sufficient individual and community is an important part of the Fifteenmile Watershed. Although there are many agencies working together on conservation issues, as previously demonstrated, they have little authority to address some of the primary goals of the conservation management programs and techniques, based on all of the limitations and barriers discussed previously. This produces the outcomes of putting much of the onus of caring for the environment on the individual land owner in the county, while government oversight becomes almost informal. This is best described by Prudham (2004) as the result of "an example of a broad regulatory failure and the systematic production of environmental risks by neoliberal governance reforms". 
I would argue that out of this self-sufficient community, a dominant narrative has emerged that has been beneficial for conservation methods in some ways and harmful in others. Every person interviewed - from farmer, to extension agent, to agency employee - regards no-till highly in the watershed and continues to talk about the improvements, especially in regards to sediment in the streams. During interviews and meetings, most people provided vivid descriptions of how soil used to run off the hillslopes before no-till was widely practiced in the watershed. For example, one no-till farmer said "We used to get a high wall of sediment in the creek, it used to be brown. It looked like chocolate milk, but now it's clean for the most part" (no-till farmer, personal interview). Another farmer said,

They [my family] kind of experimented with it [no-till] a little bit, to start with. They had it [the equipment] all around custom-fitted for a few years before they bought the no-till drill. And then my dad always tells this story of when they were driving down the road one spring- and almost everybody at that point switched to no-till except for one neighbor- and there was a big rain storm and water was just rushing off of his hill sides and everyone else was just soaking it in. They made their full commitment then and bought a drill, even though they had been doing it for a few years already. (no-till farmer, personal interview)

Given that everyone that has worked in the watershed agrees that soil erosion is better and streams have a lot less sediment, it is likely true that no-till has benefited the watershed in many ways. Past photos of the watershed show major washout areas on land managed with conventional tillage and historic imagery shows rills and ephemeral gullies throughout the landscape that prove that things are not as they were when the majority of the watershed was managed with conventional tillage or other less effective conservation techniques. Moreover, all across the U.S., studies have shown that no-till has been successful at reducing soil erosion, improving water quality, improving soil quality, 
reducing fuel costs, as well as providing a whole other array of ecosystem benefits (Huggins and Reganold, 2008; Montgomery, 2007).

However, as mentioned in previous sections of this chapter, recent studies by DEQ have indicated that sediment conditions in streams have not improved and variability in how no-till is practiced appears to be widespread. In this research, I found that approximately $63 \%$ of farmers practice no-till as it is intended, which has greatly improved the amount of loose sediment available for transport to streams. Yet, uneven implementation of no-till throughout the rest of the watershed still likely contributes to elevated levels of sediment in streams. Therefore, even though streams no longer look like "chocolate milk" during large precipitation events, sediment is still being eroded into streams while farmers use various conservation practices that they loosely refer to as notill.

Further, now that much of the grant money to support no-till is gone and farmers receive limited oversight, farmers decide what version of no-till is best for them, even when that means they are not practicing true no-till. During interviews, most farmers indicated that participating in conservation programs designed to help the environment was becoming increasingly difficult because of cuts to farm bills. These cuts limit the amount of money available to their county because of all the conservation practices they had already participated in. This is an ironic outcome, given that Wasco County is known for not only having one of the highest conversions to no-till in the state, but also because Wasco County received some of the highest payouts of conservation payments from bills associated with the farm bill such as EQIP and CSP (EWG, 2017). Since farmers participated in so many conservation payments in the late 1990s and early 2000s when 
ample grant money was available, they have essentially disqualified themselves from receiving any more payments for conservation efforts.

With declines in payments for conservation practices in recent farm bills (e.g., after 2008), farmers often feel that they do not have the means to improve on their practices without government subsidies, even though they are tasked with protecting the environment. At this point in time, many of the farmers are ineligible to receive additional conservation payments because they are participating in practices, like no-till, that are considered to be proven to work. One regulatory employee explained, "The granting organizations are looking at it and saying 'Well everybody knows that works. It's not a pilot project anymore, that's not new and innovative technology and so we are not paying for that. They should know that works"' (regulatory agency employee, personal interview).

Another farmer described his frustration with the lack of grant money available from current farm bills when he said:

Yeah, the last farm bill [2014] sucked ... They have just been beating us like an old tired dog out here. We lost tons of money. Only two of us in the county got a CSP. They became like, "Well, if you make enough before, if you make what we deem enough, then it's fine," but they did it on a 5-year rolling Olympic average. We are not going to be making any money, yet we are not going to get any government payments either. (no-till farmer, personal interview)

These statements illuminate how neoliberal policies shaping farm bills force farmers into the role of the self-sufficient individual. On the one hand, farmers are tasked with making environmental decisions that are supposed to protect the environment, while on the other, they cannot enroll in new environmental practices because of limitations in funding for such endeavors. Further, many of the conservation practices they have been 
encouraged to participate in already (such as no-till) have resulted in several negative impacts to the environment because of failings on a policy and implementation level. Herein is the rub: even though there are many actors and policies that drive unintended environmental consequences before the farmer is even involved, much of the blame for negative soil and water quality impacts are ultimately blamed on the farmer. This dynamic complicates the relationship the farmer has with the environment. In some cases this dynamic even fosters a disregard for environmental interests (i.e. if the farmer is going to be blamed either way when conservation practices fail, he may as well choose the most profitable option, regardless of environmental impact). In this type of scenario, Leitner et al. (2007) describes the emergent neoliberal individual as one that "normalizes the logics of individualism and entrepeneuralism, equating individual freedom with selfinterested choices, making individuals responsible for their own well-being, and redefining citizens as consumers and clients" (Leitner, 2007, p.2). As mentioned previously, environmental interests are often seen as contradictory and not complementary in the U.S. Given these predicaments, farmers usually try to participate in the conservation efforts that they deem to be the least harmful to avoid regulation, but the most financially beneficial. Participation in conservation programs becomes more financially than environmentally driven. In one interview, a farmer discussed how his choice to enroll in no-till was influenced more by financial considerations than environmental:

I do see the impact of the environmental one and I think it was wise for us to change [to no-till], but it wasn't that environmental first. I don't think many farmers cared that the water would run off into the creek. Now we see it and realize that it wasn't good, but it has been going on for 50 plus years. (no-till farmer, personal interview) 
During another interview, a regulatory employee explained that most farmers are not as worried about environmental regulation as they are about maintaining their livelihood:

Every now and then people are talking about, "Well, what are you going to do with the TMDL or what are you going to do with this or that?" But that alone does not seem to be enough to push them towards making those other choices. They are essentially betting their income, their ability to make their house payments, to keep their kids in school, and it was a really serious investment for them to say "Well, some water quality agency is going to come in here and get on your case." That doesn't quite rise to the level of "I might lose my farm". (regulatory agency employee personal interview)

Yet, it would be incorrect to state that only monetary incentives are driving conservation efforts. During my time of research and in interviews, many of the farmers and agency employees intimated how important it was that better conservation practices were found for the survival of the community, both in terms of preserving soil for future agriculture and sustaining water in streams that are continually stressed by multiple users. Many also expressed their pride in how widespread the use of no-till is in the watershed. Along with these comments, frustrations were relayed and several people indicated that they had been disappointed that they had not been able to produce quantifiable results in the watershed that showed how much no-till had improved stream conditions and soil runoff. This frustration in the community appears to be building, as more reports on water quality and quantity issues come out in media reports, such as The Oregonian, and efforts to improve the watershed are not recognized. During an inquiry for maps of channel modifications, I had an unexpected conversation that turned into an interview with a regulatory agency member and local landowner. The interview was generally led by the individual, who wanted to express his thoughts on the impacts of environmental responsibilities falling on the individual farmers in the community. In this exchange, the 
individual expressed his concerns over the research I was conducting for this study (because he knew I also studied herbicides) and conveyed his thoughts on all the studies that have been done on the Fifteenmile Watershed. His comments reflect the frustration experienced by some people in the watershed who have tried to improve environmental quality and not felt adequately acknowledged for their efforts. He said,

I own a lot of land out here myself and we don't let cattle into the stream anymore. I've been working here for thirty years and we're still talking about the same things. Sediment impairments, temperature impairments, the same thing ... We're still dealing with that article that came out in The Oregonian ...The important thing is people are trying ... and like with this pesticide thing ... Why would I give you the pesticide data if you're just going to stab me in the back with it? I mean, all the farmers out here have all used better equipment, and some use precision agriculture and use a lot less spray. The farmers are trying and that's what matters. We're never going be pristine, but we can provide functional habitat. (regulatory employee and landowner in watershed, personal interview)

Here, I want to say that this type of negative exchange was not typical of my interactions with farmers and agency workers that live and work in the Fifteenmile Watershed. Since no-till is perceived to be very successful in the watershed, especially in regards to how much sediment has improved, most farmers and agency employees take pride in participating in conservation methods and were fairly open about sharing their information. I am indebted for the information they supplied for this study. However, the sentiments expressed during this interview do speak to the tensions that arise when conservation efforts that took so much effort to implement fail, and individuals are left with the environmental blame for improper stewardship.

The Oregonian article referenced above is entitled "Draining Oregon: A creek in crisis" (House, 2016) and was mentioned by several farmers during interviews and during watershed meetings that I attended in the past year. While the article is focused on water 
use issues surrounding conservation, and does not mention no-till specifically, it outlines many themes that I have found to be consistent with my own research (e.g., weak regulatory oversight, lack of resources to adequately monitor water conditions, and unacknowledged environmental problems).

The contents of the article are beyond the discussion of this chapter, but what I do want to mention here, and found most interesting about the article, is the response it generated in the Fifteenmile Watershed. This response elucidated the hardships that many farmers experience as they are held accountable for environmental issues that are, in some ways out of their control, and in other ways, largely determined by their own personal choices as the state puts increasing pressure on them to become self-sufficient individuals that make critically important environmental decisions. During interviews, it was clear that the article bothered many of the farmers, many of which related the numerous ways in which they engaged in conservation and had improved the watershed. Others criticized what they perceived to be the one-sided nature of the article, which did not include many farmers' perspectives. Many of the quotes that I received during interviews were of a similar nature, but one quote reflected the sentiments of what many farmers and agency members expressed during interviews and meetings particularly well:

There was a lady who called me not too long ago who works for The Oregonian and she asked for permission to take pictures. She had already taken pictures and was trespassing, and she just called to apologize and I said, "Go ahead and use the pictures." And then I found out about two weeks later that it was pretty much an antiagriculture video in The Oregonian and on the computer, and so I changed my mind and tried to press charges on her for trespassing. And the cop, he said I already gave her permission so I couldn't do anything about it. I was really upset, all the work like you and I are talking about right now, like the no-till, the CREP program, and all we are doing, and then she had videos and pictures of Fifteenmile and Eightmile creek and how bad we're doing. It just kicked us all the way down, I couldn't believe it, the Fish and Game are working at it, the NRCS, FSA, and us, and she pretty much said 
that all the work we have been doing has been for nothing. I was very frustrated. (notill farmer, personal interview)

Comments like these and others point to the ever widening gap between what conservation programs are intended to do, how they are actually borne out in the environment, and who to hold responsible for environmental failures when they arise. Although larger agri-environmental policies are developed by politicians and agribusiness working together, much of the blame for inadequate implementation of a conservation method and its environmental problems are placed on individual agencies at a local level as well as the farmers themselves. It is clear in conversations and interviews with people living and working in the watershed that they believe they have done as much as they can to make conservation programs work, and that they have no recourse when the failures of conservation practices are placed on them.

Regrettably, the success of no-till and the creation of the self-sufficient individual is in large part also responsible for the rise in glyphosate use; both because it is culturally more or less unacceptable to not participate in no-till and because most members of the community think glyphosate is not causing environmental harm. This belief often remains unchallenged in the watershed and, in some ways, is justified through the lack of regulatory limitations on how much glyphosate can be used. Further, there are minimal (if any) consequences to farmers when glyphosate is detected in environmental samples, and farmers find that glyphosate is the only economical way to participate in no-till. Beyond this, interviewees often related that the positive impacts and benefits of no-till were greater than the negative effects that glyphosate could have on the watershed. During meetings and conversations with various people in the community, I was often told about how safe Roundup was and how it did not have persistent effects in the 
environment. The following statements about Roundup's safety and rapid degradation in the environment were repeated to me by various individuals in the watershed:

Roundup is innocuous. They may have to use more herbicide, but so what? It's Roundup, you can drink the stuff. (former NRCS district conservationist, personal interview)

Well, Roundup is made to dissolve quickly so it won't stay around for long. (nonregulatory agency employee, communication during public meeting)

My understanding is that it sticks to the soils, so I doubt you'll find it in the water. (regulatory agency employee, personal interview)

You won't get Roundup out there. It degrades once it's in the sun or water. Plus, it shouldn't be getting into the streams anyway. We don't have that type of runoff anymore. (non-regulatory agency employee, personal interview)

Although some elements of what people have said to me during various conversations are reflective of glyphosate's actual properties, much of the responses are reflective of the way glyphosate is marketed by chemical representatives in the watershed. Industry advertising that "Roundup is tough on plants, but no more toxic to people and animals than table salt" (Monsanto Europe, December 1995) or "Roundup has been used commercially for more than 20 years ... in more than 100 countries", or "Glyphosate is rapidly broken down in soil by naturally occurring soil microorganism" (Monsanto Europe, undated but pre-1997) is quite clearly reflected in the above comments. While glyphosate is supposed to have a half-life of 47 days in soils and a half-life of 91 days in water (NPIC, 2015), a variety of soil conditions can affect the length of the half-life of glyphosate and its availability in soils (Haney et al., 2000; Simonsen et al., 2008; Wardle 
and Parkinson, 1990). Additionally, the length of time between applications of glyphosate in the Fifteenmile Watershed are usually short (every 3 to 4 months). By the time that glyphosate is even approaching its half-life rate, a new application of glyphosate is generally being sprayed, so it effectively never leaves the environment.

During interviews, one of the questions that I asked was whether farmers had received any instruction on how to manage herbicides in order to mitigate resistance and runoff to streams. Most regulatory and non-regulatory managing agencies had thorough responses on how to manage for herbicide resistance or runoff, but much of this information did not seem to be actively being communicated to farmers. When I asked farmers who helped them to make decisions on how to avoid herbicide resistance, most stated that they made the decisions on their own and without involvement from agencies such as SWCD, extension, or other regulatory or non-regulatory groups. One farmer noted that much of his research was done through online research, while others generally followed manufacturers' recommendations. Some farmers noted that the former NRCS district conservationist (who retired and became the main distributor of herbicide technology around the time that the majority of the county converted to no-till) was their main source of information. This individual would write chemical prescriptions for their fields.

Even if there were more concern in the watershed about the risks glyphosate poses, the responses during much of this research indicate that most farmers see no way of participating in no-till without it and its supporting chemical technologies. This is largely reflective of a national problem, whereby alternate technologies are not available to farmers to do conservation tillage. There has been much research to show that the 
development of non-toxic agrochemicals is needed (Eggen, 2004; Grandjean and Landrigan, 2014; Schug et al., 2013; Woodhouse, 2006), but the ability to force manufacturers of herbicides and consumers to use alternatives has been largely unsuccessful thus far. Some federal regulating agencies, like the EPA, have a Green Chemistry Program, but the chemicals in research have not been widely adopted by those involved in the agricultural industry or in conservation management programs (Nelson, 2004).

Research and development of non-toxic chemicals research has also been slow and has hampered the ability of state and federal agents to recommend alternatives to the more commonly and long established agrochemicals of the past (e.g. glyphosate, 2,4-D, and many other organochlorine pesticides). More generally, government officials in the European Union, Japan, and the United States alike have little concept of how green chemistry might be used to modify traditional approaches to environmental regulation, and the top levels at EPA are not very knowledgeable about forefront science (Woodhouse, 2006). Moreover, government regulatory procedures and laws are set up negatively to limit the damage of brown chemicals (as opposed to green, non-toxic chemicals) instead of positively and actively seeking the reconstruction of chemicals to be benign by design (Eggen, 2004; Schug et al., 2006; Woodhouse, 2006).

Here, I find Woodhouse's (2006) unthinkability argument particularly useful for explaining why self-sufficient, individual farmers in the Fifteenmile Watershed and across the U.S. persist in using a chemical that is gaining increasing public concern. Woodhouse argues that the technoscience industry has played a large part in manufacturing chemicals that are known to be harmful, and the chemists producing the 
chemicals have been key in the propagation of the idea that the widespread use of chemicals is safe. In doing so, producers of the wide variety of chemicals used in agriculture have inadvertently helped teach humanity (including future chemists) that unintended consequences are a normal part of technological innovation, part of what is termed the price of progress. Woodhouse further elaborates that this cycle is perpetuated as many people come to consider it unthinkable to "go back" to an earlier state of not using chemicals because chemical engineering was so successful at producing chemicals that were good at "combating pests" that it was unthinkable to require that chemicals be proven safe prior to introducing megatons into the ecosystem. As Woodhouse argues, creating the idea of "unthinkability" is the most subtle and most potent form of technoscientific power. When these technological advances go hand in hand with new advances in agricultural management systems, many of the negative consequences of both systems may be overlooked.

In the Fifteenmile Watershed, since the farmers mostly self-educate themselves by using manufacturers' labels and recommendations, and environmental consequences seem to occur whether they enroll in conservation programs or not, it appears that the creation of the self-sufficient individual perpetuates many of the elements of technoscientic power that generates the unthinkability of glyphosate not being safe to use in the environment. Further, with few alternative technologies, and numerous incentives to participate in conservation programs, most farmers are caught between deciding to participate in conservation programs with questionable environmental outcomes while receiving payments, or not participating in conservation programs and receiving no payment. This predicament is of a complex nature and will not be easily resolved until 
social policies driving environmental degradation are addressed at national and local levels.

\section{Conclusions}

This chapter has covered myriad physical and socio-political reasons of why and how no-till has impacted soil and water quality on a national and local level. However, what I want to highlight most is this: no-till agriculture did not have to be the conservation method of choice, but was ultimately the result of aligned agribusiness, policy makers, and farm group interests that arose out of a context of increasing environmental awareness in the midst of multiple processes of neoliberalization. These processes have, and continue to, affect a large percentage of the U.S. Estimates vary but approximately 89 million acres of U.S. farmland is managed with no-till, which translates to approximately $40 \%$ percent of land in the U.S. (USDA, 2015). While no-till has addressed many issues across the U.S., this study has shown how the implementation of no-till agriculture has also resulted in real physical impacts to the environment such as increased glyphosate in the environment, and social consequences, such as reduced labor opportunities on farms and divestment from environmental causes. No-till has also not reduced soil erosion to its full potential, due to failures in its implementation.

Further, as mounting peer-reviewed literature on the harmful effects of glyphosate is produced, land managers and agencies will need to critically evaluate how to practice notill without such large quantities of herbicide. Managers should also be prepared to offer alternative farming methods that would minimize reliance on glyphosate and other herbicides. The benefit of using no-till should not be solving one environmental problem while making another one worse. Regulatory issues that could aid in shaping farm bill 
polices need to be addressed as well. At present, many regulatory restrictions designed to protect communities actually exacerbate pesticide exposures by prompting growers to shift to less-persistent but more acutely toxic pesticides that pose a greater risk to workers and people living near the site of production (Wright, 2005); restricting information access to rates of herbicide use in communities; and incentivizing more chemical use than less. These issues will have to be addressed in order to mitigate the growing impact of glyphosate in no-tillage systems.

Presently, most regulators in the Fifteenmile Watershed are focused more on the ecological health of streams as opposed to human health risks in the watershed. This focus is not entirely negative. While studies on the effects of glyphosate are numerous, it usually takes years before chemicals that have been shown to cause some type of harm are regulated (Eggen 2004; Fagin, 2012), and it could take even more years before any regulatory action is taken that would ultimately matter for human health. In addition, since the community is so dependent on glyphosate to grow crops in no-till, it is unlikely that most farmers would equate exposure to glyphosate with any health concerns in the community. Although farmers are handling large amounts of glyphosate and are likely exposed to it in various ways, the current focus on improving streams and protecting sensitive species habitat may ultimately prove more useful for reducing the amount of glyphosate that is used through increased measures to protect habitat in the Fifteenmile Watershed. Many measures are already being considered as the watershed faces increased scrutiny for what are perceived as failed implementations of practices. 


\section{Chapter 5: General Conclusions}

As an original study design incorporating suites of natural and anthropogenic factors, this study revealed the importance of considering both the social and physical components of land management as they relate to conservation management programs and techniques. Since most of this dissertation has been focused on the shortcomings of ineffective conservation policies, especially as they relate to no-till, here, I do want to relate the potential I think there still is for using conservation programs and improving areas of the U.S. that face ongoing soil erosion issues, as well as elevated herbicide use. Much has been said about problems with voluntary compliance and the pitfalls of ineffective community implementation, but management can be effective and prevail over socioeconomic and institutional challenges, especially with strong community leadership, collaboration, and support. This is how no-till was even implemented in the first place in many locations, including the study area of this research. Although there were financial incentives involved, farmers and agencies did express genuine concern about how to improve the environment around them. In order for these changes to take place, though, there needs to be greater transparency and documentation about what farmers are actually doing on the landscape. Bringing about this transparency would require participation of actors at all levels of involvement in the watershed, from regulatory to non-regulatory employees, as well as the farmers themselves.

While there are risks in being transparent about practices to the individual, especially when these risks pertain to topics of a sensitive nature like mass erosion events and herbicide use, to not disclose the information ultimately hurts the community in the long term. To some degree, this has already occurred in the Fifteenmile Watershed as the 
persistent narrative that participation in no-till is higher than it really is has led to persistent stream sedimentation issues that could have been addressed if more were known about how much erosion was coming from different properties. With this knowledge, methods to address runoff areas could have been worked out in the community collaboratively, which is what many of the policies in the watershed aim to do, but ultimately fail in because of lack of transparency.

Even though top-down policy has affected the community through farm bills, there is still a great amount of power that can be exercised on the local level that can challenge the failings of aligned state and agribusiness interests, and being transparent about motivations would bring some of these conflicts of interest into light. Advocating for farm bill policies and environmental practices that are better than those that have been previously offered could be one step towards bringing about change in failed policies. Further, farmers and agency employees on local levels could highlight environmental conditions that are likely to get worse if they participate in one program over the other and thoughtfully consider what other management options might be best for their communities. While there would be no one solution to the various environmental issues caused by certain programs- as it has been reiterated throughout this dissertation that the specificity of place matters and the complexities to agri-environmental problems are many- this would at least be a starting point to engaging in voluntary practices that ultimately end in frustration and new regulations because of new environmental issues.

On this note, incentives seem to work better than regulation. What ultimately made no-till possible was not only the financial supports given, but the incentives to participate in education that has improved erosion issues in the watershed, even if the improvements 
have not achieved the results everyone hoped they would. Throughout this dissertation, I have endeavored to illuminate that multiple laws and regulations have been put into place to prevent what many might call government over-reach. Because of these institutional barriers, regulation has very little power to enact significant change that addresses widespread environmental problems. This is especially true of many regulatory policies operated on thin budgets that do not permit for proper oversight. Although regulation is definitely needed, it is not as much of a motivator as financial incentives or community educational benefits, which beyond providing financial stability for long term sustainable practices, also has the added benefit of fostering a sense of pride in conservation efforts when they are practiced broadly in the community.

Finally, I wish to address some practices that would improve no-till's implementation in many locations. Future no-till farming will need to employ more diverse pest and weed management strategies, including biological, physical and chemical measures to lessen the threat of pesticide resistance (Huggins and Reganold, 2008). Practices from successful organic farming systems may be instructive in that regard. One such technique, crop rotation - in which farmers grow a series of different crops in the same space in sequential seasons - is already helping no-till's war on pests and weeds by helping to break up the weed, pest and disease cycles that arise when one species is continuously grown (Huggins and Reganold, 2008). Other techniques for weed management include killing weeds when they are younger, which is easier than when weeds are fully grown; maintaining soil residue cover with an organic mulch or live crop to prevent weeds from sprouting up; avoiding the maturation and seedling of weeds in the first place by not allowing weed growth in the first place during the off season; and 
determining at which point weeds are actually hurting the crop. Even though many of these techniques have been practiced in various locations of the country, these are rarely expressed as an alternative option in the county of this research and are generally not as promoted nationally (Philpott, 2013).

In this dissertation, I sought to expand the narrow focus of human impacts and solutions to encompass more thorough explanation of the causation (both human and natural) to explain why no-till has not been as effective as it has the potential to be in both my study area and many locations throughout the U.S. I believe this research succeeded in these goals and makes a substantial contribution to the knowledge that could equip land managers with starting points and tools to assess the effectiveness of the conservation management plans they intend to participate in. The unified study of social and natural factors influencing no-till systems is essential to improving their effectiveness. The synthesis of regulations and incentives relating to farm bill policies from across the U.S. and comparisons of how different conservation methods have affected landscapes over time also greatly furthers the conversation on best management practices.

It is my hope that future studies will continue to explore and expound upon the social forces that drive physical changes in the landscape, and that these will result in policy changes that do not settle for improving one environmental condition while causing others. As key areas upon which to focus research, I recommend that future studies investigate communities that have successfully implemented no-till as it was designed to be practiced, and for there to be given critical attention to the social and natural community qualities that have likely resulted in its success. I also recommend 
implementing long-term monitoring as the most compelling means to assess how well conservation management techniques are performing. While this dissertation was able to contribute much to the literature in methodologies for retracing historical impacts on the landscape, having data physically available that already indicated that environmental issues were not resolved was of extreme benefit and corroborated many of the findings in this study. Further, long term monitoring gives context to how effectively practices work and helps land managers evaluate whether environmental conditions become better, worse, or stay the same.

Areas only briefly touched upon in this dissertation that require further investigation include other co-, or even competing explanations, for self-sufficiency. As much as policies and processes of neoliberalism have affected the Fifteenmile Watershed, there are also other cultural dynamics that cause people to interact with the environment in the way they do. Other alternatives to no-till agriculture or technologies that could improve it are also largely missing, even though they are available. This dissertation only comprises one component of various recommendations that could improve implementations of notill on both a local and national level, and I hope to continue in this research in the future. 


\section{References}

Adkin, L.E. 1992. "Counter-hegemony and environmental politics in Canada." In Organizing Dissent: Contemporary Social Movements in Theory and Practice. W.K. Carroll (ed.). Toronto: Garamond Press, pp. 247-63.

Armiliato, N., Ammar, D., Nezzi, L., Straliotto, M., Muller, Y.M., Nazari, E.M., 2014. Changes in ultrastructure and expression of steroidogenic factor-1 in ovaries of zebrafish Danio rerio exposed to glyphosate. J. Toxicol. Environ. Health A 77, 405e414.

Austin, A.P., Harris, G.E., and Lucey, W.P., 1991, "Impact of an organophosphate herbicide (glyphosate) on periphyton communities developed in experimental streams." Bulletin of Environmental Contamination and Toxicology, v. 47, 29-35.

Baker, B.P., 1988. Pest control in the public interest: crop protection in California. Journal of Environmental Law and Policy 8, 31-77.

Bakker, Karen, 2010. “The Limits of 'neoliberal Natures': Debating Green Neoliberalism.” Progress in Human Geography 34, no. 6: 715-35. doi:10.1177/0309132510376849.

Basran, G. and Hay, D., 1988. The Political Economy of Agriculture in Western Canada. Toronto: Garamond

Battaglin, William A., Karen C. Rice, Michael J. Focazio, Sue Salmons, and Robert X. Barry., 2009. "The Occurrence of Glyphosate, Atrazine, and Other Pesticides in Vernal Pools and Adjacent Streams in Washington, DC, Maryland, Iowa, and Wyoming, 2005-2006." Environmental Monitoring and Assessment 155, no. 1-4: 281-307. doi:10.1007/s10661-008-0435-y.

Battaglin, W.A., Meyer, M.t., Kuivila, K.M. and Dietze, J.E., 2014. "Glyphosate and Its Degradation Product AMPA Occur Frequently and Widely in U.S. Soils, Surface Water, Groundwater, and Precipitation." JAWRA Journal of the American Water Resources Association 50, no. 2: 275-90. doi:10.1111/jawr.12159.

Bellamy, P. Loveland, A., P. J., Bradley, R. I., Lark, R. M. and Kirk, G. J. D. 2005. "Carbon losses from all soils across England and Wales 1978-2003." Nature 437:245248.

Benbrook, C.M., 2012. "Impacts of Genetically Engineered Crops on Pesticide Use in the U.S. -- the First Sixteen Years." Environmental Sciences Europe 24, no. 1: 24. doi:10.1186/2190-4715-24-24.

Benbrook, C.M., 2016. "Trends in Glyphosate Herbicide Use in the United States and Globally." Environmental Sciences Europe 28, no. 1: 3. doi:10.1186/s12302-016-0070-0. 
Bergström, L., Börjesson, E. and Stenström, J., 2011. "Laboratory and Lysimeter Studies of Glyphosate and Aminomethylphosphonic Acid in a Sand and a Clay Soil.." Journal of Environmental Quality 40, no. 1: 98-108.

Blake, W.H., Ficken, K.J., Taylor, P. Russell, M.A. and Walling, D.E., 2012. "Tracing Crop-Specific Sediment Sources in Agricultural Catchments." Geomorphology 139-140: 322-29. doi:10.1016/j.geomorph.2011.10.036.

Boone, M. D., Bishop, C.A., Boswell, L.A., Brodman, R.D., Burger, J., Davidson, C., Gochfeld, M., et al., 2014. "Pesticide Regulation amid the Influence of Industry." BioScience. biu138. doi:10.1093/biosci/biu138.

Borggaard, O.K, and Gimsing, A.L., 2008. "Fate of Glyphosate in Soil and the Possibility of Leaching to Ground and Surface Waters: A Review." Pest Management Science 64, no. 4: 441-56. doi:10.1002/ps.1512.

Brenner, N., Theodore, N., 2002. Cities and the geographies of " actually existing neoliberalism. Antipode 34 (3), 349-379.

Brierley, G., Fryirs, K. and Jain, V., 2006. "Landscape Connectivity: The Geographic Basis of Geomorphic Applications.” Area 38, no. 2: 165-74. doi:10.1111/j.14754762.2006.00671.x.

Bridge, G., 2008. "Environmental economic geography: a sympathetic critique." Geoforum, 39(1): 76-81.

Brown A.G., Carey C., Erkens, G., Fuchs, M., Hoffman T., Macaire J.J., Moldenhauer, K.M., Walling, D., 2009. "From sedimentary records to sediment budgets: multiple approaches to catchment sediment flux." Geomorphology 108: 35-47.

Brown, L.R., 1981, World population growth, soil erosion, and food security: Science, v. 214, p. 995-1002, doi: 10.1126/science.7302578.

Buttel, F.H., 2006. Sustaining the unsustainable: agro-food systems and environment in the modern world. In: Cloke, P., Marsden, T., Mooney, P. (Eds.), Handbook of Rural Studies. Sage, London, pp. 213-229.

Buttel, F.H., 1993. "Socioeconomic impacts and social implications of reducing pesticide and agricultural chemical use in the United States." The Pesticide Question: Environment, Economics and Ethics. D. Pimenthal and H. Lehman (eds.). New York: Chapman and Hall, pp. 153-81.

Byers, H.G., Miller, J.T., Williams, K.T., Lakin, H.W., 1938. Selenium occurrence in certain soils in the United States III. U.S. Department of Agricultural Tech. Bull 60: 1-74. 
Castree, N., 2010. "Neoliberalism and the Biophysical Environment 1: What 'Neoliberalism' Is, and What Difference Nature Makes to It." Geography Compass 4, no. 12: 1725-33. doi:10.1111/j.1749-8198.2010.00405.x.

Canberra, 2000. Genie 2000. Basic Spectroscopy Software. http://www.canberra.com/products/radiochemistry_lab/pdf/G2K-BasicSpect-SSC40220.pdf

Carson, R., 1962. Silent Spring. Houghton Mifflin, Boston.

Chang F., Simcik, M.F., Capel, P.D. 2011. "Occurrence and fate of the herbicide glyphosate and its degradate aminomethylphosphonic acid in the atmosphere." Environ Toxicol Chem 30(3):548-555

Chiverrell R.C., Harvey, A.M., Hunter, S.Y., Millington, J., Richardson, N.J., 2008. "Late Holocene environmental change in the Howgill Fells, northwest England." Geomorphology 100: 41-69.

Church M., Slaymaker O., 1989. "Disequilibrium of Holocene sediment yield in glaciated British Columbia." Nature 337: 452-454.

Clark, J. 2003. Fifteenmile Watershed Council and Wasco County Soil and Water Conservation District http://www.wasco.oacd.org/15mile\%20Watershed\%20Assessment.pdf

Clifford, N. J. 2002. "The future of geography: When the whole is less than the sum of its parts." Geoforum 33: 431-436.

Coupe, R.H., Kalkhoff S.J., Capel P.D., Gregoire, C, 2012. "Fate and transport of glyphosate and aminomethylphosphonic acid in surface waters of agricultural basins." Pest Manag Sci. 2012;68(1):16-30. doi: 10.1002/ps.2212

Culpepper, A. S., 2006. "Glyphosate-Induced Weed Shifts.” Weed Technology 20, no. 2: 277-81. doi:10.1614/WT-04-155R.1.

DEQ, 2010. Cost Estimate to Restore Riparian Forest Buffers and Improve Stream Habitat in the Willamette Basin, Oregon. http://www.deq.state.or.us/wq/tmdls/docs/WillametteRipCost030310.pdf

De Roos, A.J., Blair, A., Rusiecki, J.A., Hoppin, J.A., Svec, M., Dosemeci, M., Sandler, D.P., and Alavanja, M.C., 2005. "Cancer Incidence among Glyphosate-Exposed Pesticide Applicators in the Agricultural Health Study." Environmental Health Perspectives 113, no. 1: 49-54. 
de Rugy. V., 2012. “The History of Farm Bill Spending.” George Mason University. Mercatus Center. George Mason University. http://mercatus.org/publication/updatedhistory-farm-bill-spending

Dosseto, A., Hesse, P., Maher, K., Fryirs, K., Turner S.P., 2010. "Climate and vegetation control on sediment dynamics during the last glacial cycle." Geology 38(5): 395-398.

Dragović, S., N. Mihailović, and B. Gajić., 2008. "Heavy Metals in Soils: Distribution, Relationship with Soil Characteristics and Radionuclides and Multivariate Assessment of Contamination Sources." Chemosphere 72, no. 3: 491-95. doi:10.1016/j.chemosphere.2008.02.063.

Dudal, C. 2004. "The Sixth Factor of Soil Formation." Paper Presented at the International Conference on Soil Classification 2004. Petrozavodsk, Russia, August 3-5, 2004. http://www.itc.nl/ rossiter/research/siuma/Dudal_6thfactor.pdf

Eggen, R.I. L., Behra, R. Burkhardt-Holm, P., Escher, B.I., and Schweigert, N., 2004 "Peer Reviewed: Challenges in Ecotoxicology." Environmental Science \& Technology 38, no. 3: 58A-64A. doi:10.1021/es040349c.

Engel-Di Mauro, S., 2014. "Ecology, Soils, and the Left: An Ecosocial Approach." New York, NY: Palgrave Macmillan, (http://archive.org/details/saed2014_Ecology-SoilsLeft241

EPA, 1993a. "Reregistration Eligibility Decision (RED): Glyphosate; EPA-738-R-93014"; U.S Environmental Protection Agency, Office of Prevention, Pesticides, and Toxic Substances, Office of Pesticide Programs, U.S. Government Printing Office: Washington, DC, 1993.

EPA, 1993b. Reregistration Eligibility Decision (RED) Facts http://www.epa.gov/oppsrrd1/reregistration/REDs/factsheets/0178fact.pdf

EPA, 1994. Eco Update. Field Studies for Ecological Risk Assessment. https://www.epa.gov/sites/production/files/2015-09/documents/v2no3.pdf

EPA, 2012. "What is a 303(d) list of impaired waters?" Overview of impaired waters and Total Maximum Daily Loads Program.

http://water.epa.gov/lawsregs/lawsguidance/cwa/tmdl/overview.cfm

EPA, 2015. "Impaired Waters and TMDLs in Region 10." Overviews and Factsheets. http://www.epa.gov/tmdl/impaired-waters-and-tmdls-region-10.

EPA, 2016. "Table of Regulated Drinking Water Contaminants." https://www.epa.gov/ground-water-and-drinking-water/table-regulated-drinking-water- 
contaminants\#one

EPA, 2017. Summary of the Toxic Substances Control Act. https://www.epa.gov/laws-regulations/summary-toxic-substances-control-act

Estrin, S. "Drones And Their Positive Impact On Precision Agriculture." Drone Universities, September 15, 2015. http://www.droneuniversities.com/drones/drones-andtheir-positive-impact-on-precision-agriculture/.

EWG, 2017a. https://conservation.ewg.org/whip_regions.php?fips=41000\&regionname=Oregon

EWG, 2017b. Subtotal, Farming Subsidies in Wasco County, Oregon, 1995-2014 https://farm.ewg.org/top_recips.php?fips $=41065 \&$ progcode $=$ totalfarm $\&$ page $=0$

Evans, M., Slaymaker, O. 2004. "Spatial and temporal variability of sediment delivery from alpine lake basins, Cathedral Provincial Park, southern British Columbia." Geomorphology 61: 209-224.

Fagin, D., 2012. “Toxicology: The Learning Curve.” Nature 490, no. 7421: 462-65. doi:10.1038/490462a.

Fernandez-Cornejo, J. and Hallahan, C. 2013. "Conservation Tillage, Herbicide Use, and Genetically Engineered Crops in the United States: The Case of Soybeans." January 6, 2013. http://www.agbioforum.org/v15n3/v15n3a01-fernandez-cornejo.htm.

Florsheim, J. L., Pellerin, B. A. Oh, N. H., Ohara, N.. Bachand, P. A. M, Bachand, S. M. Bergamaschi, B. A., Hernes, P. J and Kavvas. M. L., 2011. "From Deposition to Erosion: Spatial and Temporal Variability of Sediment Sources, Storage, and Transport in a Small Agricultural Watershed." Geomorphology 132, no. 3-4: 272-86. doi:10.1016/j.geomorph.2011.04.037.

Folmar, L.C., Sanders, H.O., Julin, A.M., 1979. "Toxicity of the herbicide glyphosate and several of its formulations to fish and aquatic invertebrates." Archives of Environmental Contamination and Toxicology, v 8, 269-278.

Fomsgaard, I.S., Spliid, N.H., and Felding, G., 2003. "Leaching of Pesticides through Normal-Tillage and Low-Tillage Soil--a Lysimeter Study. II. Glyphosate.” Journal of Environmental Science and Health. Part. B, Pesticides, Food Contaminants, and Agricultural Wastes 38, no. 1: 19-35. doi:10.1081/PFC-120016603.

Friedrich, T., and Kassam. A., 2012. "No-till Farming and the Environment: Do NoTill Systems Require More Chemicals?" Outlooks on Pest Management 23, no. 4: 15357. doi:10.1564/23aug02. 
Fryirs, K., and Brierley, G.J., 2001. "Variability in sediment delivery and storage along river courses in Bega catchment, NSW, Australia: implications for geomorphic river recovery." Geomorphology 38: 237-265.

Fryirs K., Brierley G.J., Preston N.J., Kasai, M., 2007. Buffers, barriers and blankets: the (dis)connectivity of catchment-scale sediment cascades. Catena 70: 49-67.

Fryirs, K., 2013. “(Dis)Connectivity in Catchment Sediment Cascades: A Fresh Look at the Sediment Delivery Problem." Earth Surface Processes and Landforms 38, no. 1: 30-46. doi:10.1002/esp.3242.

Fu, G., Chen, S., and McCool, D.K., 2006. Modeling the impacts of no-till practice on soil erosion and sediment yield with RUSLE, SEDD, and ArcView GIS. Soil and tillage research, 85(1), 38-49.

Galbraith, J. M. 2006. "ICOMAND: International Committee on Anthrosol Soils." Available from Virginia Polytech and State University, Blacksburg, VA, http://clic.cses.vt.edu/icomanth/.

Gale, F., 2013. U.S. Exports Surge as China Supports Agricultural Prices. http://www.ers.usda.gov/amber-waves/2013-october/us-exports-surge-as-china-supportsagricultural-prices.aspx\#.VIijCzHF_iM

GAO, 2011. Drinking Water: Unreliable State Data Limit EPA's Ability to Target Enforcement Priorities and Communicate Water Systems' Performance GAO-11-381: Published: June 17, 2011. Publicly Released: Jul 19, 2011.

Gerzabek, M. H., G. Haberhauer, and H. Kirchmann. 2001. "Soil organic matter pools and carbon-13 natural abundances in particle-size fractions of a long-term agricultural field experiment receiving organic amendments.” Soil Sci. Soc. Am. J. 65: $352-358$.

Giesy, J.P., Dobson, S. and Solomon, K., 2000. "Ecotoxicological Risk Assessment for Roundup_ Herbicide". Reviews of Environmental Contaminant Toxicology. no. 167:35-120.

Givens, W.A., Shaw, D.R., Johnson, W.G., Weller, S.C., Young, B.G, Wilson, R.G., Owen, M.D.K., and Jordan, D., 2009. "A Grower Survey of Herbicide Use Patterns in Glyphosate-Resistant Cropping Systems.” Weed Technology 23, no. 1 (2009): 156-61.

Glenna, L., 1999. Systemic constraints to ecological well-being: the case of the 1985 food security act. Rural Sociology 64 (1), 133-157.

Goodman, D. and Redclift, M., 1991. Refashioning Nature: Food, Ecology and Culture. New York: Routledge. 
Gonzalez-de-Soto, M., Emmi, L., Benavides, C., Garcia, I. and Gonzalez-de-Santos, P., 2016. "Reducing Air Pollution with Hybrid-Powered Robotic Tractors for Precision Agriculture." Biosystems Engineering 143: 79-94.

doi:10.1016/j.biosystemseng.2016.01.008.

Goudie, A. S. 1986. "The integration of human and physical geography." Transactions of the Institute of British Geographers 11(4): 454-458.

Grandjean, P., and Landrigan, P.J., 2014, "Neurobehavioural Effects of Developmental Toxicity." The Lancet. Neurology 13, no. 3: 330-38. doi:10.1016/S14744422(13)70278-3.

Griffith, J.A., 2002. "Geographic Techniques and Recent Applications of Remote Sensing to Landscape-Water Quality Studies.” Water, Air, and Soil Pollution 138, no. 14: 181-97. doi:10.1023/A:1015546915924.

Grunewald, K., Schmidt, W., Unger, C. and Hanschmann, G., 2001., "Behavior of Glyphosate and Aminomethylphosphonic Acid (AMPA) in Soils and Water of Reservoir Radeburg II Catchment (Saxony/Germany)." Journal of Plant Nutrition and Soil Science 164, no. 1: 65-70. doi:10.1002/1522-2624(200102)164:1<65::AID-JPLN65>3.0.CO;2-G.

Hager, A.G., and Nordby, 2008. "Herbicide Persistence and How to Test for Residues in Soils.” In Illinois Agricultural Pest Management Handbook, 279-86. University of Illinois at Urbana-Champagne, Cooperative Extension Service.

Hall, P., 1998. "Sustainable agriculture and conservation tillage: managing the contradictions." The Canadian Review of Sociology and Anthropology 35, 221-251.

Harrison, J., 2008. "Abandoned Bodies and Spaces of Sacrifice: Pesticide Drift Activism and the Contestation of Neoliberal Environmental Politics in California." Geoforum, Rethinking EconomyAgro-food activism in California and the politics of the possible. Culture, nature and landscape in the Australian region, 39, no. 3: 1197-1214. doi:10.1016/j.geoforum.2007.02.012.

Harrison, S., Massey, D., and Richards, K., 2006. "Complexity and emergence." Area, 38 (4), 465-471.

Harvey, A.M., 2002. "Effective timescales of coupling within fluvial systems." Geomorphology 44: 175-201.

Hedley, C., 2015. “The Role of Precision Agriculture for Improved Nutrient Management on Farms." Journal of the Science of Food and Agriculture 95, no. 1: 12-19. doi:10.1002/jsfa.6734. 
Hembree, K., and Shrestha, A., 2005. "Glyphosate-Resistant Horseweed In California." University of California, Davis.

Henry, W. B., Shaw, D.R. Reddy, K.R., Bruce, L.M., and Tamhankar, H.D, 2004. "Remote Sensing to Detect Herbicide Drift on Crops." Weed Technology 18, no. 2: 35868. doi:10.1614/WT-03-098.

Higgins, V., Lockie, S., 2002. Re-discovering the social: neoliberalism and hybrid practices of governing in rural natural resource management. Journal of Rural Studies $18,419-428$.

Hodge, E. T., 1932, Geological map of north central Oregon: Univ. Oregon Publ., Suppl. to Geology Series v. I, no. 5, 7 p., scale 1:250,000

Houben P., Wunderlich J., Schrott L., 2009. "Climate and long-term human impact on sediment fluxes in watershed systems. Geomorphology 108: 1-7.

House, K., 2016. Draining Oregon: A creek in crisis. http://www.oregonlive.com/environment/index.ssf/page/draining_oregon_day_3.html, Accessed September 2016.

Huggins, D.R., and Reganold, J.P., 2008. "No-Till: The Quiet Revolution.” Scientific American 299, no. 1 (July 2008): 70-77.

Hunt, E. R., Hively, W.D., Fujikawa, S.J., Linden, D.S., Daughtry, C.S.T, and McCarty, G.W., 2010. “Acquisition of NIR-Green-Blue Digital Photographs from Unmanned Aircraft for Crop Monitoring.” Remote Sensing 2, no. 1: 290-305. doi:10.3390/rs2010290.

Hunter, 1907. Farm Practice in the Columbia Basin Uplands. USDA Farmers' Bulletin 294.

https://naldc.nal.usda.gov/naldc/download.xhtml?id=ORC00000189\&content=PDF

IARC, 2015. "IARC Monographs Volume 112: evaluation of five organophosphate insecticides and herbicides" International Agency for Research on Cancer. World Health Organization. https://www.iarc.fr/en/mediacentre/iarcnews/pdf/MonographVolume112.pdf

International Survey of Herbicide Resistant Weeds in Oregon, 2017. http://www.weedscience.org/Details/USState.aspx?StateID=38. Accessed April 20, 2017.

Jessup, B. National Water Quality Initiative Technical Assistance for Fifteenmile Creek (Oregon): Comparison of Substrate Measures through 2016. Tetra Tech, Inc. Final Report. December 29. 
Keeney, D. 2010. “Monsanto's Round-Up Ready Crops Increasing Herbicide Use.” Think Forward. http://www.tcdailyplanet.net/blog/iatp/monsantos-roundup-ready-cropsincreasing-herbicide-use

Kremer, R.J., and Means, N.E., 2009. "Glyphosate and Glyphosate-Resistant Crop Interactions with Rhizosphere Microorganisms.” European Journal of Agronomy, Glyphosate Interactions with Physiology, Nutrition, and Diseases of Plants: Threat to Agricultural Sustainability? Mineral Nutrition and Disease Problems in Modern Agriculture: Threats to Sustainability?, 31, no. 3: 153-61. doi:10.1016/j.eja.2009.06.004.

Koger, C.H., Poston, D.H., Hayes, R.M. and Montgomery, R.F, 2004. "'GlyphosateResistant Horseweed (Conyza Canadensis) in Mississippi." Weed Technology 18, no. 3: 820-25.

Koiter, A.J., Owens, P.N., Petticrew, E.L., Labb, D.A., 2013. The behavioural characteristics of sediment properties and their implications for sediment fingerprinting as an approach for identifying sediment sources in river basins. Earth Sci. Rev. 125, 2442 .

Lake, R.W., Disch, L., 1992. Structural constraints and pluralist contradictions in hazardous waste regulation. Environment and Planning A 24, 663-681.

Lane S.N., Reid S.C., Tayefi, V., Yu,D., Hardy RJ., 2008. "Reconceptualising coarse sediment delivery problems in rivers as catchment-scale and diffuse." Geomorphology 98: 227-249.

Lane, S. N., 2001. "Constructive comments on D Massey - 'Space-time, “science" and the relationship between physical geography and human geography'." Transactions of the Institute of British Geographers 26(2): 243-256.

Lasier, P.J., Urich, M.L., Hassan, S.M., Jacobs, W.N., Bringolf, R.B., and Owens, K.M., 2016. "Changing Agricultural Practices: Potential Consequences to Aquatic Organisms.” Environmental Monitoring and Assessment 188, no. 12: 672. doi:10.1007/s10661-016-5691-7.

Langdale, G.W., Leonard, R.A., and Thomas, A.W. 1985. "Conservation practice effects on phosphorus losses from Southern Piedmont watersheds." Journal of Soil and Water Conservation, Vol. 40, no. 1: 157-61.

Lauer, J.W., and Parker, G., 2008. Net local removal of floodplain sediment by river meander migration. Geomorphology 96:123-49.

Lave, R., Wilson, M.W., Barron, E., Biermann, C., Carey, M., Doyle, M. Duvall, C., Johnson, L., Lane, M., Lorimer, J., McClintock, N., Munroe, D., Pain, R., Proctor, J., Rhoads, B., Robertson, M.M., Rossi, J., Sayre, N.F, Simon, G., Tadaki, M., Van Dyke, 
C., 2013. "Intervention: Critical Physical Geography." The Canadian Geographer 58: 110.

Lave, R. 2014. "Engaging within the Academy: A Call for Critical Physical Geography." ACME: An International E-Journal for Critical Geographies 13, no. 4: 508-15.

Lehrer, N. 2010. U.S. Farm Bills and Policy Reforms: Ideological Conflicts over World Trade, Renewable Energy, and Sustainable Agriculture in Politics, Institutions, and Public Policy.

Leitner, H., Sheppard, E.S., Sziarto, K., Maringanti, A., 2007b. Contesting urban futures: decentering neoliberalism. In: Leitner, H., Peck, J., Sheppard, E.S. (Eds.), Contesting Neoliberalism: Urban Frontiers. Guilford, New York.

Lenihan, M.H., and Brasier, K.J., 2010. "Ecological Modernization and the US Farm Bill: The Case of the Conservation Security Program." Journal of Rural Studies 26, no. 3: 219-27. doi:10.1016/j.jrurstud.2009.12.004.

Li, S., Lobb, D.A., Lindstrom, M.J., and Farenhorst, A., 2007. "Tillage and Water Erosion on Different Landscapes in the Northern North American Great Plains Evaluated Using 137Cs Technique and Soil Erosion Models." CATENA 70, no. 3: 493-505. doi:10.1016/j.catena.2006.12.003.

Majewski, M.S,, Coupe R.H., Foreman W.T., Capel P.D., 2014. "Pesticides in Mississippi air and rain: a comparison between 1995 and 2007." Environ Toxicol Chem. 2014;33(6):1283-1293. doi: 10.1002/etc.2550.

Marshall, L. 2000. "Bad for Business": Contextual Analysis, Race Discrimination, and Fast Food, 34 J. MARSHALL L. REV. 207, 227.

McClintock, N., 2015. "A Critical Physical Geography of Urban Soil Contamination.” Geoforum 65: 69-85. doi:10.1016/j.geoforum.2015.07.010.

McCool, D.K., Papendick, R.I., and Hammel, J.E., 1995. Surface residue management. Pages 10-16 in R.I. Papendick and W.C. Moldenhauer (eds.). Crop Residue Management to Reduce Erosion and Improve Soil Quality. USDA-Agricultural Research Service, Conservation Report Number 40.

McCool, O.K., K.E. Saxron. and P.K. Kaliu, 2006 Winter Runoff and Erosion on northwestern USA cropland, Paper No. 062190. 1112006 Annual International Meeting American Society of Agricultural and Biological Engineers. Portland, Oregon, USA, 9-12 July.

McGregor A.C., 1982. Counting Sheep: From Open Range to Agribusiness on the 
Columbia Plateau. Seattle, WA: University of Washington Press

Mesnage, R., Defarge, N., Spiroux de Vendômois, J., and Séralini, G. E., 2015. "Potential Toxic Effects of Glyphosate and Its Commercial Formulations below Regulatory Limits." Food and Chemical Toxicology 84: 133-53. doi:10.1016/j.fct.2015.08.012.

Mesnage R, Bernay B, Seralini GE., 2013. "Ethoxylated adjuvants of glyphosatebased herbicides are active principles of human cell toxicity. Toxicology." 313(2-3):1228 .

Montgomery, D.R., 2007. “Is Agriculture Eroding Civilization's Foundation?” GSA Today 17, no. 10: 4-9. doi:10.1130/GSAT01710A.1.

Motha, J.A., Wallbrink, P.J., Hairsine, P.B., Grayson, R.B., 2002. Tracer properties of eroded sediment and source material. Hydrol. Process. 16, 1983-2000.

Myers, J.P., Antoniou, M.N., Blumberg, B., Carroll, L., Colborn, T., Everett, L.G., Hansen, M., Landrigan, P., Lanphear, B.P., Mesnage, R., Vandenburg, L.N., vom Saal, F.S., Welshons, W.V., Benbrook, C., 2016. "Concerns over Use of Glyphosate-Based Herbicides and Risks Associated with Exposures: A Consensus Statement." Environmental Health 15: 19. doi:10.1186/s12940-016-0117-0.

Nagle, G. N. and Ritchie, J. C., 2003. "Wheat Field Erosion Rates and Channel Bottom Sediment Sources in an Intensively Cropped Northeastern Oregon Drainage Basin.” Land Degradation \& Development 15 (1): 15-26. doi:10.1002/ldr.587.

NASA, 2017. "Landsat Satellite Missions". https://landsat.usgs.gov/landsat-dataaccess. Accessed January 5, 2017.

Nash, L., 2004. The fruits of ill-health: pesticides and workers' bodies in post-World War II California. Osiris 19, 203-219.

Nelson, William M., 2004. "Green Chemistry and the Path to Sustainable Agriculture." In Agricultural Applications in Green Chemistry, 887:7-21. ACS Symposium Series 887. American Chemical Society. http://dx.doi.org/10.1021/bk-20040887.ch002.

Nelson, L., 2000. Fifteenmile Creek Subbasin Summary (including Oregon (including Oregon Tributaries between Hood River and The Dalles Dam).

http://docs.streamnetlibrary.org/Subbasin_Plans/Columbia_Gorge/Fifteenmilesumm2000 .pdf

NPIC, 2008. Glyphosate Technical Fact Sheet. Oregon State University, National Pesticide Information Center, Corvallis, Oregon, 14 pp. 
NPIC, 2015. Glyphosate technical Fact Sheet.

http://npic.orst.edu/factsheets/archive/glyphotech.html\#toxbox. Accessed July 3, 2017.

NRCS, 1982. Soil Survey of Wasco County Oregon, Northern Part. http://www.nrcs.usda.gov/Internet/FSE_MANUSCRIPTS/oregon/OR673/0/or673_text.p df

NRCS, 2000. Technical Notes: Soil Disturbance in No-Till and Direct Seed Planting Systems. Agronomy Technical Note No. 39. http://www.nrcs.usda.gov/Internet/FSE_DOCUMENTS/nrcs142p2_042675.pdf

NRCS, 2006. Tillage Practice Guide. A Guide to USDA-NRCS Practice Standards 329 No Till/Strip Till/Direct Seed and 345 Mulch Till. Practice Standard 329NoTill/Strip Till/Direct Seed. U.S. Department of Agriculture Natural Resources Conservation Service (August 2006).

NRCS, 2015a. "EQUIP Yourself with these conservation facts." http://www.nrcs.usda.gov/wps/portal/nrcs/detail/national/newsroom/features/?cid=stelprd b1241401

NRCS, 2015b. Erosion Conservation Analysis. Lower Deschutes Agricultural Water Quality Plan Assessment. Presentation October 2015.

NRCS, 2016. "Seeing Is Believing: How No-till Farming Transformed the Landscape | NRCS Oregon.” Accessed January 23, 2017.

https://www.nrcs.usda.gov/wps/portal/nrcs/detail/or/newsroom/stories/?cid=nrcseprd130 3806.

New York Times (NYT), 2006. Editorial: Muzzling those pesky scientists. December 11.

ODA, 2017. Pesticide Drift.

https://www.oregon.gov/ODA/programs/Pesticides/RegulatoryIssues/Pages/PesticideDrif t.aspx. Accessed May 1, 2017.

ODA, 2014. Oregon Agriculture: Facts and Figures.

http://www.nass.usda.gov/Statistics_by_State/Oregon/Publications/facts_and_figures/fact s_and_figures.pdf

ODA, 2012. Oregon Agriculture Water Quality Report. https://www.oregon.gov/ODA/shared/Documents/Publications/NaturalResources/ORAg WaterQualityReport.pdf

Osteen, C.D., and Fernandez-Cornejo, J, 2013. "Economic and Policy Issues of U.S. 
Agricultural Pesticide Use Trends." Pest Management Science 69, no. 9: 1001-25. doi:10.1002/ps.3529.

Peck, J., Tickell, A., 2002. Neoliberalizing Space. Antipode 34 (3), 380-404.

Peart, M.R. and Walling, D.E., 1988. "Techniques for establishing suspended sediment sources in two drainage basins in Devon, U.K.: a comparative assessment." Sediment Budgets (ed. M.P. Bordas and D.E. Walling) (Proc. Porto Alegre Symp., December. 41-55 IAHA Publ. no 159

Public Employees for Environmental Responsibility (PEER), 2006. http://www.peer.org/news/news_id.php?row_id=786.

Perkowski, M., 2014. "Farm regulators increase scrutiny of water quality." http://www.capitalpress.com/Water/20141222/farm-regulators-increase-scrutiny-ofwater-quality. Accessed May 12, 2016.

Philpott, T., 2013. "One Weird Trick to Fix Farms Forever." Mother Jones.. http://www.motherjones.com/environment/2013/09/cover-crops-no-till-david-brandtfarms. Accessed May 12, 2016

Polyakov, V. O., Nearing, M. A. and Shipitalo, M. J., 2004. "Tracking Sediment Redistribution in a Small Watershed: Implications for Agro-Landscape Evolution." Earth Surface Processes and Landforms 29, no. 10: 1275-91. doi:10.1002/esp.1094.

Porter, W., 2010. "Literature Review on biological effects of Roundup herbicide and evaluation of materials safety data sheet and use instructions for Aquamaster." Department of Zoology, University of Wisconsin, Madison.

Powles, S.B, 2008. "Evolved Glyphosate-Resistant Weeds around the World: Lessons to Be Learnt." Pest Management Science 64, no. 4: 360-65. doi:10.1002/ps.1525.

PRISM, 2017. Climate Group, Oregon State University, http://prism.oregonstate.edu, created 4 Feb 2004. Accessed January 3, 2017.

Prudham, S, 2004. "Poisoning the Well: Neoliberalism and the Contamination of Municipal Water in Walkerton, Ontario." Geoforum, Themed issue on "Neoliberal nature and the nature of neoliberalism," 35, no. 3: 343-59. doi:10.1016/j.geoforum.2003.08.010.

Quindós, L. S., Sainz, C., Fuente, I., Nicolás, J., Quindós, L., and Arteche, J., 2006. "Correction by Self-Attenuation in Gamma-Ray Spectrometry for Environmental Samples." Journal of Radioanalytical and Nuclear Chemistry 270, no. 2: 339-43. doi:10.1007/s10967-006-0354-8.

Reid S.C., Lane S.N., Berney J.M., Holden J., 2007. "The timing and magnitude of 
coarse sediment transport events within an upland, temperate gravel-bed river." Geomorphology 83: 152-182

Relyea, R.A., 2005. "The Lethal Impact of Roundup on Aquatic and Terrestrial Amphibians." Ecological Applications 15, no. 4: 1118-24. doi:10.1890/04-1291.

Rhoads, B.L., 1999. "Beyond Pragmatism: The Value of Philosophical Discourse for Physical Geography." Annals of the Association of American Geographers 89, no. 4: 760-71. doi:10.1111/0004-5608.00176.

Richter, D., 2007. 'Humanity's transformation of Earth's soil: Pedology's new frontier." Soil science. 172 (12):957-967.

Richter, D. and Markewitz, D., 2001. "Understanding soil change: soil sustainability over millennia, centuries and decades." Cambridge: Cambridge University Press.

Rigdon, K.C., 2011. "Stop the Planting! The 1985 Farm Bill, Conservation Compliance, and America's Agricultural Conservation Failure.” Drake Journal of Agricultural Law 16, no. 3: 487-507.

Robbins, P., and Sharp, J.T., 2003. "Producing and Consuming Chemicals: The Moral Economy of the American Lawn.” Economic Geography 79, no. 4: 425-51. doi:10.1111/j.1944-8287.2003.tb00222.x.

Rull, R.P., Ritz, B., Shaw, G.M., 2006. "Neural tube defects and maternal residential proximity to agricultural pesticide applications.” Am. J. Epidemiol. 163, 743e753.

Schaetzl, R., and S. Anderson. 2005. "Soils: Genesis and Geomorphology." Cambridge Univ. Press, UK.

Schinasi, L. and Leon, M.E, 2014. "Non-Hodgkin Lymphoma and Occupational Exposure to Agricultural Pesticide Chemical Groups and Active Ingredients: A Systematic Review and Meta-Analysis." International Journal of Environmental Research and Public Health 11, no. 4: 4449-4527. doi:10.3390/ijerph110404449.

Schreiber, J. D.,. Rebich, R. A, and Cooper, C.M, 2001. Dynamics of diffuse pollution from US southern watersheds. Water Research, 35(10), 2534-2542.

Schug, T. T., Abagyan, R., Blumberg, B., Collins, T.J., Crews, D., DeFur, P.L., Dickerson, S.M., et al., 2012. "Designing Endocrine Disruption out of the next Generation of Chemicals." Green Chemistry 15, no. : 181-98. doi:10.1039/C2GC35055F.

Service, R.F., 2007. “Glyphosate--The Conservationist's Friend?" Science 316, no. 5828: 1116-17. doi:10.1126/science.316.5828.1116. 
Showers, K. B. 2006. "A history of African soil: Perceptions, use and abuse". Soils and Societies. J. R. McNeill and V. Winiwarter (eds.). The White Horse Press, Isle of Harris, UK. pp. 118 176.3390/ijerph110404449.

Shrestha, A., Hembree, K. J., and Va, N., 2007. "Growth stage influences level of resistance in glyphosate-resistant horseweed." California Agriculture, 61(2), 67.

Simonsen, L., Fomsgaard, I.S., Svensmark, B. and Spliid, N.S., 2008. "Fate and Availability of Glyphosate and AMPA in Agricultural Soil." Journal of Environmental Science \& Health, Part B -- Pesticides, Food Contaminants, \& Agricultural Wastes 43, no. 5: 365-75. doi:10.1080/03601230802062000.

Small, L.F., McIntire, C.D., MacDonald, K.B., Lara-Lara, J.R., Frey, B.E., Amspoker, M.C., and Winfield, T, 1990. "Primary Production, Plant and Detrital Biomass, and Particle Transport in the Columbia River Estuary." Progress in Oceanography 25, no. 1-4: 175-210. doi:10.1016/0079-6611(90)90007-O.

Sorenson, A., 1994. Agricultural Conservation Alternatives: The Greening og the Farm Bill. American Farmland Trust Center for Agriculture in the Environment. http://www.farmlandinfo.org/sites/default/files/AGRICULTURAL_CONSERVATION_ ALTERNATIVES_THE_GREENING_OF_THE_FARM_BILL_OCTOBER_1994_1.pd f

Stout, J.C., Belmont, P., Schottler, S.P., and Willenbring, J.K, 2014. "Identifying Sediment Sources and Sinks in the Root River, Southeastern Minnesota." Annals of the Association of American Geographers 104, no. 1: 20-39.

doi:10.1080/00045608.2013.843434.

Strachnov, V., LaRosa, J., Dekner, R., Zeisler, R. Fajgelj, A., 1996. Report on the Intercomparison Run IAEA-375: Determination of Radionuclides in Soil Sample IAEA375, IAEA/AL/075. Analytical Quality Control Services International Atomic Energy Agency, Vienna (1996)

Stroganova, M. N., Myagkova, A. D. and Prokofieva, T. V., 1997. "The role of soils in urban ecosystems." Eurasian Soil Sci. 30:82-86.

SWCD, 2015. “Our History”. http://wascoswcd.org/wcswcd_002.htm

SWCD, 2009. Wasco County Rural Living Handbook. https://wascoswcd.org/linked/wasco_rlh.pdf. Accessed January 12, 2015.

Swidler, E.M., 2009. “The Social Production of Soil.” Soil Science: January 2009 Volume 174 - Issue 1 - pp 2-8 doi: 10.1097/SS.0b013e318194274d

Syvitski, J.P.M., Vorosmarty, C.J., Kettner A.J., Green, P., 2005. Impact of humans 
on the flux of terrestrial sediment to the global coastal ocean. Science 308: 376-380.

Tadaki, Marc, Brierley, G., Dickson, M. Le Heron, R. and Salmond, J., 2015. "Cultivating Critical Practices in Physical Geography." The Geographical Journal 181, no. 2: 160-71. doi:10.1111/geoj.12082.

Trimble, S.W., 1999. Decreased Rates of Alluvial Sediment Storage in the Coon Creek Basin, Wisconsin, 1975-93. Science, 285(5431), 1244-1246.

Trivero, P., Borasi, M., Biamino, W., Cavagnero, M., Rinaudo, C., Bonansea, M., and Lanfri, S., 2013. "River Pollution Remediation Monitored by Optical and Infrared HighResolution Satellite Images." Environmental Monitoring and Assessment 185, no. 9: 7647-7658. doi:10.1007/s10661-013-3125-3.

Tsui, M.T. K., and Chu, L.M.., 2004. "Comparative Toxicity of Glyphosate-Based Herbicides: Aqueous and Sediment Porewater Exposures." Archives of Environmental Contamination and Toxicology 46, no. 3: 316-23. doi:10.1007/s00244-003-2307-3.

University of Oregon Aerial Photograph Collection. Accessed June 2014. http://library.uoregon.edu/map/orephoto/imagery.html

Urstadt, B., 2004. "A four-year plague: President Bush's anti-environmental agenda has succeeded not in leaps but in inches." Harpers 38 (48), 81-83.

USDA NASS CDL, 2017. Published crop-specific data layer [Online]. Available at https://nassgeodata.gmu.edu/CropScape/ (accessed January 3, 2017). USDA-NASS, Washington, DC

USDA, 2017. Pesticide Use and Markets. https://www.ers.usda.gov/topics/farmpractices-management/chemical-inputs/pesticide-use-markets.aspx

USDA, 2015. "Conservation Fact Sheet." http://www.fsa.usda.gov/Assets/USDAFSA-Public/usdafiles/FactSheets/archived-fact-sheets/consv_reserve_program.pdf

USDA, 2012. "2012 Agricultural Wheat Use Survey." http://www.nass.usda.gov/Surveys/Guide_to_NASS_Surveys/Chemical_Use/ChemUseH ighlights-Wheat-2012.pdf

U.S. Fish and Wildlife Service, 2009. CREP BO 2009_final.doc TS Number: 09-314 TAILS: 13420-2009-F-0047. https://www.fsa.usda.gov/Internet/FSA_File/crepbo2009final.pdf

US Office of Management and Budget (US OMB), 2006. Budget of the United States Government. Budget Authority for US Environmental Protection Agency. 
Vera, M.S., Lagomarsino, L., Sylvester, M., Pérez, G.L., Rodríguez, P., Mugni, H., Sinistro, R. Ferraro, M., Bonetto, C., Zagarese, H., Pizarro, H., 2010. "New Evidences of Roundup (Glyphosate Formulation) Impact on the Periphyton Community and the Water Quality of Freshwater Ecosystems.” Ecotoxicology (London, England) 19, no. 4: 710-21. doi:10.1007/s10646-009-0446-7.

Vogelmann, J. E, Helder, D. Morfitt, R., Choate, M.J., Merchant, J.W., and Bulley, H., 2001. "Effects of Landsat 5 Thematic Mapper and Landsat 7 Enhanced Thematic Mapper Plus Radiometric and Geometric Calibrations and Corrections on Landscape Characterization." Remote Sensing of Environment, Landsat 7, 78, no. 1-2: 55-70. doi:10.1016/S0034-4257(01)00249-8.

Wainwright J., Turnbull L., Ibrahim T.G., Lexartza-Artza I., Thornton, S.F., Brazier R.E., 2010. "Linking environmental regimes, space and time: interpretations of structural and functional connectivity." Geomorphology 126: 387-404

Wallbrink P.J., and Murray, A.S., 1996. "Distribution and variability of Be-7 in soils under different surface cover conditions and its potential for describing soil redistribution processes." Water Resources Research 32: 467-476.

Wallbrink, P.J., Murray, A.S., Olley, J.M., 1998. "Determining sources and residence time of suspended sediment in the Murrumbidgee River, New South Wales, Australia, using fallout Cs-137 and Pb-210.” Water Resour. Res. 34, 879-997.

Walling D.E., Fang D., 2003. Recent trends in the suspended sediment loads of the world's rivers. Global and Planetary Change 39:111-126.

Walling, D.E., 2005. Tracing suspended sediment sources in catchments and river systems. Sci. Total Environ. 344, 159-184.

Wasco County Soil and Water Conservation District, 2009. Wasco County Rural Living Handbook. A Resource for Country Living and Land Stewardship. http://wascoswcd.org/linked/wasco_rlh.pdf

Wasco County Planning Department (WCPD), 2017. Comprehensive Plan, Chapter 2. http://www.co.wasco.or.us/Planning/Comp_Plan/02Physical_Characterist.pdf

Weier, J. and Herring, D., 2000. "Measuring Vegetation (NDVI \& EVI) : Feature Articles." http://earthobservatory.nasa.gov/Features/MeasuringVegetation/. Accessed December 15, 2016.

Wells, L. E., and J. S. Noller. 1999. "Holocene coevolution of the physical landscape and human settlement in northern Coastal Peru." Geoarchaeology 14:755-789.

Williams, J. D., Wuest, S. B., 2001 'No-Till Influence on Hydrology and Stream 
Morphology in Dryland Crop Areas." Columbia Basin Agricultural Research Annual Report. Spec. Rpt. 1026, pp.84-95, 2001 Oregon State University in cooperation with USDA-Agricultural Research Service, Pendleton, OR

Williams, J. D., S. B. Wuest, and D. S. Long, 2014. "Soil and Water Conservation in the Pacific Northwest through No-Tillage and Intensified Crop Rotations." Journal of Soil and Water Conservation 69, no. 6: 495-504. doi:10.2489/jswc.69.6.495.

Winson, A. 1992. The Intimate Commodity. Toronto: Garamond Press.

Witmer, G., Sayler, R., Huggins, D. and Capelli, J., 2007. "Ecology and Management of Rodents in No-till Agriculture in Washington, USA.” Integrative Zoology 2, no. 3: 154-64. doi:10.1111/j.1749-4877.2007.00058.x.

Woodhouse, E.J., 2006. "Nanoscience, Green Chemistry, and the Privileged Position of Science" in The New Political Sociology of Science. Kelly Moore and Scott Frickel, eds., University of Wisconsin Press.

Wright, A., 2005. The Death of Ramon Gonzalez. University of Texas Press, Austin.

WSU Extension, 2017. "High Residue Farming Under Irrigation." Center for Sustaining Agriculture and Natural Resources. http://csanr.wsu.edu/high-residuefarming-under-irrigation/. Accessed March 10, 2017.

Wulder, Michael A., Jeffrey G. Masek, Warren B. Cohen, Thomas R. Loveland, and Curtis E. Woodcock. "Opening the Archive: How Free Data Has Enabled the Science and Monitoring Promise of Landsat." Remote Sensing of Environment, Landsat Legacy Special Issue, 122 (July 2012): 2-10. doi:10.1016/j.rse.2012.01.010.

Zapata, F., 2003. ed. Handbook for the Assessment of Soil Erosion and Sedimentation Using Environmental Radionuclides. Dordrecht: Kluwer Academic Publishers. http://link.springer.com/10.1007/0-306-48054-9.

Zhang, X. C., Zhang, G.H., Liu, B.L., and Liu, B., 2016. "Using Cesium-137 to Quantify Sediment Source Contribution and Uncertainty in a Small Watershed." CATENA 140: 116-24. doi:10.1016/j.catena.2016.01.021.

Zitong, G., Ganlin, Z., and Guobao. L. 1999. "Diversity of Anthrosols in China." Pedosphere. 9:193-204.

Zuzel, J.F., and Pikul, Jr., J.L., 1987. "Infiltration into a seasonally frozen agricultural soil." Journal of Soil and Water Conservation 42(6):447-450. 